ROMANIAN ACADEMY

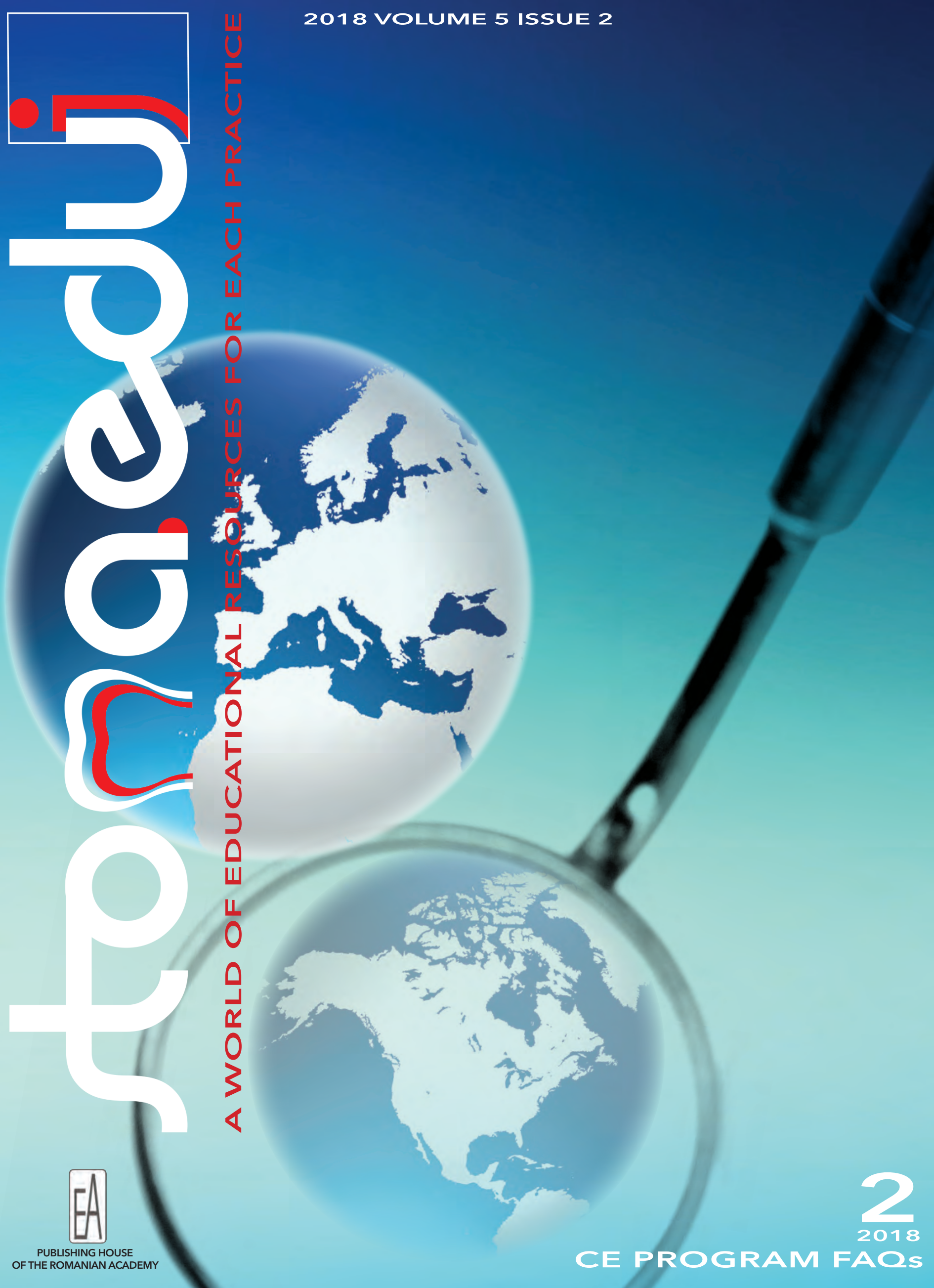

STOMATOLOGY ED U J O UR NAL 2018 VOLUME 5 ISSUE 2 


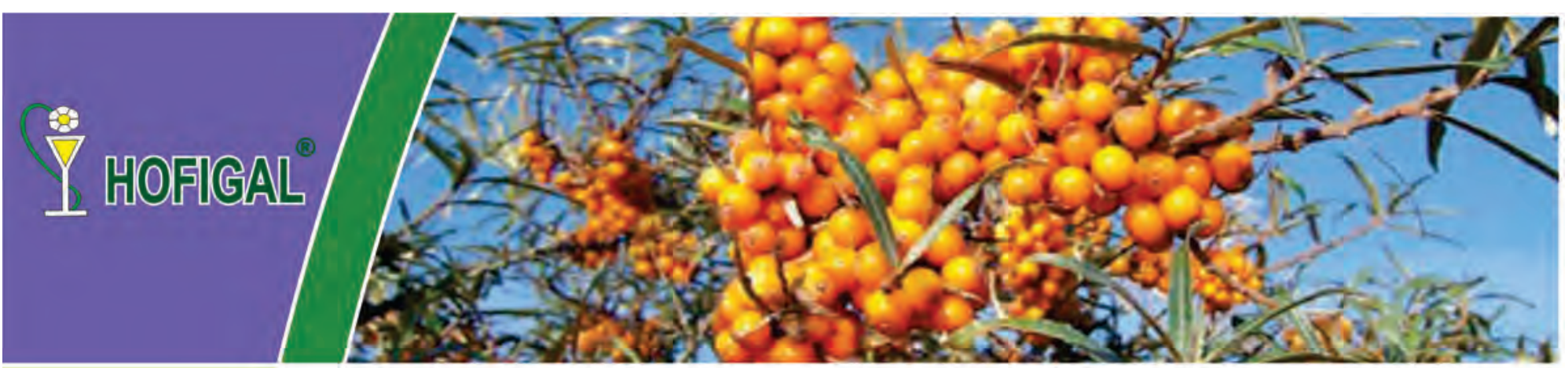

\section{Hofident $Q_{10}$}

Product presentation: Solution for oral hygiene.

Composition (INCI): aqua/water, alcohol, Capsella Bursa Pastoris extract, Plantago Lanceolata extract, Chamomilla Recutita extract, Achillea Millefolium extract, Aesculus Hippocastanum extract, Mentha Piperita extract, Ubiquinone.

Action: The product has antiseptic, healing, hemostatic, anti-inflammatory aetion, it acts as a antioxidant, detoxifier, deodorant. It is strongly recommended in gingivitis, stomatitis, thrush, compression pain causedby dental prostheses, after tooth extraction, in case of nipple lesion, bleeding gums, mouth and gum ulcers.

Recommendations: It delays dental plaque formation, it prevents bad odour and provides daily mouth hygiene.

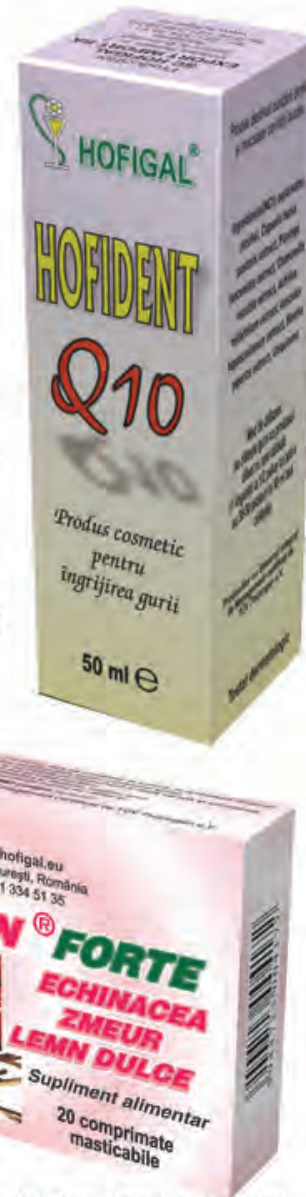

\section{Hoflmun ${ }^{\oplus}$ FORTE}

Product presentation:

Chewable tablets to stimulate the immune system

Composition: Each chewable tablet contains raspberry fruit extract (Rubii idaei fructus), Echinacea extract (Echinacea purpurea), concentrated extract of licorice root (Glycyrrhiza radix), magnesium ascorbate and excipients.

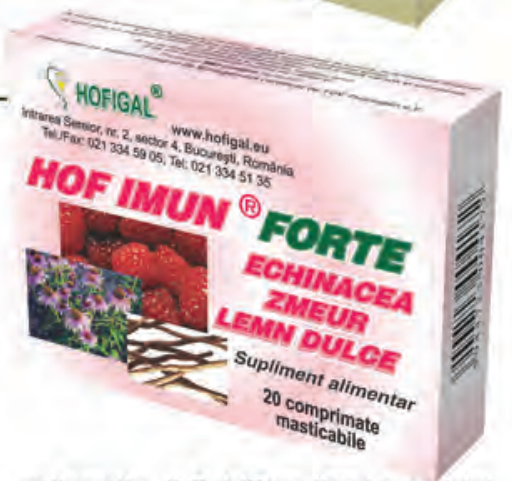

Action:It stimulates the immune system, it is antiinflammatory, antiviral, antiseptic, it fluidifies the bronchial and pharyngeal secretions, antioxidant, cardioprotective, vasoprotective, it has antineoplastic antileukimic action, (due to the ellagic acid), it contributes to wound healing, fortifies and remineralizes (it regulates the potassium balance), it has antiulcer effects and is an overall body tonic.

Recommendations: to supplement the diet with nutrients and bioactive substances in: acute and chronic infections of the upper airways (angina, pharyngitis, laryngitis, bronchitis), prophylactic during periods with increased risk of infection with influenza viruses, it has sweating effects in fever, in recurrent herpes episodes of mucocutaneous rash, frequent urinary tract infections, inflammatory urogenital processes; immunodepression after radiotherapy or chemotherapy, bacterial skin infections, psoriasis, neurodermitis, chronic cardiovascular diseases associated with hypercholesterolemia, adjuvant in the diet indicated in the treatment of gastroduodenal ulcers, tonic during periods of physical and mental strain, exhaustion.

2 Intrarea Serelor Str., Sector 4, 042124, Bucharest, ROMANIA $+4021-334.74 .86$ $+4021-492.00 .69$. office@hofigal.eu, marketing@hofigal.eu exportimport@hofigal.e

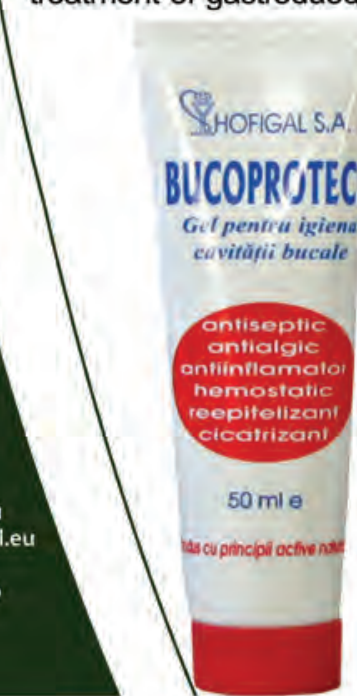

\section{Bucoprotect gel}

Product presentation: Gel for oral hygiene.

Composition (INCI): aqua, capsella bursa pastoris, calendula officinalis, achillea milefolium, hippophae rhamnoides, olea europea, hypericum perforatum, carbomer, triethanolamine, collagen, foeniculum vulgare, mentha piperita, citrus amara.

Action: Antiseptic, anti-inflammatory, healing, stimulates the inside lining of the mouth and gums trophicity, reduces pain caused by specific oral diseases (gingivitis, stomatitis, lesions of the prosthesis, thrush, periodontitis). Recommendations: Fights against bad breath (halitosis). 


\section{stomaeduj}

2018 Volume 5 Issue 2

Pages 67-134

\section{EDITOR OFFICE:}

Stomatology Edu Journal

102-104 Mihai Eminescu st., 2 2d District

RO-020082 Bucharest, ROMANIA

Tel/Fax: +40314 327930

e-mail: stomatology.edu@gmail.com

www.stomaeduj.com

EDITORS

Jean-François ROULET

Rolf EWERS

Marian-Vladimir CONSTANTINESCU

MANAGING EDITOR:

Florin-Eugen CONSTANTINESCU

ROPOSTURO

Romanian Association of Oral Rehabilitation and Posturotherapy

10, Ionel Perlea St., 1st District

R0-010209 Bucharest, Romania

Tel: +40213141062

Fax: +4021 3121357

e-mail: roposturo@gmail.com

www.roposturo.stomaeduj.com

TECHNICAL EDITOR:

Gabriel Octavian LAZAR

Edgar MORARU

PROJECT EDITOR:

lrina-Adriana BEURAN

DESIGN EDITOR:

Dragoș Georgian GUȚOI

COVER BY:

Arch. Florin ADAMESCU

\section{PUBLISHER OFFICE:}

Romanian Academy Publishing House

13, Calea 13 Septembrie, 5th District

RO-050711 Bucharest, Romania

Tel: +4021 3188146,40213188106

Fax: +4021318244

e-mail: edacad@ear.ro

www.ear.ro

TECHNICAL EDITOR:

Doina ARGESTANU

EDITORIAL ASSISTANT:

Monica STANCIU

COMPUTER EDITING:

Iolanda POVARĂ

\section{SUBSCRIPTIONS}

S.C. MANPRES DISTRIBUTION S.R.L.

1, Piața Presei Libere, Corp B

3rd floor, room 301-302, 1st District

R0-013701 Bucharest, Romania

Tel/Fax: +402131463 39

e-mail: abonamente@manpres.ro

www.manpres.ro

ISSN 2360 - 2406 (Print)

ISSN 2502- 0285 (Online)

ISSN - L 2360 - 2406

All the original content published is the sole responsibility of the authors.

All the interviewed persons are responsible for their declaration and the advertisers are responsible for the information included in their commercials.

\section{Contents}

\section{Editorials}

70 Peer Review - The Noblest Duty of Every Researcher Jean-François Roulet

72 How to empower the Editorial Board and give a new impetus to its activity: how to increase its quality, number of readers, and the way to go Marian-Vladimir Constantinescu

In memoriam

75 Summing up Adi Garfunkel's life Gabi Chaushu

\section{News}

77 Engaging on gerodontology with the platform for better oral health in Europe Gerry McKenna

79 The Second International Congress of the Faculty of Dental Medicine, "Carol Davila" University of Medicine and Pharmacy Bucharest, Romania, and the 17th International Congress for Students and Young Doctors "stuDENT" Paula Perlea, Radu Gabriel Toma

\section{Continuing Education Online}

83 JADA CE Online

\section{Original Articles}

84 DENTAL MATERIALS: Beam profile characterization of a dental light curing unit using a spectrometer-based method

Jean-François Roulet, Mateus Garcia Rocha, Chiayi Shen, Marwah Majid Khudhair, Dayane Carvalho Ramos Salles de Oliveira

92 RESTORATIVE DENTISTRY: Comparative study regarding the effect of different finishing and polishing systems on a bulk-fill composite resin surface Irina Nica, Simona Stoleriu, Gianina lovan, Cristina-Angela Ghiorghe, Galina Pancu, Adriana Munteanu, Sorin Andrian

98 ORTHODONTICS: Soft-tissue facial asymmetry before and after orthognathic surgery: application of a new 3D protocol

Filippo Da Pozzo, Francesca M.E. Rusconi, Giada Anna Beltramini, Daniele M. Gibelli, Valentina Pucciarelli, Aldo Bruno Giannì, Chiarella Sforza

102 ORTHODONTICS: Bonding orthodontic resin cement to zirconium oxide under orthodontics load and thermocycling effect

Hind S. Hussein, Nader Abdulhameed, Chiayi Shen, Calogero Dolce, Jean-François Roulet

110 COMPUTERIZED DENTAL PROSTHETICS: Intraoral scans for CAD/CAM application

Judit Borbély, Alexandra Czigola, Viktoria Vitai, Ivett Róth, Péter Hermann

118 GERODONTOLOGY: Comparison of dental status and oral function between the elderly with and without temporomandibular disorders Minh Son Nguyen, Ülle Voog-Oras, Triin Jagomägi, Mare Saag

\section{Dentistry Conferences}

\section{Product News}

The way to reach the gold standard in dental surgery: Integrated Surgical Studio Design KYRI

Florin - Eugen Constantinescu

\section{Books Review}

\section{Author Guidelines}

\section{Subscription}




\section{stomacduj}

\section{EDITORIAL BOARD}

\section{Editors-in-Chief}

Jean-François Roulet

DDS, PhD, Dr hc, Prof hc, Professor

Department of Restorative Dental Science

College of Dentistry

University of Florida

Gainesville, FL, USA

\section{Rolf Ewers}

MD DMD, PhD, Professor and Chairman em.

University Hospital for Cranio-

Maxillofacial and Oral Surgery

Medical University of Vienna

Vienna, Austria
Marian-Vladimir Constantinescu

DDS, MSc, PhD, Professo

Department of Prosthetic Dentistry

Faculty of Dental Medicine

"Carol Davila" University of Medicine and Pharmacy Bucharest, Romania

\section{Deputy Editors-in-Chief}

\section{Adrian Bejan}

Eng, PhD

J.A. Jones Distinguished Professor, Acad (AR)

Mechanical Engineering Faculty

Duke University, Durham, NC, USA

Constantin lonescu-Tîrgoviște

$\mathrm{MD}, \mathrm{PhD}$

Professor, Acad (AR), Faculty of Medicine

"Carol Davila" University of Medicine and Pharmacy

Bucharest, Romania
Gabriel Octavian Lazăr

CPhys, PhD

Professor, Faculty of Engineering

"Vasile Alecsandri" University of Bacău

Bacău, Romania

\section{Co-Editors-in-Chief (Americas)}

Hom-Lay Wang

DDS, MSD, PhD

Professor and Director of Graduate Periodontics

Department of Periodontics and Oral Medicine

University of Michigan, School of Dentistry

Ann Arbor, MI, USA

\section{Mauro Marincola \\ George E. Romanos}

MD, DDS

Clinical Professor

State University of Cartagena

Cartagena, Colombia
DDS, PhD, DMD

Professor, Department of Periodontology

School of Dental Medicine

Stony Brook University

Stony Brook, NY, USA

\section{Co-Editors-in-Chief (Europe)}

Nicoleta llie

Dipl-Eng, PhD, Professor

Department of Operative Dentistry and

Periodontology, Faculty of Medicine

Ludwig-Maximilians-Universität München

München, Germany

\section{Alexandre Merse}

DDS, PhD

Professor, Director FDI Europe

Geneva-Cointrin, Switzerland
Constantinus Politis

MD, DDS, MM, MHA, PhD

Professor and Chairperson, Department of Oral and Maxillofacial Surgery, Faculty of Medicine University of Leuven

Leuven, Belgium

\section{Co-Editors-in-Chief (Asia-Pacific)}

Lakshman Perera Samaranayake

DSc (hc), DDS (Glas), DSRCSE (hon)

FRCPath (UK), FRACDS (hon)

Professor, Department of Oral Microbiomics and

Infection, Head, School of Dental Medicine

University of Queensland

Brisbane, Australia

\section{Hiroshi Ogawa}

DDS, MDSc, PhD

Associate Professor

Department of Oral Health Science Graduate

Graduate School of Medical and Dental Sciences Niigata University

Niigata, Japan
Mahesh Verma

BDS, MDS, MBA, FAMS, FDSRCS (England), FDSRCPSG (Glasgow), FDSRCS (Edinburgh), PhD ( $\mathrm{HC}$ )

Professor, Department of Prosthodontics

Director - Principal

Maulana Azad Institute of Dental Sciences

New Delhi, India

\section{Senior Editors}

\section{Bruce R. Donoff Adrian Podoleanu}

DMD, MD

Professor, Department of Oral and Maxillofacial Surgery

Dean, Harvard School of Dental Medicine

Harvard University

Boston, MA, USA
, FinstP, FOSA, FSPIE

Professor of Biomedical Optics, Head of the

Applied Optics Group, School of Physical Sciences

University of Kent, Canterbury Kent, UK

\section{David Wray}

MD (Honours), BDS, MB ChB, FDS, RCPS (Glasgow) FDS RCS (Edinburgh) F Med Sci, Professor Emeritus Professor, Department of Oral Medicine

Dental School, University of Glasgow Glasgow, UK

\section{Emeritus Editors-in-Chief}

Birte Melsen, DDS, Dr Odon

Professor, Aarhus University Aarhus, Denmark

\section{Prathip Phantumvanit, DDS, MS, FRCD} Professor, Thammasat University Bangkok, Thailand

Julian B. Woelfel, DDS, FACD, FICD

Professor Emeritus, The Ohio State University

Columbus, USA ( $t)$

\section{Associate Editors-in-Chief}

Mariano Sanz Alonso, DDS, MSD, PhD, Professor Complutense University of Madrid

Madrid, Spain

Radu Septimiu Câmpian, DMD, MD, Professor Dean "Iuliu Hatieganu" University of Medicine and Pharmacy, Cluj-Napoca, Romania

Sergiu Ciobanu, DDS, PhD, Profesor, Dean, “Nicolae Testemițanu" State Medical and Pharmaceutical University
Chișinău, Moldova

François Duret, DDS, DSO, PhD, MS, MD, PhD Professor Acad (ANCD), Úniversity of M'ontpellie Montpellier, France

Michael Frank, DDS, PhD ERO President Elect, President Dental Chamber Hesse Frankfurt am Main, Germany

Luigi M Gallo, PhD, Dr Eng, MEng Professor and Chairman, University of Zürich Zürich, Switzerland

Maria Greabu, MD, PhD

"Carol Davila" University of Medicine and Pharmacy Bucharest, Bucharest, Romania Professor and Head, Vice-Rector, Semmelweis University Budapest, Hungary

Ecaterina lonescu, DDS, PhD, Professo Vice-Rector, "Carol Davila" University of Medicine and Pharmacy, Bucharest, Romania

Vjekoslav Jerolimov, DDS, PhD Acad (CASA), University of Zagreb Zagreb, Croatia

Veronica Mercut, DMD, PhD, Professor, Dean University of Medicine and Pharmacy Craiova Dolj, Romania

Georg B. Meyer, DMD, PhD, Dr hc Professor and Chairman, Ernst-Moritz-Arndt University, Greifswald, Germany

Rade D. Paravina, DDS, MS, PhD, Professor Director, University of Texas, Houston, TX, USA

Poul Erik Petersen, DDS, Dr Odont, BA, MSC Professor, WHO Senior Consultant University of Copenhagen, Denmark
Rudolf Slavicek, MD, DMD

Professor, Medical University of Vienn Vienna, Austria 


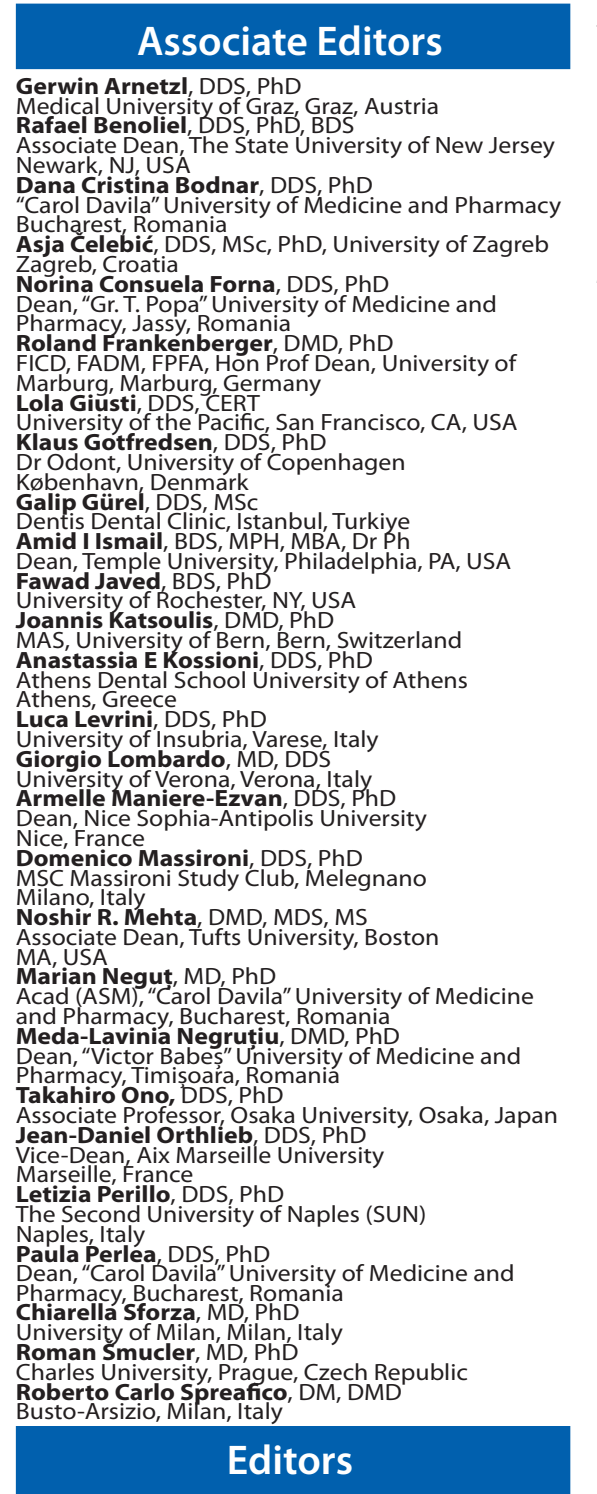

Sorin Andrian, DDS, PhD
"Gr. T. Popa" University of Medicine and Pharmacy Jassy Romania
Vasile Astărăstoae, MD, PhD

Vasile Astărăstoae, MD, PhD
"Gr.T.Popa"University of Medicine and Pharmacy Jassy Gamaniela Băncescu, MD, MSc, PhD

"Carol Davila", University' of Medicine and Pharmacy

Bucharest, Bucharest, Romania
Emanuel Adrian Bratu, DDS, MD, PhD, "Victor Babes" University of Medicine and Pharmacy Timișoara, Románia

Chairman, Dentists' College, Bucharest, Romania

"Carol Davila" University of Medicine and Pharmacy

Bucharest, Romania

"Carol Davila" University of Medicine and Pharmacy

Bucharest, Romania
Arnaldo Castellucci, DDS, PhD

Arnaldo Castellucci, DDS, P

Florence Italy
Ingrida Céma, DDS, PhD

Riga Stradins University, Riga, Latvia

Gabi Chaushu, DMD, MD D

Tel Aviv University, Tel Aviv, Israel
Rayleigh Ping-Ying Chiang, MD, MMS

Taipei Veterans General Hospital,'Taipei, Taiwan

Robert A. Convissar, DDS, AGD
New York Hospital Medical Center of Queens

New York, USA

"Gr. T. Popa" University of Medicine and Pharmacy Jassy

Paulo Ribeiro de Melo, DDS

University of Porto, Porto, Portugal

Luc De Visschere, DDS, PhD

Gent University, Gent, Belgium
Yuri Dekhtyar, Eng, Dr phys

Riga Technical University, Riga, Latvia
Mohamed Sherine El-Attar, DDS, PhD

University Alexandria, Alexandria, Egypt
Valeriu Eala DDS PhD

"Nicolae Testemitannu" State University of Medicine and "Pharmacy, Chișinäu, Republic of Moldova

Paul B. Feinmann, DDS, PhD

Canton of Geneva, Switzerland
Luis J. Fujimoto, DDS, PhD

New York University, New York, NY, USA

Adi A. Garfunkel DiDS PhD

Hebrew University Hadassah Jerusalem Jerusalem, Israel Razvan lonut Ghinea, PhD, MSC, BSc

University of Granada, Granada, Spain
Daniela Aparecida Godoi Gonçalves, DDS, PhD

UNESP - Univ Est Paulista, Araraquara, Brazil
Martin D Gross, BDS, LDS, RCS, MSC

Tel Aviv University, Tel Aviv, Israe

Emilian Hutu, DDS, PhD

"Carol Davila" University of Medicine and Pharmacy

Bucharest, Romania
Alexandru A. lliescu, DDS, PhD, University of Medicine

and Pharmacy of Craiova, Dolj, Romania

University of Milan Milan to

Abdolreza Jamilian, DDS, PhD

Islamic Azad University, Téhran, Iran
Hercules Karkazis, BDS, PhD

Hercules Karkazis, BDS, PhD
University of Athens, Athens, Greece

Joanna Kempler, DDS, PhD

University of Maryland,' Baltimore, MD, USA

Amar Hassan Khamis, , PhD, DEA, MSC, BSC College

Robert L. Ibsen, DDS, OD
Ros

Santa Maria, CA,'USA,
Henriette Lerner, DDS, PhD

Henriette Lerner, DDS, PhD

Baden-Baden, Germany
Annalisa Monaco, DDS, PhD

University of L'Aquila, 'L'Aquila, Italy
Nina Mussurlieva, DDS

Medical University of Plovdiv, Plovdiv, Bulgaria

Radmila R. Oobradovic, DDS, PhD

University of Niš, Nišs, Serbia

"uliu Hațieganu" Úniversity of Medicine and Pharmacy

Cluj-Napoca, Romania

"Titu Maiorescu" University, Bucharest, Romania

Matjaz Rode, Dob, PhD

Iulia Georgievna Romanova DMS PhD

Odessa National Medical University "ONMedU", Odessa

Ukraine

Mare Saag, DDS, PhD

University of Tartu, Tartu, Estonia

Esthetics Institute of Esthetic \& Restorative Dentistry

Constantin Marian Vârlan DDS, PhD

"Carol Davila" University of Medicine and Pharmacy

Bucharest, Romania

Emilio Carlos Zanatta, DDS, PhD, MS
Santa Cecilia University (UNISSANTA), Santos, SP, Brasil

Irina Nicoleta Zetu, DDS, PhD

"Gr.T. Popa"University of Medicine and Pharmacy Jassy

\section{Editorial Advisory Board}

Marcus Oliver Ahlers, DDS, PD

Department of Operative Dentistry and Preventive Dentistry Center for Oral and Maxillofacial Surgery

University Medical Center Hamburg-Eppendorf
Hamburg University Eppendorf, Hamburg, Germany

Cristina Maria Borttun, DDS, PhD

Cristina Maria Bortun, DDS, PhD

Department Faculty of Dental Medicine "Victor

Babeș" University of Medicine and Pharmacy Timișoara

Bogdan Calenic, DDS, PhD

Associate Professor, Biochemistry Department Faculty

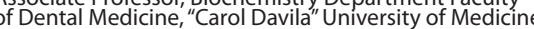

and Pharmacy Bucharest, Bucharest, Romania

Nardi Casap-Caspi, DMD, MD

Dertmat

Hebrew University Hadassah Jerusalem, Jerusalem, Israe

Paulo G. Coelho, DDS, PhD

Associate Professor, Department of Biomaterials College of Dentistry, New Y'ork University, New York NY, USA
Bogdan Alexandru Dimitriu, DDS, PhD Bogdan Alexandru Dimitriu, DDS, PhD
Professor and Head, Endodontic Department Professor and Head, Endodontic Department
Faculty of Dental Medicine, "Carol Davila" University of Faculty of Dental Medicine, "Carol Davila Un

Medicine and Pharmacy, Buchar
Daniel Edelhoff, CDT, DMD, PhD

Professor and Head, Department of Prosthodontics

Professor and Head, Department of Prosthodontics

University, München, Germany

Claudia Maria de Félicio, MD, PhD

Professor, Orofacial Motricity Únit, Department of

Ophthalmology and Otolaryngology, School of

Medicine Universidade de São Paulo (USP) Ribeirão

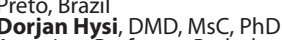

Associate Professor, Pedodontics Department Faculty

Tirana, Albania

Heinz Kniha, DDS, MD,
Associate Professor, Oral and Maxillofacial Surgery

Department, Faculty of Medicine Ludwig-Maximilian

München University, München, Germany

Rodica Luca, DDS, PhD

Professor, "Carol Davila" University of Medicine and

Pharmacy Bucharest, Bucharest, Romania

Mariam Margvelashvili, DDS, MSC, Ph

Professor, Department of Prosthodontics and Operative

Dentistry, School of

Rodolfo Miralles $\mathrm{MD}$ PhD

Rodersor, Physiology, and Biophysics Department
Profestitute of Biomedical Sciences, Faculty of Medicine

University of Chile, Santiago, Chile
Mutlu Ozcan, DDS PhD

Professor, Head of Dental Biomaterials Unit, Clinic

of Fixed and Removable Prosthodontics and

Dental Material Science, Center of Dental Medicine

Mariana Păcurar, DDS, Ph'D

Professor and Head, Orthodontics and DentoFacial

Orthopedics Department, Faculty of Dental Medicine

University of Medicine and Pharmacy, Târgu Mures

Romania

Alexandru Petre, DDS, PhD

Professor, Department of Fixed Prosthodontics and

Occlusology, "Carol Davila" University of Medicine and

Pharmacy, Bucharest, Romania
Sanda Mihaela Popescu, DDS, PhD

Sanda Mihaela Popescu, DDS, PhD
Professor and Head, Dental Reabilitation and Medical

Professor and Head, Dental Reabilitation and Medical
Surgery Emergencies Department, Faculty of Dental

Medicine, University of Medicine and Pharmacy of

Craiova, Dolj, Romania
Sorin Claudiu Popșor, DDS, PhD

Professor and Head', Removable Prosthodontics

Department, Faculty of Dental Medicine, University of Medicine and Pharmacy, Tg. Mureș, Romania

Elena Preoteasa,

Professor and Head, Complete Denture Department Faculty of Dental Medicine, "Carol Davila" University of Alina Pürienè, DDS, PhD

Professor, Periodontics Department Institute of

Odontology Faculty of Medicine, Vilnius University

Vilnius, Lithuania

Lucien Reclaru, Eng, PhD

Biomaterials Consultant, University of Geneva

Stephen F. Rosenstiel, BDS, MSD

Stephen F. Rosenstiel, BDS, MSD
Professor and Chair, Restorative and Prosthetic

Dentistry College of Dentistry, The Ohio State University

Hande Sar Sancakli, DDS, PhD

Professor, Department of Operative Dentistry, Faculty of Dentistry, Istanbul University, Istanbul, Turkiye

Martina Schmid-Schwap, DDS, PhD
Professor, Department of Prosthodontics, Bernhard

Professor, Department of Prosthodontics, Bernhard
Gottlieb University of Dentistry, Medical University of

Vienna, Vienna, Austria

Gregor Slavicek, DDS, PhD

Professor, Steinbeis-Transfer-Institute of Biotechnology

in Interdisciplinary Dentistry, Steinbeis University, Berlin

Marius Steigmann, DDS, PhD

Professor, Steigmann Implant Institute, Neckargemund

Stefan-loan Stratul, PhD, MSc, MDiv

Associate Professor, Restorative Dentistry and

Endodontics Faculty of Dental Medicine "Victor Babes"

University of Medicine and Pharmacy, Timișoara

Gianluca Martino Tartaglia, DDS, PhD

Associate Professor, Functional Anatomy Research

Center Laboratory of Functional Anatomy of the

Stomatognathic Apparatus, Department of Biomedical

Milan, Milan, Italy

Bernard Touati, DDS, PhD of Odontology, Paris V University, Paris, France

Tamara Tserakhava, DDS, PhD

Professor and Chair, Department of Pediatric Dentistry

Minsk, Belarus

Sorin Uram-Tuculescu, DDS, PhD

Assistant Professor, Prosthodontics Department School of Dentistry, Virginia Commonwealth University
Richmond, VA, USA

\section{Reviewers-in-Chief}

Stephen F. Rosenstiel, BDS, MSD

Professor Emeritus

Mihaela Rodica Păuna, DDS, PhD

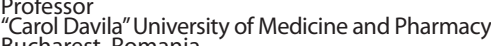

Bucharest, Romania
Sheldon Dov Sydney, DDS, FICD

Associate Professor

University of Maryland, Baltimore, Maryland, USA

World Editor, International, College of Dentists

\section{Reviewers}

Petr Bartak, Prague, Czech Republic
Cristian Niky Cumpătă, Bucharest, Romania

Andrezza Lauria de Moura, São Paulo, Braz

Nikolay Ishkitiev, Sofia, Bulgaria

Barbara Janssens, Gent, Belgium

John Kois, Seattle, WA, USA

Cinel Mana, Bucharest, Romanic

Enrico Manca, Cagliari, Italy

Costin Marinescu, München, Germany

Marina Melescanu-Imre, Bucharest, Romania

Joel Motta Júnior, Manaus, AM, Brazil

Hazem Mourad, Qassim, Saudi Arabi

Paula Perlea, Bucharest, Romania

Nikola Petricevic, Zagreb, Croatia

Preoteasa, Bucharest, Romania

Robert Sabiniu Şerban, Bucharest, Romania

Mei-Qing Wang, Xi'an, China

\section{English Language Editor-in-Chief}

Roxana-Cristina Petcu, Phil, PhD

Professor, Faculty of Foreign Languages

University of Bucharest, Bucharest, Romania

\section{English Language Editors}

Valeria Clucerescu, Biol.

Niculina Smaranda lon, Phil.

Honorary Statistical Advisers

Radu Burlacu, PhD, Bucharest, Romania

loan Opris, PhD, Associate Scientist, Miami, USA

Book Reviewers

Iulia Ciolachi, DMD, Bucharest, Romania
Florin-Eugen Constantinescu, DMD, PhD Student Bucharest, Romania

\section{Project Editor}

Irina-Adriana Beuran, DMD, PhD
Faculty of Dental Medicine, "Carol Davila" University of Medicine and Pharmacy Bucharest, Bucharest, Romania 


\section{Peer Review - The Noblest Duty of Every Researcher}

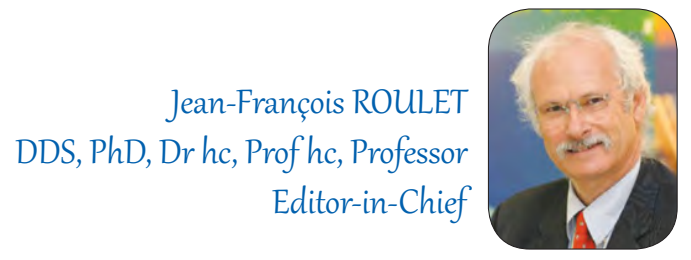

Dear readers,

In the very first editorial for the Stomatology Edu Journal, I have stated the importance of the peer review process. It is designed to guarantee that "Nothing is scientifically shown or proven before it has been published in a scientific journal with a peer review system, so one can critically judge what was done, how it was done and evaluate how solid it is." as Andreas Linde, the editor of the Scandinavian Journal Dental Research has stated.

Have you ever searched ("googled") a topic you are very familiar with on the internet? 1 did this several times and was shocked every time. For instance, if you google "Fluoride" you get 26,00o,ooo hits in 0.43 seconds. You could argue that this is proof that Fluoride is probably the most investigated substance in the world. True. The first hit shown is Fluoride Wikipedia, which presents a neutral description of its chemical properties, occurrence, biologic interactions etc. This is how it should be. However, the second hit is titled "Fluoride - Dangers of Fluoridation" and leads you to www.mercola.com. What you find is a collection of all the fairy tales about Fluoride which are disseminated by an active group of people. We all know from scientifically based literature that these claims are faulty and misleading and that fluoride, regarding its therapeutic width, is safer than table salt or even water. You find Fluoride articles "sort by recent". 1 quote the first eight following headlines: "The lawsuit that could end water fluoridation in the US, Two major league victories in federal court cases to end water fluoridation, Update on the movement against water fluoridation, Chinese herb shows promise against tooth decay, Fluoride - A little bit at the wrong time is devastating, Fluoride: Poison on tap, Maternal fluoride exposure during pregnancy correlates to lower $1 \mathrm{Q}$ in their children, Short Film reveals the lunacy of water fluoridation." Under the last quoted title 1 can read: "What has been hailed as one of the top 10 public health achievements of the zoth century is instead ripe with lies and deception, with absolutely no science to support it. That's why I'm working tirelessly to put an end to this lunacy that's wrecking health."

My question is, how should someone not informed, seeking for knowledge be able to validate these two sources that are equal in the result of the internet search? You see now my point why the peer review process is the noblest duty of every scientist.

It is wonderful and very beneficial to have peer review. The reviewer almost becomes a member of the author team, although anonymous, and contributes to the quality of the paper. However, peer reviewing has its problems: Editors worldwide notice that it gets more and more difficult to find colleagues who are willing to perform peer reviews. We editors sometimes send out 5-6 requests hoping to get at least two answers. 1 think this is very sad and damaging to the idea of high-quality publications. Furthermore, 1 think that a crew of professional reviewers is not the answer, because to do a good review one must be deeply involved in the mater that has to be reviewed. 
Therefore, dear colleagues say "YES", when you are asked to do a peer review! 1 know, we are all very busy, busier than ever. Furthermore, to perform a good review is time-consuming. However, think about it: If there are no reviewers anymore there will be no peer review as well. Where would you then publish your papers, with the mandatory request for your career that they must be peer reviewed?

J-FRoulet

Editor-in-Chief

References

Roulet]-F. Why Peer Review? Stoma Edu]. 2014;1(1):6.

DOI: 10.25241/stomaeduj.2018.5(2).edit.1 


\section{How to empower the Editorial Board and}

\section{give a new impetus to its activity: how to}

increase its quality, number of readers, and

\section{the way to go}

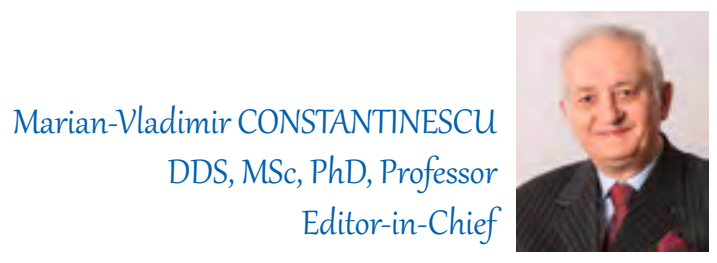

Dear readers,

Now, when the Stomatology Edu Journal (Stoma Edu J) has reached five years of publication, let me confess that approaching the most important national and international personalities in the field of research, education and dental practice was not a simple and barrier-free undertaking. By allowing your names to be associated with the Stomatology Edu Journal (Stoma EduJ), you might have thought of the words uttered by Educator, Civil Rights Activist and advisor to United States presidents, Booker Taliaferro Washington (1856-1915): "If you want to lift yourself up, lift up someone else."

1 am deeply satisfied to tell you that via the presence of your consequential names the Stomatology Edu Journal (Stoma Edu J) managed to overcome the critical mass of its potential readers, the over 85,00o dentists in the Central and Eastern European countries. Indeed, the 2013 census indicated there were 85,00o dentists, and, even though there has been an increase in number by a few thousand, despite the constant migration to the Western European countries, by May 2018 the magazine has been accessed by more than 145,500 readers, the difference being accounted for by readers in the United States, Great Britain, China, South Korea, India, Germany, Morocco, France, Seychelles, Greece, Turkey, Brazil, Austria, Honduras, Italy, Canada, Belize, Malaysia, United Arab Emirates and so on [1].

Overcoming the critical addressability figure is due to several assets accumulated over the five years that have increased the visibility of Stomatology Edu Journal (Stoma Edu J), namely:

- constantly increasing the quality of the articles published as a result of the demanding work by the team of reviewers coordinated by Professor Emeritus, Stephen F. Rosenstiel, from the Ohio State University, Columbus, USA, Reviewer-in-Chief, joined by a series of the prestigious Academic Editors since 2017;

- regular access granted by the American Dental Association, ADA, to our readers since the first 2017 issue to an article per issue with CE Program FAQs courtesy of Professor Michael Glick, Journal of The American Dental Association Editor, JADA, Mr. Michael Springer, Publisher, JADA, Mr. Nawin Gupta, Director of Business Operations, ADA and Mrs Stefanie K. Jewell-Thomas, Elsevier;

- the Crossref allocation of a Digital Object Identifier (DOI) since 2017 to a unique alphanumeric string, and the DOI identification will be retrospectively attributed to all articles published starting with the first number; - as of 2017, adding active links from PubMed, Google Scholar and Scopus to all references in the articles published alongside the Digital Object Identifier (DOI) so as to join the quoted publications circuit; - positioning the magazine in significant databases such as: Academia.edu [2], InfoBase Index [3], Google Scholar [4], SHERPA/RoMEO [5], National Library of Medicine (NLM) [6]. 
As a celebration of your presence in the editorial team in 2018, the Stomatology Edu Journal (Stoma Edu J) was evaluated and accepted by the Directory of Open Access Journals (DOAJ) $[7]$ and in the months ahead we are looking forward to the assessment by PubMed Central (PMC) and Clarivate.

Our objective is to provide an upward development of the Stomatology Edu Journal (Stoma Edu J), therefore it is necessary that the activity of the editorial board should be in line with the idea on teamwork uttered by the founder of the American automobile industry Henry Ford (1863-1947): "Coming together is a beginning. Keeping together is progress. Working together is a success."

As it is known, since 2016 the Stomatology Edu Journal (Stoma Edu J) has been published under the auspices of the Romanian Academy, the highest scientific forum in Romania founded in 1866.

This year, the Romanian Academy has elected a new president, Professor loan-Aurel Pop, historian and a particularly active scholar.

In the meeting he had with the publishers of magazines included in the portfolio of the Romanian Academy, he set their increase in quality as a priority. He suggested that all the publishers' activity should be evaluated at the end of this year. If an editor has not contributed any article for the last three years, it has been suggested to replace him with another editor.

Please take note of this provision and review yourwork at the Stomatology Edu Journal (Stoma EduJ) accordingly. In order to respond to the invitation launched by the Romanian Academy to stimulate the international circulation of scientific information via the electronic archive - "Academica Romanian Index", let me renew my request addressed to every publisher who wishes to bring his scientific contribution to the Stomatology Edu Journal (Stoma Edu J) to send, by September 15, a CV of maximum 250 words on the contribution in the field, surname, names, scientific titles, current administrative titles, the logo of the institution and a recent color photograph 3.5 $\times 4.5 \mathrm{~cm}$.

To enhance the quality of the articles published by the Stomatology Edu Journal (Stoma Edu J), and in order to honor Professor Adi A Garfunkel, from the Hebrew University Hadassah Jerusalem, Jerusalem, lsrael, a life-long friend and editor of our Journal, master of Professor Michael Glick, Editor of the Journal of The American Dental Association, JADA, we have created the "Award Professor Adi A Garfunkel" since 2019 that will be awarded to the most widely read and cited article of the previous year.

Let me thank you for allowing your name to be present in the Editorial Board throughout these five years and please do not forget that the over 145,500 readers of the Stomatology Edu Journal (Stoma Edu J) are waiting to read an article written by you and colleagues as soon as possible. 
When you finish reading these lines, please remember and ponder upon what the American author Felice Leonardo "Leo" Buscaglia (1924-1998), professor in the Department of Special Education at the University of Southern California, stated on the power of love: "You can be a follower of Muhammad or Jesus or Buddha or whomever. Always, they said that the most important factor is to love your neighbor. And to love you."

Sincerely yours,

$M-V$ Constantinescu

Editor-in-Chief

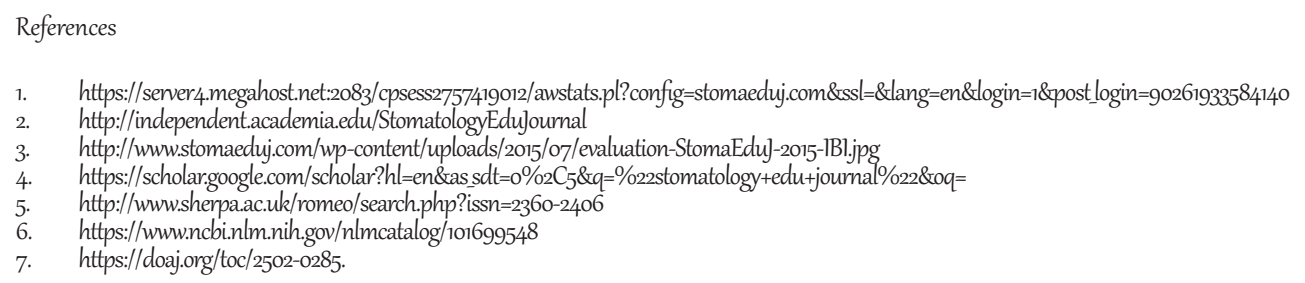

DOI: 10.25241/stomaeduj.2018.5(2).edit.2 


\section{Summing up Adil Gartunkell's lifie}

Summing up Adi Garfunkel's life, I keep coming back to one thought. "Never will you meet a man who loved his students more than Adi".

1 met him when 1 was in my third year of Dentistry. He was serving as the Dean of the Dental school in Jerusalem. Still, he had time to instruct students and encourage their scientific work. Adi was a teacher of all things. His method was simple. He taught by example. At any age, when faced with a dilemma, 1 have found myself coming back to one simple question. What would Adi do? Adi's teachings are endless. Let me share a few. Adi was one of my instructors for the MSc degree. When 1 first approached him with a result he said "it's nice, but one observation equals zero observation". Later in my life 1 have found myself "selling" the same advice to my students. Adi taught me to concentrate my research on few issues, but to have deep knowledge of them and do everything 1 can to be the best in the world at those issues. Later, when 1 was appointed Head of Maxillofacial Department he called to congratulate me and was prouder than me of my achievements. He

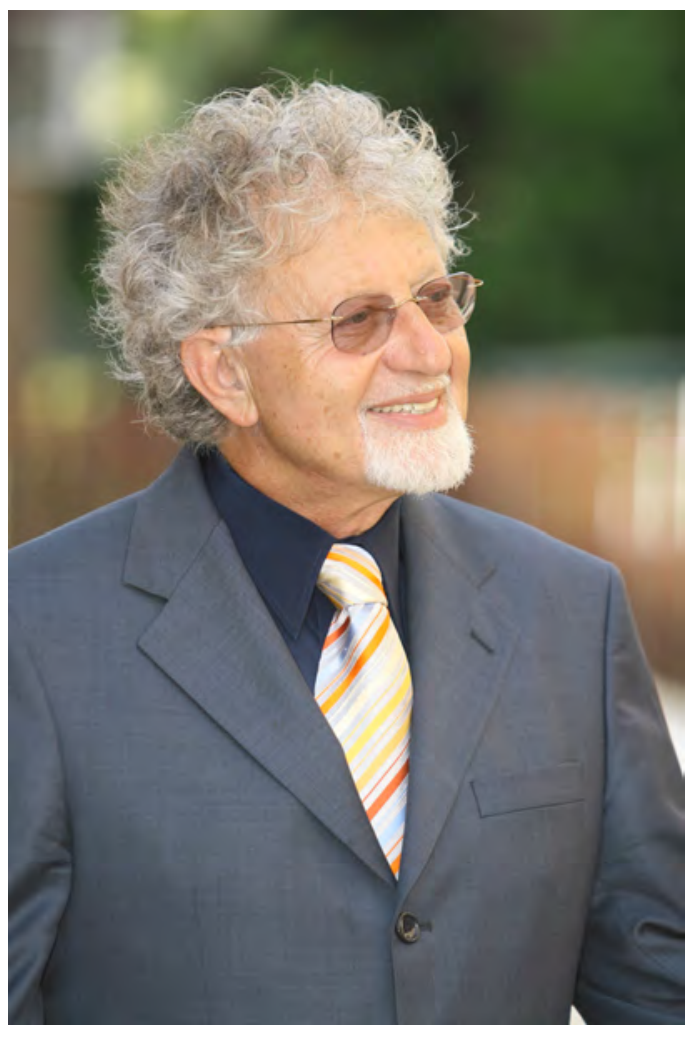
supported every step in my career with advice, recommendations, introducing me to people, writing articles or any other thing 1 needed. 1 was only one of his students. This approach was intended for all his students.

Adi always treated all the people around him as equals. Students, professors, young, old, rich, poor everybody was treated the same and spoken to as Adi's best friend. Adi never let another person down. He fulfilled all his obligations. He always kept his word and everyone knew it. Adi was self-made and self-reliant. From his education to his career, Adi was proud to be a dentist. In his clinic, he kept instruments from the first days of Dentistry. Adi loved the good things in life including art and music, travel and photography, food and wine, and friends and family. He was an amazing cook and could establish intense relationships in minutes. The number of people who called Adi their friend was immense. Adi never made an enemy. While he came across people he had to confront, he solved the problem by simply avoiding them. He always insisted that every crisis may be solved in a peaceful way. Adi was loyal to his friends. He maintained good ties even with his childhood friends. Adi loved a good joke, including every imaginable kind of ethnic joke. Yet his humor was never mean spirited, nor designed to hurt or humiliate. I never once heard him utter a racial slur, nor did he ever treat anyone with anything other than respect and kindness. Adi spoke openly of his admiration for the female figure. Adi's support for women's development in career and life created a perfect balance for his character. Adi had a quiet dignity, respecting himself the way 
he respected others. As he faced his final days, his body ravaged with the malady that ate his body, he never lost his good humor. He never had one moment of self-pity.

Farewell, Adi. You did good. You did real good. We miss you so much.......

Prof. Gabi Chaushu, DMD, MSc

Head, Department of Oral \& Maxillofacial Surgery

Rabin Medical Center, Beilinson Campus, Petah Tikva, lsrael

Head, Department of Oral \& Maxillofacial Surgery

The Maurice and Gabriela Goldschleger School of Dental Medicine

Tel Aviv University, Tel Aviv, lsrael

Editor Stomatology Edu Journal

DOI:10.25241/stomaeduj.2018.5(2).letter.1 


\section{Engaging on gerodontology with the platform for better oral health in Europe}

The platform for better oral health in Europe is a joint initiative of the Association for Dental Education in Europe (ADEE), the Council of European Chief Dental Officers (CECDO), the European Association of Dental Public Health (EADPH) and the European Dental Health Foundation (EDHF). The platform is made up of five core member organisations and thirteen associate members, including the European College of Gerodontology. Now under the leadership of Dr. Georgios Taskos, the goal of the platform is to create a common European approach towards improved oral health education, promotion, and access to care in Europe (http://www.oralhealthplatform.eu).

The associate members of the platform meet on a yearly basis in Brussels where the European College of Gerodontology is represented by its past President Dr. Gerry McKenna. The role of the platform has evolved in recent times and it has refocused its strategy towards lobbying for the inclusion of oral health indicators in the next iteration of the EU/ OECD Health at a Glance report. This report collates a vast range of health data across Europe, but cur-

\section{Dr. Gerry McKenna}

Past President, European College of Gerodontology

Senior Lecturer / Consultant in Restorative Dentistry

Centre for Public Health

Queen's University Belfast

Belfast BT7 1NN, UK rently does not include any oral health statistics. The platform's secretariat has made good progress on this front, after a series of meetings with DG SANTE officials.

The second key focus for the platform remains the collection of best practices in oral health. However, now there is more focus on aligning these initiatives with those already underway at the EU Commission level. The platform is currently drafting up a set of criteria which will be used to assess each best practice and how it matches the output from the Joint Action on Chronic Diseases (CHRODIS). The Platform remains supportive of suitable examples focused on older adults and from the European College of Gerodontology.

Engaging with the platform for better oral health in Europe remains an important focus for the European College of Gerodontology. The platform provides an avenue for meaningful engagement with European policymakers in order to ensure that the oral health of older people is prioritized. 


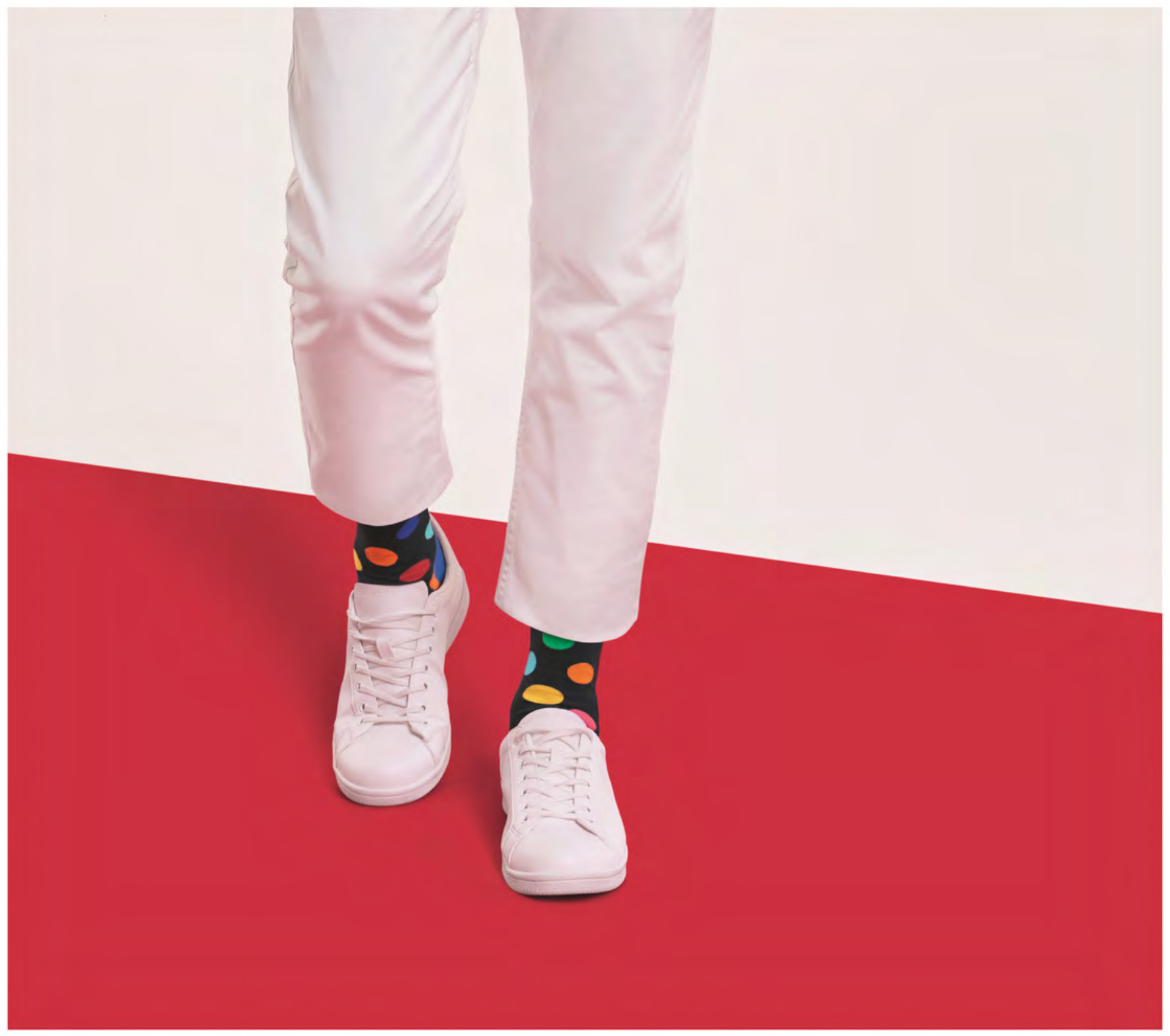

\section{CEREC}

Do it your way

CEREC is just what you need it to be. From the initial scan to a full CAD/CAM system providing single-visit solutions - CEREC is your partner every step of the way. Be free to start your digital workflow just the way you want. With CEREC.

Conquer your future now at dentsplysirona.com/CEREC

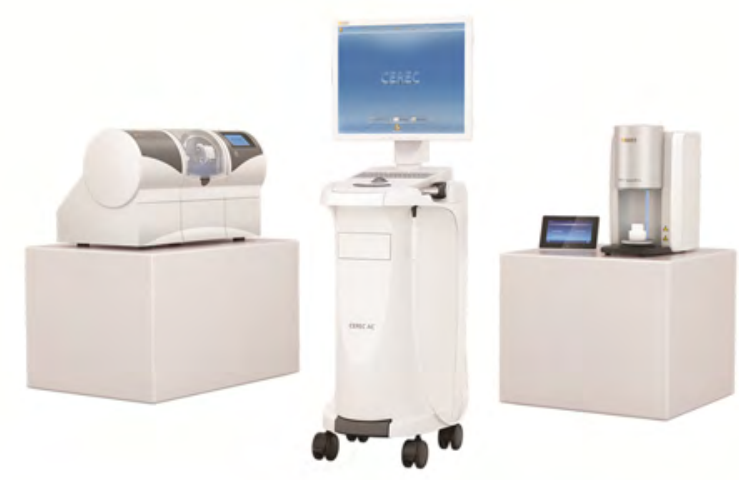

Office \& Showroom

98A Vulturilor Street, $3^{\text {rd }}$ District

RO-030857 Bucharest, Romania

Tel: +40 774074094

e-mail: office.romania@dentsplysirona.com

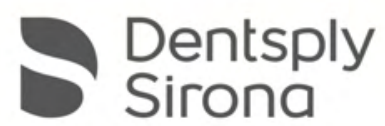




\section{The Second International Congress of the Faculty of Dental Medicine, "Carol Davila" University of Medicine and Pharmacy Bucharest, Romania, and the 17th International Congress for Students and Young Doctors "stuDENT"}

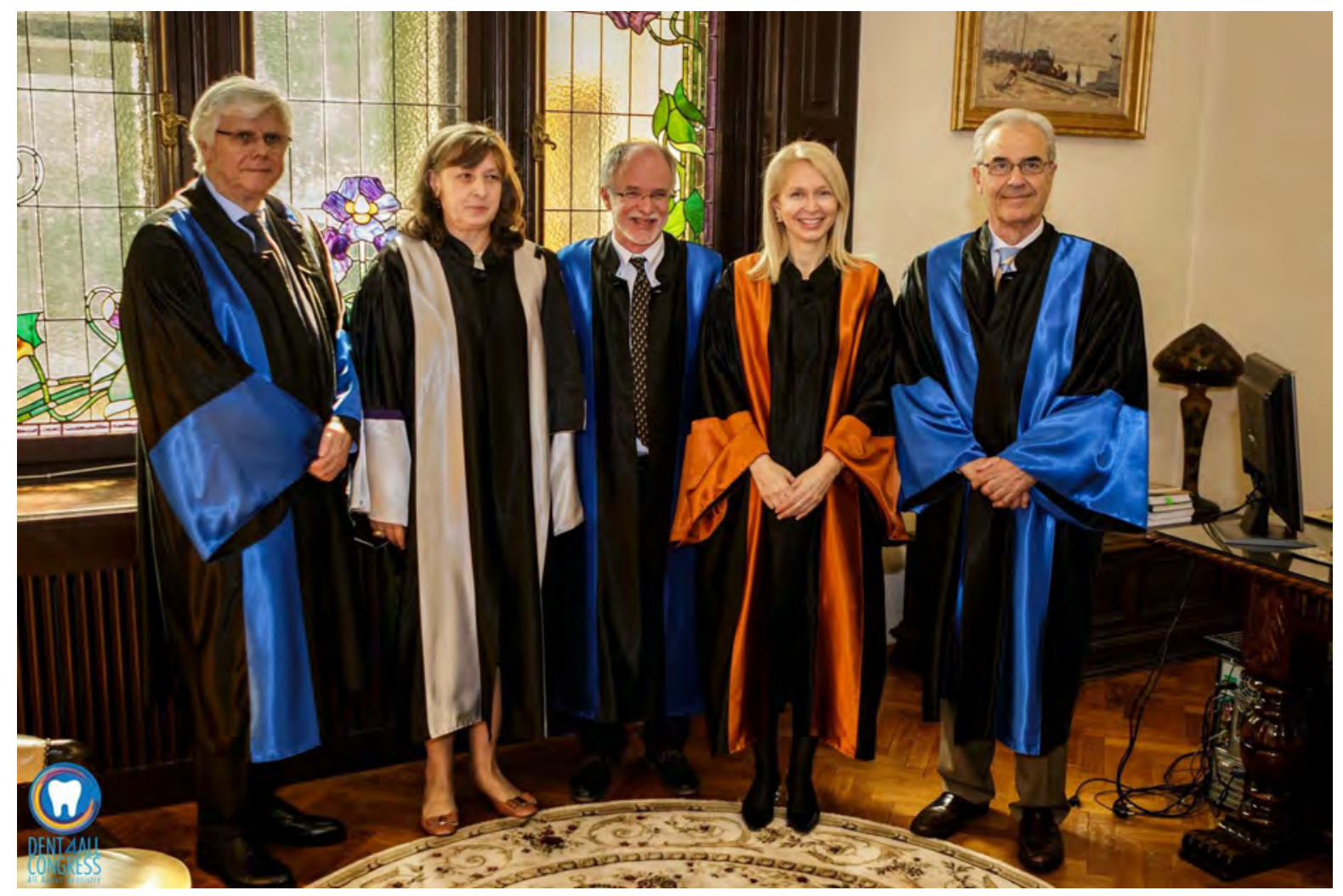

Prof. Dr. Gottfried Schmalz, Vice Rector Prof. Dr. Ecaterina Ionescu, Dean Prof. Dr. Aaron Palmon, Dean Assoc. Prof. Dr. Paula Perlea, Prof. Dr. lannis latrou

March was a month full of dental scientific events in Romania. But a core event took place in Bucharest, on March 15th-18th, at the Palace of the National Military Circle, where we had the pleasure to organize the Second International Congress of the Faculty of Dental Medicine, "Carol Davila" University of Medicine and Pharmacy, along with the 17th International Congress for Students and Young Doctors "stuDENT".

The congress was a great opportunity to relate to other professionals in the field of dentistry, to exchange knowledge, discuss and cover the major concerns that dentists face nowadays and hear about the latest information on modern dentistry. The Military Club was built in 1912 on the site of the former Sarindar Monastery (the name is inscribed on the fountain in front of the building). This neoclassic masterpiece, designed by the Romanian architect Dimitrie Maimaroiu, was built to host the social, cultural and educational events organized by the Romanian army. Nowadays, its elegant and wonderful halls are also used to host different cultural, educational and scientific events.

With a rich scientific program, the Congress was held 
in five different congress halls, where different conferences, oral communications and workshops took place. Part of the venue was reserved for the presentation of the latest products and technologies in dentistry.

The three days rich in scientific activities included eighteen sessions and 10 workshops. Out of the total18 sessions, 2 sessions - preclinical and clinical - were dedicated to the dental students and young doctors who had the chance to present their own research achievements.

As previously mentioned, the congress was intended for any dentist or even student who wanted to enhance his/her knowledge of dentistry, as all dental specialties were covered. This year, the main topic of the Congress was 'Dentistry nowadays', and subjects on all dental topics were presented: Endodontology, Periodontology, Oral and maxillofacial surgery, Orthodontics, Oral Medicine, Prosthodontics, Operative Dentistry, but also subjects related to Dentistry, such as: Neurology, Otorhinolaryngology, Anatomy and others.

More than 20 international speakers honored our invitation:

- Prof. Dr. Peter Eickholz, Goethe-Universität, Frankfurt, Germany (Periodontology - Chief of the department);

- Prof. Dr. Thomas Humel, University of Dresden, Germany (Dental Pharmacology and Toxicology);

- Prof. Dr. Michele Mignogna, University of Napoli, Italy (Oral Medicine - Chairmanof the department);

- Prof. Dr. Apostolos I. Tsolakis, University of Athens, Greece (Orthodontics);

- Prof. Dr. Anda Kfir, Goldschleger School, Tel Aviv, Israel (Endodontology - Chairman of the department);

- Prof. Dr. Igor Shugailov, Department of Stomatology, RMAPO, Moscow, Ministry of Health of the Russian Federation, Rector of the Academy for Innovative Dentistry (General Dentistry);

- Prof. Dr. Svante Twetman, University of Copenhagen, Denmark (Restorative Dentistry);

- Prof. Dr. Aaron Palmon, Dean at the Hadassah Hebrew University, Jerusalem, Israel (Oral Medicine);

- Prof. Dr. Betul Kargul, Marmara University, Istanbul, Turkey (Pediatric Dentistry - Chairman of the department);

- Prof. Dr. Gottfried Schmalz, University of Regensburg, Germany (Restorative Dentistry and Periodontology);

- Visiting Prof. Dr. Domenico Baldi, University of Genova, Italy (Prosthodontics);
- $\quad$ Prof. Dr. Giuseppe Colella, Universitaty of "Luigi Vanvitell" District, Italy (Dental Surgery - head of department);

- $\quad$ Prof. Dr. Stylianos Dalampiras, Aristotle University, Thessaloniki, Greece (OMF Surgery);

- Prof. Dr. Elisabetta Cotti, University of Cagliari, Italy (Endodontology-Chair of the department);

- Prof. Dr. Ioannis latrou, University of Athens, Greece (OMF Surgery);

- Prof. Dr. Itzhak Abramovitz, Hadassah Hebrew University, Jerusalem, Israel (Endodontology Chief of the department);

- Dr. Miriam Grushka, Toronto, Canada (Oral Medicine);

- Dr. Gabriel Tuluş, Germany (Endodontology);

- Dr. Martin Koch, University of Heidelberg, Germany (Pediatric Dentistry);

- Dr. Basel Azar, Palacký University, Prague, Czech Republic (Prosthodontics) and

- Dr. Giorgios Tsiogkas, Greece, Member of the FDI's Standing Committee of Liaison and Support.

The workshops approached interesting and useful topics: Laser in Dentistry, the Latest Generation of Composite, Dental Imagistic, Oral Surgery, Basic Life Support, Knots and Sutures, Impressions from A to $Z$, the Isolation with Rubber Dam, Implantology and Endodontics.

Last year Prof. Dr. Michael Glick and Prof. Dr. Jean François Roulet were presented with the DOCTOR HONORIS CAUSA of the "Carol Davila" University of Medicine and Pharmacy title, while this year other three important professors and scientists were honored with this prestigious title: Prof. Dr. Aaron Palmon, Prof. Dr. Gottfried Schmalz and Prof. Dr. loannis latrou.

The event could not have been made possible without the intense work and passion of the very comprehensive organizing team, with Faculty members of Faculty of Dental Medicine, and members of the Bucharest Dental Students' Association.

We were honored to cooperate with the most prestigious scientific and academic institutions that represent dentists from different specialties in matters related to the Congress organization:

- Romanian Association of Endodontics

- Romanian Society of Oral Medicine

- National Association of Pediatric Dentistry from Romania

- Romanian Society of Stomatology

Also, other doctors' and medical students' organizations supported us and were our official partners:

- National Association of Neurologists

- EDSA - European Dental Students' Association

- IADS - International Association of Dental Stu- 


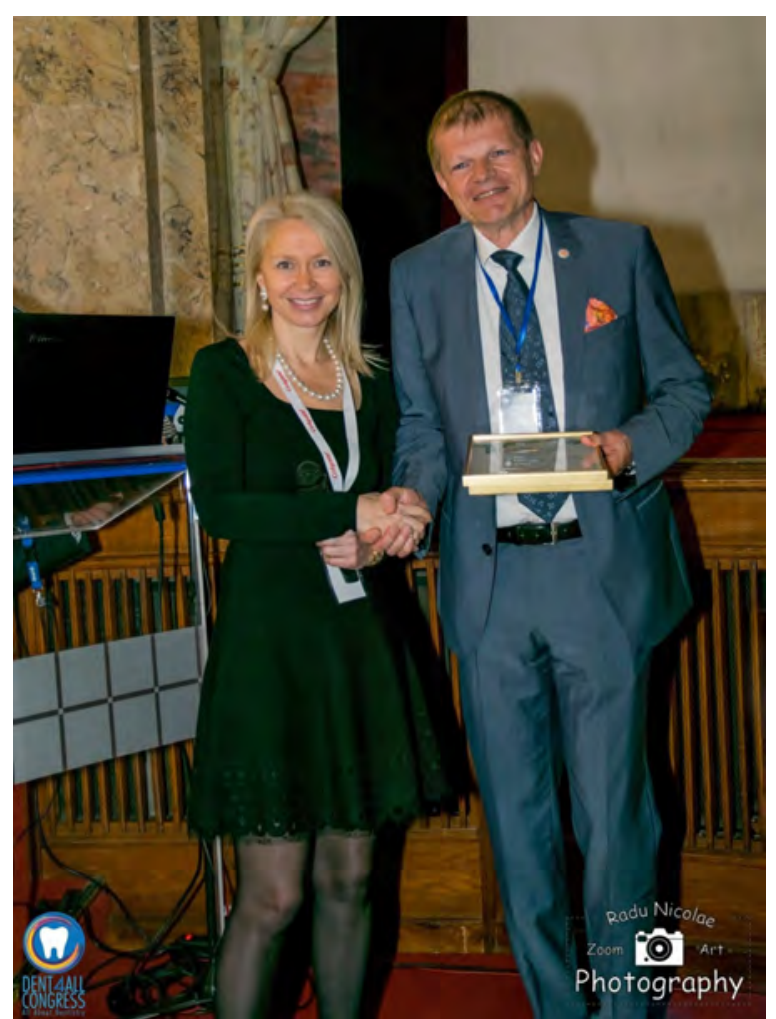

Awarding the Invited Speaker Diploma Prof. Dr. Peter Eickholz, Chief of Department of Periodontology, Faculty of Medicine, Goethe University Frankfurt / Main, Germany.

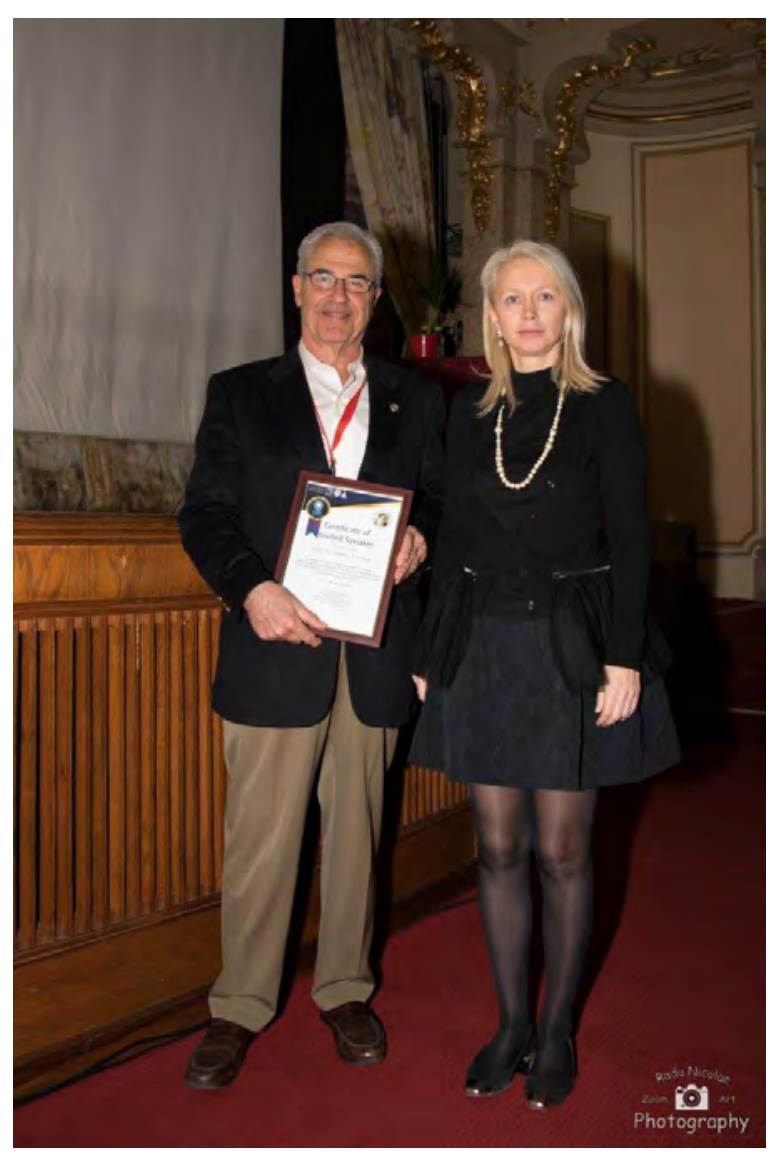

Awarding the Invited Speaker Diploma Prof. Dr. loannis latrou, Head of Department of Oral and Maxillofacial Surgery (OMFS) at the Dental School of the National and Kapodistrian University of Athens.

\section{dents}

- $\quad$ SSCR - Romanian Surgery Students' Society

- $\quad$ SSMB - Bucharest Medical Students' Society

- USR - Romanian Students' Union

The Second International Congress of the Faculty of Dental Medicine, "Carol Davila" University of Medicine and Pharmacy was a memorable scientific event, which contributed essentially towards the development of dentistry. It is a project, launched in 2017 by the Dean of the Faculty of Dental Medicine, Assoc. Prof. Dr. Paula Perlea. Each new edition of the congress is a mile stone in the scientific and practice-related field of dentistry, while helping improve knowledge in dental medicine.

Assoc. Prof. Dr. Paula Perlea

President of the Congress

Dean of the Faculty of Dental Medicine

"Carol Davila" UMPh Bucharest, Romania

Radu Gabriel Toma

President of the Dental Students Association

Bucharest, Romania

DOI: 10.25241/stomaeduj.2018.5(2).news.2 


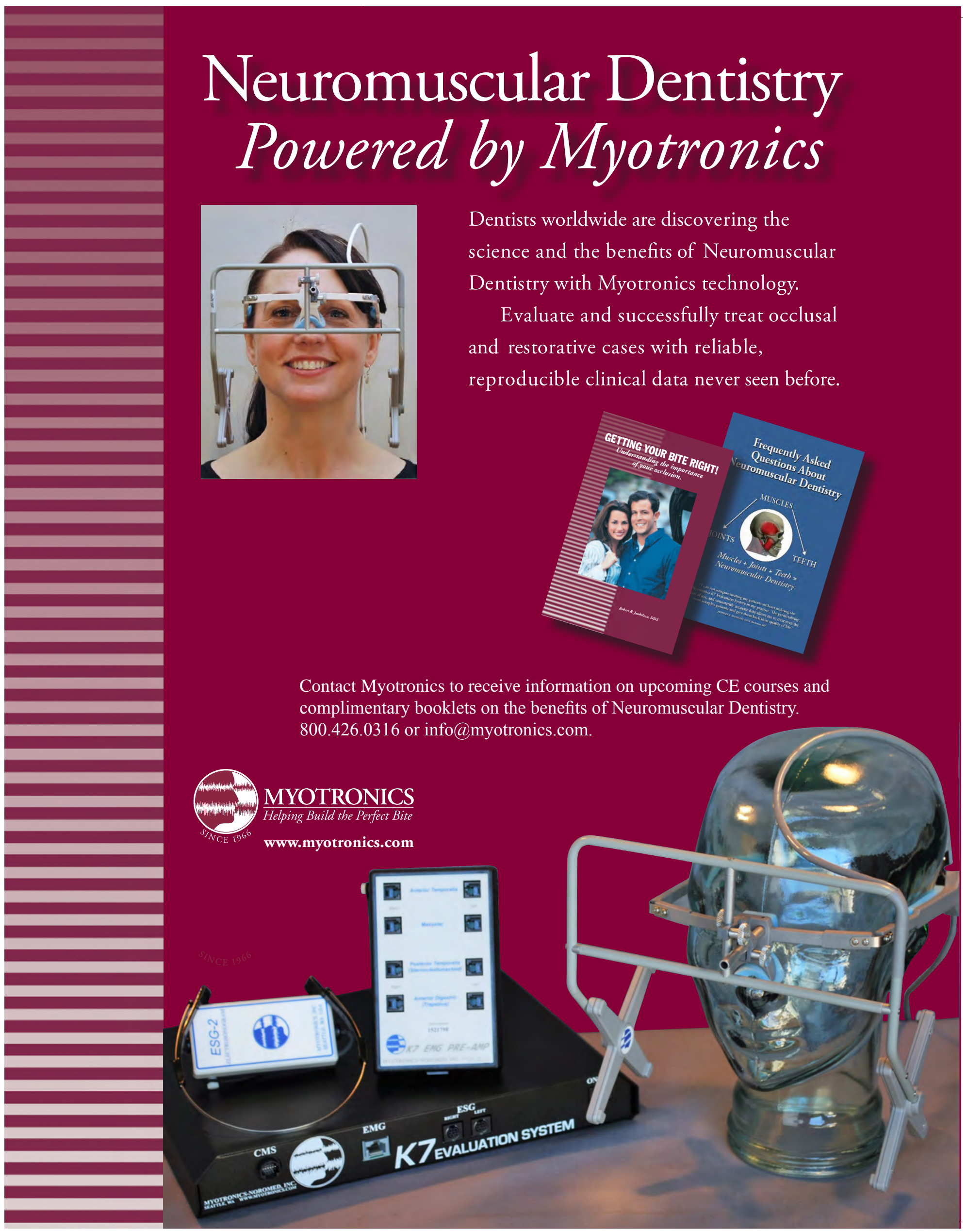




\section{stonacdij}

Stoma Edu J. 2018;5(2):83

From The Journal of the American Dental Association

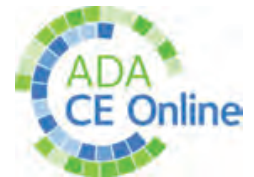

\section{JADA ONLINE CE EXAMS}

http://jada.ada.org/ce/home

http://jada.ada.org/ceworksheets

January 2018

VWilliam Parker, DDS; Cameron G. Estrich, MPH; Elliot Abt, DDS, MS, MSc; Alonso Carrasco-Labra, DDS, MSc; Jonathan B. Waugh, PhD; Aaron Conway, BN (Hons), PhD; Ruth D. Lipman, PhD; Marcelo W. B. Araujo, DDS, MS, PhD BENEFITS AND HARMS OF CAPNOGRAPHY DURING PROCEDURES INVOLVING MODERATE SEDATION $A$ rapid review and meta-analysis

J Am Dent Assoc. 2018 Jan;149(1):38-50. doi: 10.1016/j.adaj.2017.08.030.

This article has an accompanying online continuing education activity available at: http://jada.ada.org/ce/home.

https://doi.org/10.1016/j.adaj.2017.08.030.

https://jada.ada.org/article/S0002-8177(17)30786-9/fulltext 


\title{
BEAM PROFILE CHARACTERIZATION OF A DENTAL LIGHT CURING UNIT USING A SPECTROMETER-BASED METHOD \\ Jean-François Roulet ${ }^{1 a^{*}}$, Mateus Garcia Rocha ${ }^{2 b}$, Chiayi Shen'c, Marwah Majid Khudhair'1d, Dayane Carvalho Ramos Salles de Oliveirae
}

\author{
'Department for Restorative Dental Sciences, Center for Dental Biomaterials, College of Dentistry, University of Florida, 1395 Center Drive \\ Gainesville, FL-32610, USA \\ 2Department of Restorative Dentistry, Piracicaba Dental School, State University of Campinas, Areiao 13419-110, Piracicaba SP, Brazil
}

\author{
a Dr med dent, Drhc, Professor, Director of Center for Dental Biomaterials \\ bDS, MSC, PhD, Researcher \\ PhD, Professor \\ dDDS, Preceptor \\ eDDS, MSC, PhD, Post-Doctoral Researcher
}

\begin{abstract}
DOI: 10.25241/stomaeduj.2018.5(2).art.1

Aim: The study aimed to characterize a broad spectrum light curing unit (LCU) by measuring the light beam profile output of the LCU using a spectrometer-based method and correlate it with a standard camera-based beam profile method.

Materials and Methods: A broad spectrum LED LCU (Ascent OL5, CAO Group) was mounted above a spectrometer (MARC ${ }^{\circledR}$ Resin Calibrator, BlueLight Analytics) at exposure distances of 1.0, 1.5 or $2.5 \mathrm{~mm}$. The position of the center of the LCU was aligned with the spectrometer's cosine corrector sensor, and then moved in 1-mm increments in the $x$-y plane, while concomitantly recording the irradiance. The recorded irradiance was systematically organized and reported in function of the distance from the center of the LCU exiting window. Using a standard camera-based beam profiler, a beam profile of the LCU was obtained and the above approach was emulated to the beam profile. For both methods, the irradiance decreases related to the value measured at the center position was analyzed by calculating the slope, using a linear correlation.

Results: Both methods showed that moving away from the center showed decreased irradiation. The beam profile of the LCU is asymmetric. The inhomogeneity of the beam was slightly lower with farther distance from the LCU's light exciting window. Conclusion: The spectrometer-based method was able to characterize the beam profile of the LCU and can be used in the evaluation of LCUs.

Keywords: light curing units, beam profile, spectrometric analysis.

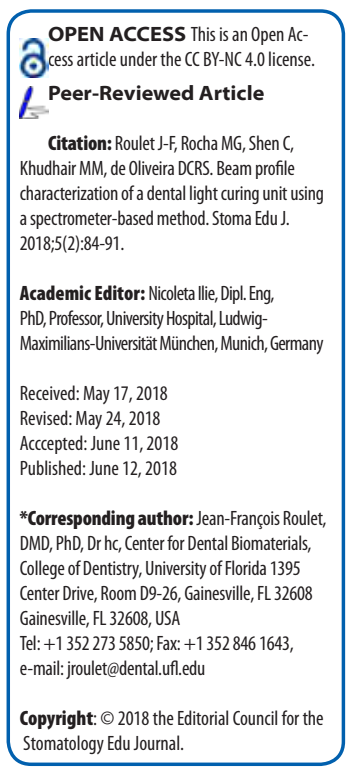

\section{Introduction}

Light curing has revolutionized the placing of composite restorations [1]. Furthermore, light curing is used for multiple other applications such as cementing dental fixed prostheses, including indirect restorations made from ceramics or composites, sealing fissures, and bonding orthodontic brackets. Nowadays, market available light curing units (LCUs) are very well build and really intuitive which make dentists assume that light curing is a simple procedure, however it is not. First, to be cured properly, a resin-based composite (RBC) must be exposed to a visible light energy at the proper wavelength range (blue or blue and violet) and a radiant exposure ranging from $8-16 \mathrm{~J} / \mathrm{cm}^{2}$ [2], which means that, depending on the irradiance the RBC is receiving, exposure times up to $60 \mathrm{~s}$ are required [3]. The key problem is that dentists believe that a single irradiance value of LCU reported and stated by the LCUs' manufacturer homogeneously reaches the entire RBC surface, which is not the case [4].

It starts with the correct positioning of the LCU on top of the RBC, controlled by the dentist only. Very large differences have been documented when comparing the light curing of untrained vs trained dentists [5]. Furthermore, the dentist should be aware that the irradiance of an LCU diminishes as the distance increases from the light output window [6] and, besides that, the cleanliness aspect of the LCU light tip is fundamental, because any residual RBC stuck onto the light exiting window may also reduce the light irradiance, which is a huge problem that affects the geometry of the light tip which may create shadows $[7,8]$, and thus the depth of the cure may be reduced. Furthermore, depending on their composition (filler, resin mix, pigments and opacifiers), RBCs absorb more or less light [9], which reduces the depth of the cure as well. Based on this knowledge, recommendations for dentists about how to light cure were formulated by a group of researchers, industry representatives, editors and dentists [10-12]. This group is very active and has published recommendations in dental journals, newsletters and websites of associations worldwide. Multiple studies have shown that the LCUs as used in practices do not yield the light intensity output stated by the manufacturers [13-16]. The outcome of light curing can be influenced as well by factors which are governed by the design of the LCU and of course by the RBCs themselves $[9,17]$. The characteristics of the LCUs have a strong influence on the incident irradiance received by a material due to a multitude of 
factors. This was observed for the first LCUs operating in the visible light range, based on Quartz-tungsten halogen bulbs which had been developed for other purposes than dentistry [18]. These light curing units had the advantage of a broad light spectrum [19]. However, since only the blue light was usable to cure RBCs, infrared-blocking blue bandpass filters (at $510 \mathrm{~nm}$ ) were built in the LCUs. These filters would deteriorate over time, diminishing the light emission properties of the LCUs [20]. There were more characteristics that basically made them problematic [21], such as instability of the output, spectral distribution and unreliable timers. Some LCUs had a quite homogeneous beam profile, which means that the surface of the irradiated composite gets the same energy density on every area. This is possible because in a halogen light the hot wire creating the light is almost a point light source, which can be captured with a reflector and guided into a beam. However already in 1986 it was shown that some LCUs had an inhomogeneous light beam [21]. This was confirmed using an acrylic optical fiber with a $1 \mathrm{~mm}$ diameter moved at $1 \mathrm{~mm}$ steps in $x-y$ direction in front of the light emitting tip of the LCU. With this method the local light intensity of three QTH lights, a plasma arc light and a LED light was measured [22].

For many reasons LED LCUs were a big improvement. LEDs are not considered a point light source, since they have the shape of a flat surface emitting the light. Early LEDs had very little power $(1.2 \mathrm{~mW})$ and thus were not usable for light curing devices [20]. But, over the years they became much more powerful (e.g. $123 \mathrm{~mW}$ ), thus multiple LEDs were used as a light source which made it difficult to bundle the emitting light [20]. Modern LED LCUs use 1-8 LEDs in an array which is flat [23], which makes bundling the light more difficult and may result in an inhomogeneous beam profile, despite being a mono-wavelength unit (peak at around 450-470 nm). Finally, the last step in development is the broad spectrum LED LCU, which uses different types of LEDs, emitting light with different wavelengths (violet light (380 - $420 \mathrm{~nm}$ ) and blue light $(420-495 \mathrm{~nm})[8,20]$. Therefore they are able to activate different types of photoinitiators [24]. However, these LED LCUs show more or less pronounced inhomogeneity of the beam profiles [2528]. This means that not every point on an irradiated surface gets exposed to the same level of irradiation from the different wavelengths, especially in depth [29-31]. Thus, if the dentist aims for a short exposure time, some areas of the irradiated RBC may not obtain the minimally required light radiant exposure for optimal monomer conversion [24].

The power of the light source determines the energy it can emit; the design of the optical system to capture and bundle the light emitted from the light source determines the degree of spread of the light after it exits the light curing fiber bundle or lens. Turbo tips, which concentrate the light on a smaller surface to increase the irradiation usually have a larger spread than conventional tips [24]. Usually, the spread is considerable, yielding to less irradiation the farther away the target RBC is from the light exciting window $[25,26]$.
A light beam profile is the $2 \mathrm{D}$ irradiance intensity plot for a camera-based beam profiling system, requires a thermopile (power meter), a spectrometer, a CCD or CMOS camera, a modern computer with a frame grabber card to digitize the signal, and software for controlling the frame grabber card, displaying beam profiles and making respective quantitative calculations. Also, an optomechanics apparatus, such as diffusive glasses and band pass filters, is almost always needed to attenuate and/or filter the light beam before going into the camera $[27,28]$. In general, it cannot be bought together, and requires knowledge to buy the complete and right equipment. Moreover, the operator needs to know how to use all these parts together.

Thus, the objective of the present study was to characterize a broad spectrum LED LCU with a known inhomogeneous beam profile using a spectrometerbased method and correlate it with a standard camera-based beam profile method. The following null hypotheses were tested: 1) The irradiation is at the same level all over the irradiated surface. 2) The irradiation as captured with the spectrometerbased method is similar to the irradiation shown by a standard camera-based beam profiler.

\section{Materials and Methods}

For this method-validation study a broad-spectrum LED LCU (Ascent OL5, CAO Group South Jordan, UT, USA) was used. Its design leads to the assumption that it will generate an inhomogeneous beam profile, since it has one LED emitting blue light mounted in the center and 4 small LEDs emitting violet light mounted at the periphery (Fig. 1). The LCU was attached to an $x-y-z$ positioning device mounted on an optical bench in order to standardize the positioning of the light beam centered above the cosine corrector light signal collector of a spectrometer (MARC $®$ Resin Calibrator, BlueLight Analytics, Halifax, Canada) with the handle towards the right side ("EAST", Fig. 2) at an exposure distance of $1.0,1.5$ or $2.5 \mathrm{~mm}$. The diameter of the cosine corrector was $3.9 \mathrm{~mm}$. Using the translation stage, the position of the geometrical center of the LCU was first aligned with that of the cosine corrector and then moved in 1-mm steps in the $x-y$ plane ("EAST" - "WEST" and "NORTH" - "SOUTH") (Fig. 2).

The irradiance was assessed at each above described condition. The irradiance loss was visualized using bar graphs for the East-West (long axis of the LCU) and the North - South direction. The slopes of the irradiation decrease were calculated and compared.

To obtain standard camera-based beam profile images, the same LCU was attached to an $x-y-z$ positioning device mounted on an optical bench in order to standardize the positioning of the light beam in contact with a diffusive surface of a frosted diffuser target (DG20-1500, Thorlabs, Inc., Newton, NJ, USA) while the resulting image was recorded using a camera (NEX-F3, Sony Corporation, Tokyo, Japan) with a $50 \mathrm{~mm}$ focal length lens. To assess the irradiance distribution of the different LED emission wavelengths from the broad spectrum LED, the beam profiler was used with the addition of bandpass filters (Thorlabs, 


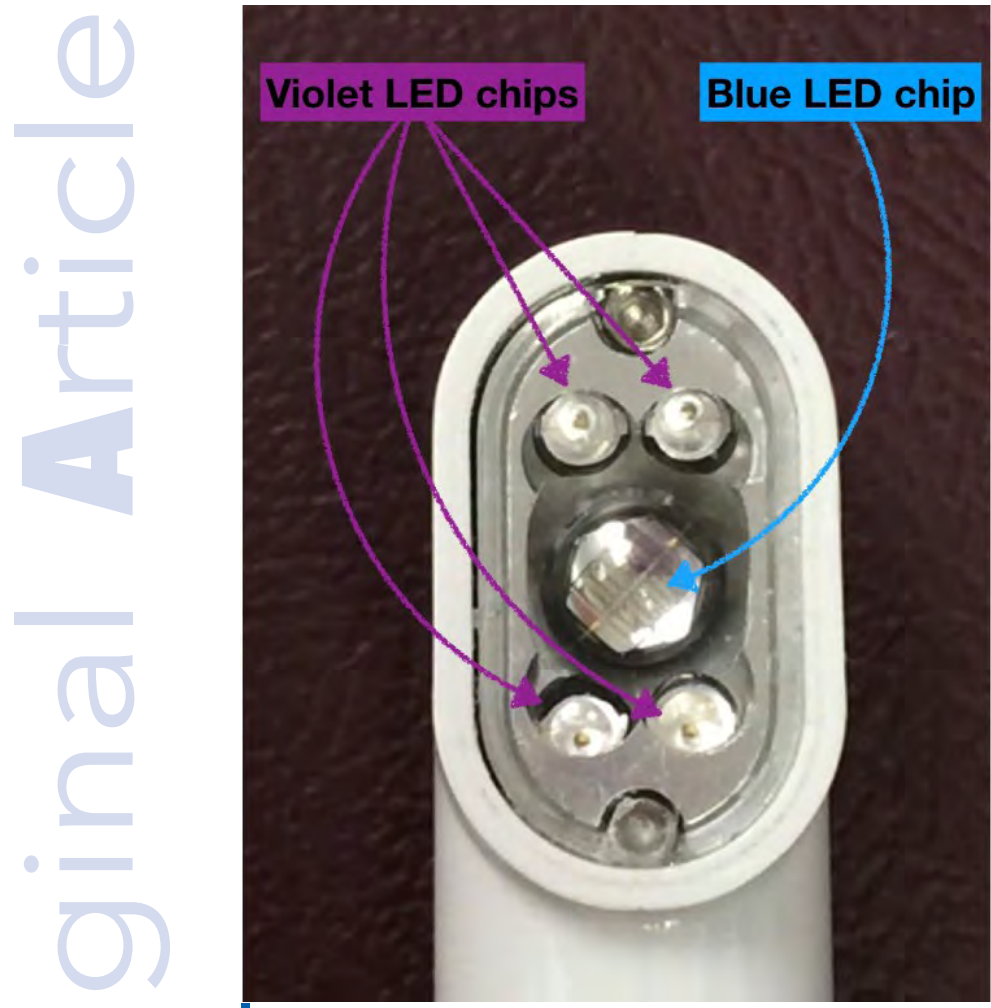

Figure 1. LED positions in the Ascent OL5 LCU.

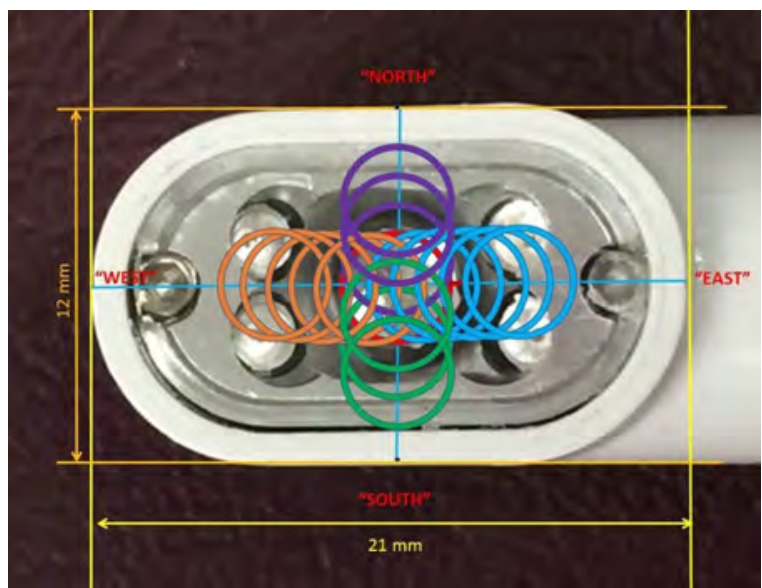

Figure 2. Measuring points as related to the position within the light exit window. Blue cross $=$ geometrical center of the light exiting window. Orange circles ="WEST",Light blue circles ="EAST", Purple circles ="North" and green circles = "SOUTH".

Inc., Newton, NJ, USA) placed in front of the camera lens. A bandpass filter centered first at $400 \mathrm{~nm}$ with a $40 \mathrm{~nm}$ full width at half maximum (FB400-40) was used to identify the LED chips with spectrum emission peaks at $400 \mathrm{~nm}$ (violet light). A different bandpass filter, centered at $450 \mathrm{~nm}$ with a $40 \mathrm{~nm}$ full width at half maximum (FB450-40) was used to identify the LED chips generating emission peaks near $450 \mathrm{~nm}$ (blue light). To produce calibrated images and data showing the irradiance patterns across the surface of the broad spectrum LED, the mean power values, obtained using the MARCD resin calibrator were entered into an open source optical analysis software (Fiji, ImageJ, National Institute of Health, Bethesda, MD, USA) [32] to process the camera-based method beam profile images. The total spectral power output was integrated with each bandpass filter spectral optical density to calibrate each image. The scaled numerical data associated with each image were exported into a computer graphic software (Origin Pro, OriginLab Co., Northampton, MA, USA).

The beam profiles were captured at 1, 1.5 and 2.5 $\mathrm{mm}$ from the light exciting window of the LCU and further analysis of the local intensities was performed the identical way as done with the MARC ${ }^{\circledR}$ resin calibrator. A virtual aperture of $3.9 \mathrm{~mm}$ was created using the computer graphic software and the average irradiation on this surface was measured by first placing this aperture in the geometrical center of the beam profile and then moving it into $1 \mathrm{~mm}$ steps in the "EAST - WEST" and "NORTH - SOUTH" direction. Bar graphs comparable to the ones created with the spectrometer-based method were generated. In a second step, to calculate the magnitude of the decrease in the light irradiance according to the distance from the center of the LCU, a linear correlation fit was made to compare the slopes produced by the spectrometer-based method with the slopes generated from the camera-based method.

\section{Results}

At $1 \mathrm{~mm}$ distance from the light exciting window, the broad-spectrum LED had a total irradiance of 1159 $\mathrm{mW} / \mathrm{cm}^{2}$, however, $1088 \mathrm{~mW} / \mathrm{cm}^{2}$ was within the blue wavelength range (420 - $495 \mathrm{~nm}$ ) and only $71 \mathrm{~mW} /$ $\mathrm{cm}^{2}$ was within the violet wavelength range (380 $420 \mathrm{~nm}$ ). As shown in Fig. 3, it is clear that the majority of the power emitted ( $\mathrm{mW}$ ) by the broad-spectrum was within the blue wavelength range and the violet emission from this LED is considered insignificant.

The results of the irradiance measurements at 1, 1.5 and $2.5 \mathrm{~mm}$ distance from the light exciting window are shown in Fig. 4. As expected, there is a decrease in irradiance the farther away the measuring area is from the center. To allow better direct comparisons, the slopes of these decreases were calculated as shown in Table 1. Higher absolute value means greater rate of reduction in irradiance with distance from the geometric center of the LCU. Note that the farther away the light source is from the sensor, the flatter the slope, which means that the inhomogeneity of the beam profile decreases.

Fig. 5 shows the beam profiles obtained at 1, 1.5 and $2.5 \mathrm{~mm}$ distance from the light exciting window of the LCU. Note the spread of the beam and the inhomogeneity of the irradiation. Fig. 4c, Fig. $4 d$ and Table 1 show the data as extracted from the beam profiles. Note the similarity of the pattern.

\section{Discussion}

The LCU used in this study was selected because based on its design an inhomogeneous beam profile was to be expected. The objective of the study was to use a spectrometer-based method to detect inhomogeneity in the light beam profile output of a LCU. Therefore, it makes sense to use a LCU, where this characteristic is to be expected.

The Ascent OL5 broad spectrum LCU had a significant higher amount of blue light being emitted than violet 

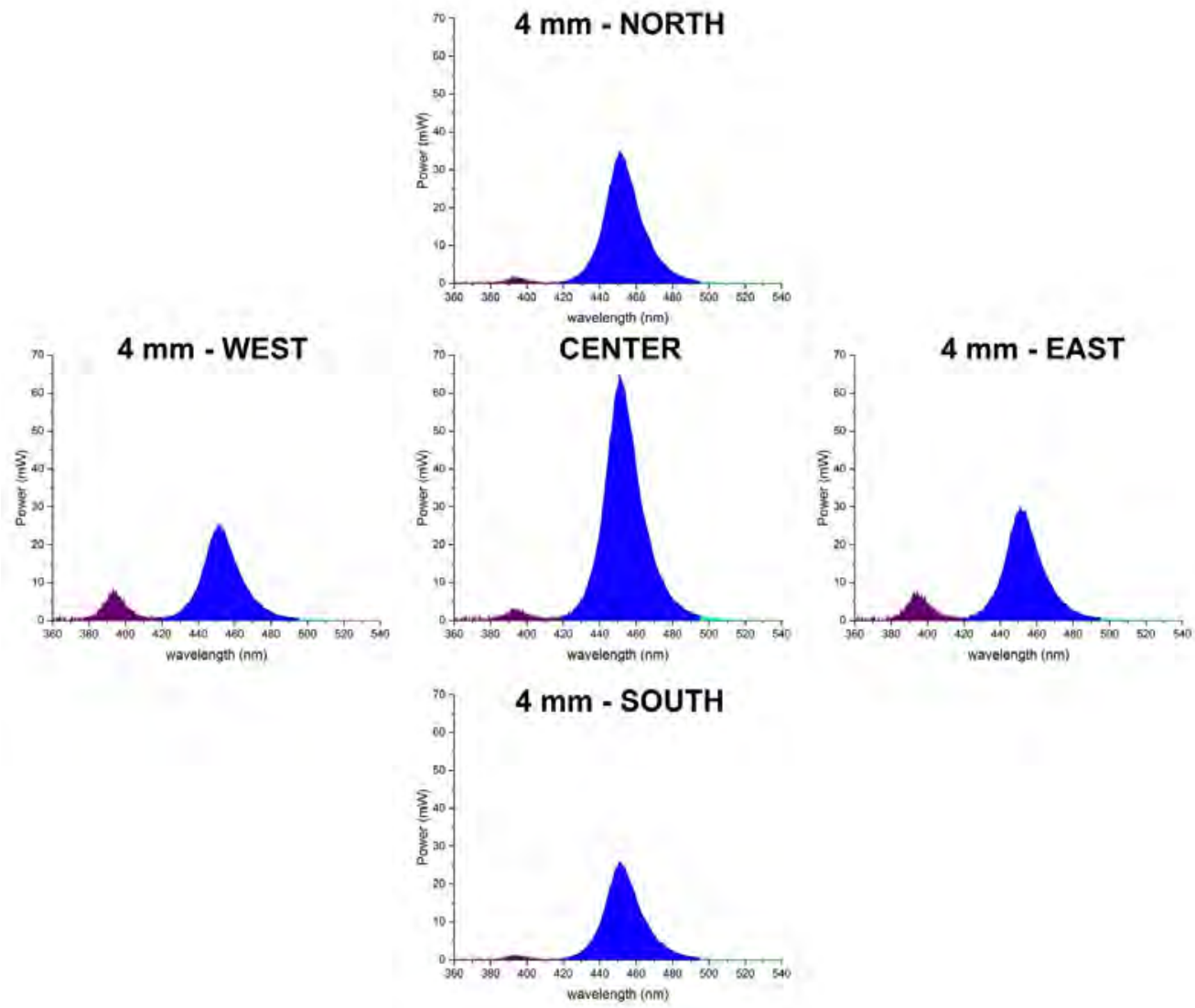

I Figure 3. Spectral radiant power ( $\mathrm{mW} / \mathrm{nm}$ ) of the broad spectrum LED at $1 \mathrm{~mm}$ distance according to the CENTER and $4 \mathrm{~mm}$ distant from the CENTER in the NORTH-SOUTH and WEST-EAST directions.
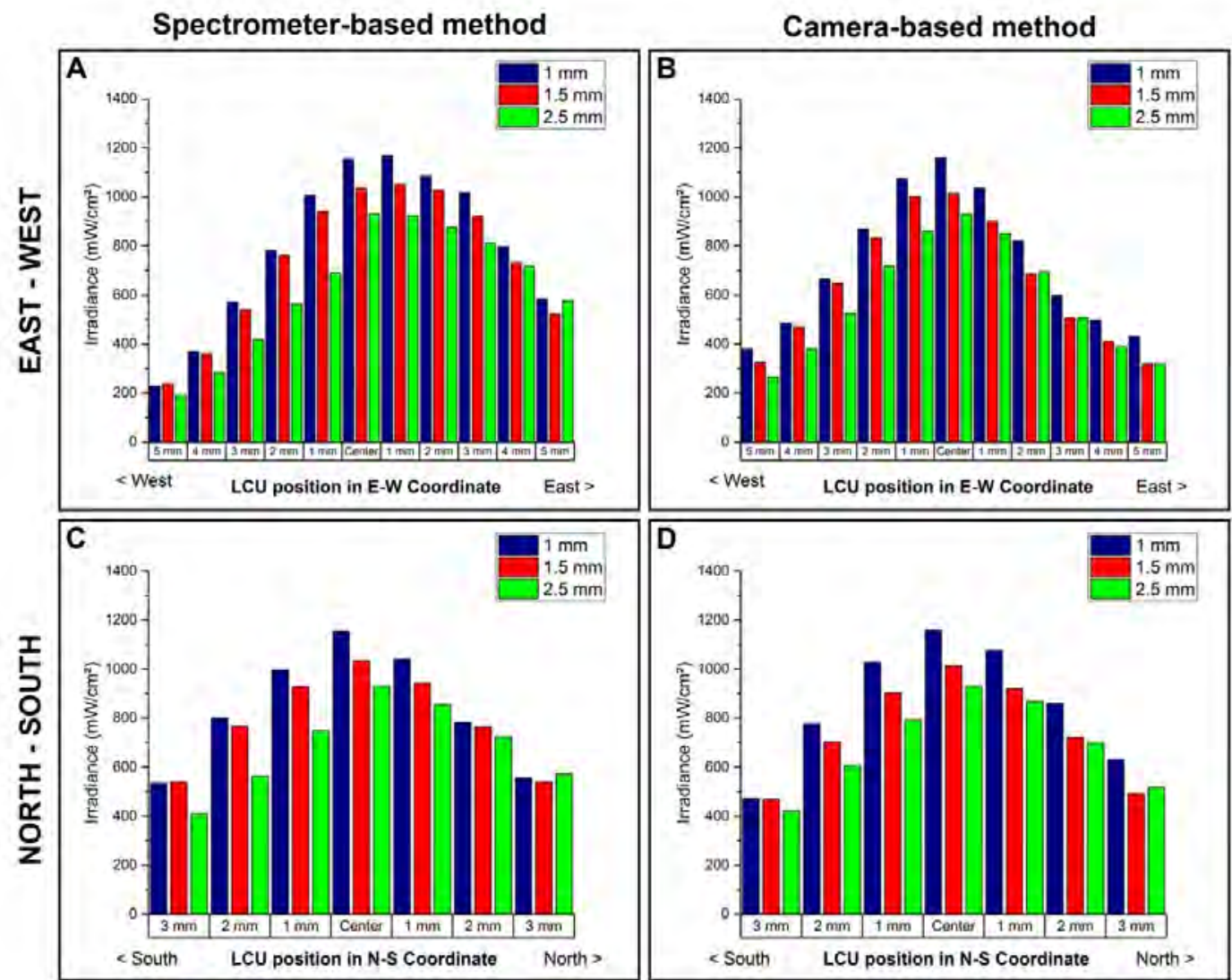

I Figure 4. Irradiation measured at 1, 1.5, 2.5 mm distance from the light exiting window as a function of the offset in $\mathrm{mm}$ from the center position in the East-West and North-South direction using the spectrometer-based and the camera-based methods. 


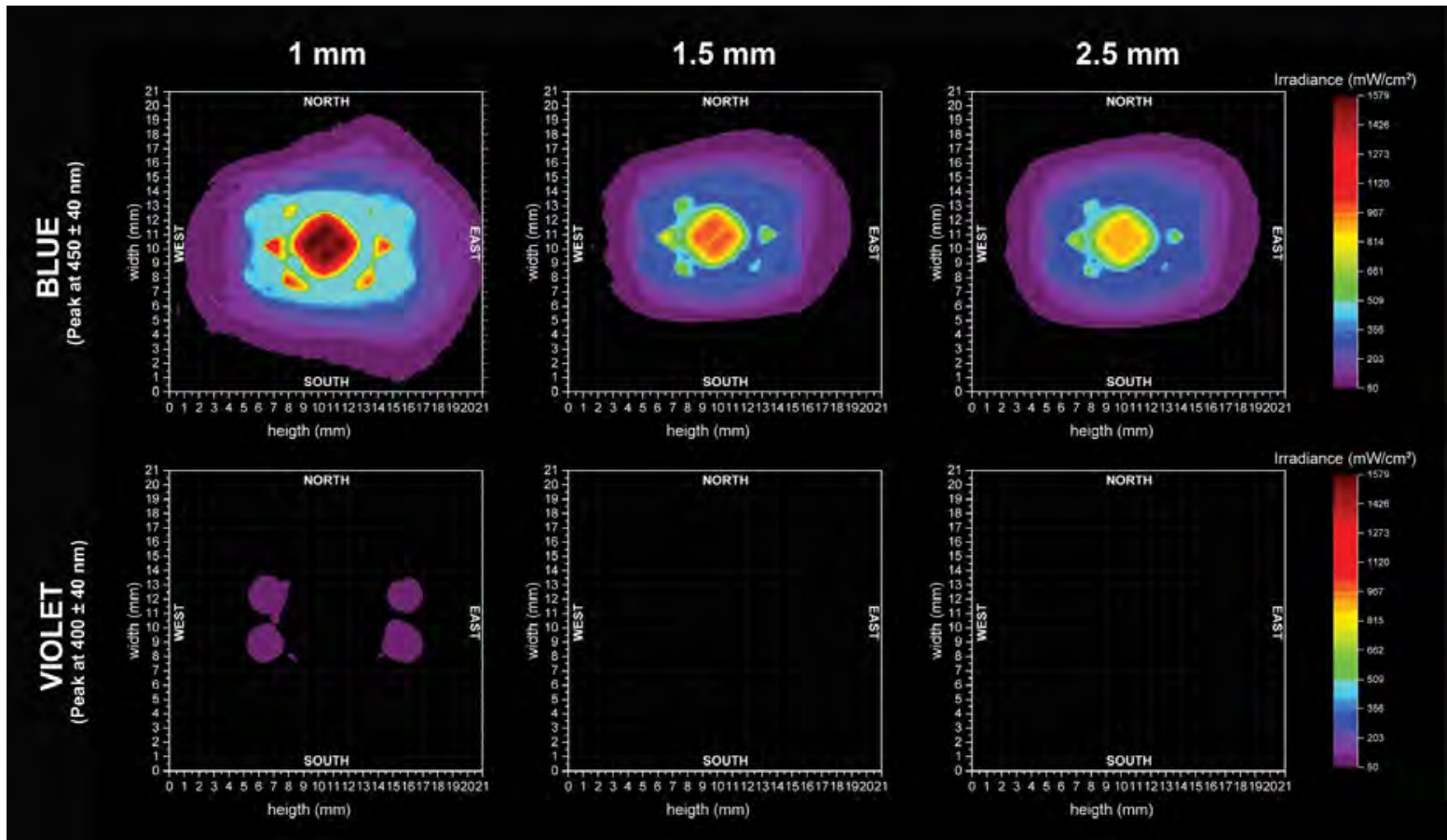

I Figure 5. Beam profile images using the camera-based beam profiler method for the blue and violet wavelength ranges at 1, 1.5, $2.5 \mathrm{~mm}$ distance from the light tip.

Table 1. Slope of the decrease in irradiance in $\mathrm{mW} / \mathrm{cm}^{2} / \mathrm{mm}$ with respect to the vertical distance of the geometric center of $L C U$ and the NORTH, SOUTH, WEST and EAST directions using the spectrometer-based method or the camera-based method.

\begin{tabular}{|c|c|c|c|c|c|c|}
\hline & \multicolumn{2}{|c|}{$1 \mathrm{~mm}$} & \multicolumn{2}{|c|}{$1.5 \mathrm{~mm}$} & \multicolumn{2}{|c|}{$2 \mathrm{~mm}$} \\
\hline & $\begin{array}{l}\text { Spectrometer- } \\
\text { based method }\end{array}$ & $\begin{array}{l}\text { Camera-based } \\
\text { method }\end{array}$ & $\begin{array}{l}\text { Spectrometer- } \\
\text { based method }\end{array}$ & $\begin{array}{c}\text { Camera-based } \\
\text { method }\end{array}$ & $\begin{array}{l}\text { Spectrometer- } \\
\text { based method }\end{array}$ & $\begin{array}{c}\text { Camera-based } \\
\text { method }\end{array}$ \\
\hline NORTH & -232 & -231 & -195 & -183 & -169 & -171 \\
\hline SOUTH & -244 & -180 & -201 & -176 & -142 & -141 \\
\hline WEST & -173 & -167 & -171 & -148 & -100 & -142 \\
\hline EAST & -197 & -156 & -181 & -146 & -127 & -132 \\
\hline
\end{tabular}

light as shown in Fig. 3. In Figure 1 the position of the LEDs in the head of the light is clearly visible. Using the beam profiler and different filters the center LED was identified to emit light blue light $(420-495 \mathrm{~nm})$ with a peak emission at $450 \mathrm{~nm}$ with a high intensity (1579 $\mathrm{mW} / \mathrm{cm}^{2}$ ) and the four LEDs in the "corners" emitting violet light ( $380-420 \mathrm{~nm}$ ) with a peak emission at 390 $\mathrm{nm}$, confirming measurements on other LCUs $[23,27]$. Furthermore it was noticed that the irradiance from the violet LEDs was quite low $\left(102 \mathrm{~mW} / \mathrm{cm}^{2}\right)$ and localized to the corners only. This discrepancy in the blue and violet light emission could be attributed to the type of the LED chip used to build the LCU. Despite the fact that the majority of LED chips are violet, they appear to be a dual in-line package (DIP) LED type, which have much lower energy efficiency than the blue light chip that appears to be a chip on-board (COB) LED type, which is considered a high-powered LED chip and the most recent development in LED LCUs. But, the fact is that "alternative" photoinitiators such as TPO or Ivocerin that have been used in commercial formulations are known as high reactive photoinitiators because they usually have higher molar extinction coefficient than CQ. This means that these photoinitiators absorb light more efficiently than $\mathrm{CQ}$ at their peak wavelength absorptions. Moreover, these photoinitiators form more free radicals (two or more) that have higher nucleophilicity and electron resonance than the one amino radical formed by the CQ-amine electron donor/ hydrogen abstraction reaction. Thus, despite the less amount of violet light being emitted by broad spectrum LCUs, the initiation of the polymerization is effective enough to keep the physical and chemical properties of RBC containing "alternative" photoinitiators. However, it is important to bear in mind that broad spectrum LCUs typically have a ratio of 66 to $86 \%$ of blue light emission and 14 to $34 \%$ of violet light emission from the total spectral radiant power emitted [33] by the LCU. However, the LCU used in this study had $94 \%$ of blue light emission and $6 \%$ of violet light emission and further investigation should be performed to check if the LCU used in this study would efficiently cure RBC containing "alternative" photoinitiators. Therefore, it was decided that the impact on polymerization of these violet emitting LEDs was low and for further considerations we concentrated on the blue light.

In the present study, the LCU was laterally moved in a controlled way in the $x$-and $y$-direction of a coordinated 
system. This was to simulate in a reproducible way operator errors in light curing, which have a deleterious effect on the light energy administered to a restoration [33]. With a homogeneous beam profile, as long as a restoration is smaller than the diameter of the light exciting window of the LCU slight positioning errors may result only in minimal decrease of exciting irradiation if any at all. However, with an LCU that has a centered beam profile as the one of the Ascent OL5 used in the present study, the positioning even within the confines of the light exiting window has significant effects on the exciting irradiation, as can be seen in Fig. 4 , where a marked decrease in irradiation is noticed when the LCU is moved in the $X-Y$ direction.

The first null hypothesis that the irradiation would be at the same level all over the irradiated surface was rejected, since with both methods to characterize the LCU significant differences in local irradiance were found. In this study beam inhomogeneity could be shown as other researchers have done with different methods [25-28]. The second null hypothesis could be accepted, since the slopes of the decrease (in absolute numbers) were quite similar (Table 1). It is known that the irradiance a target surface received is a function of the exposure distance $[25,26]$. This is also visible in Figs. 3 and 5 confirming the results of others $[25,26]$. Furthermore, in Figs. 3 and 5 the irradiance dropped significantly from the center to the periphery in all measured directions ("East"-"West" and "North""South"). Looking at the absolute numbers of the slopes, the farther away from the LCU light exciting windows the smaller the numbers are, which means that the inhomogeneity decreases.

With controlled lateral movements, the inhomogeneity of the beam could be roughly reproduced with the spectrometer. The same could be shown with the beam profiler emulating a cosine corrector light collector with a diameter of $3.9 \mathrm{~mm}$, which limits the precision. It is suggested to use a smaller cosine corrector diameter for future measurements. With the methods used, area specific mean irradiations could be shown. Therefore, one has to rely on the known minimal irradiance needed to cure a specific resin-based material in order to assess the performance of a given LCU/RBC combination.

The differences between the spectrometer-based vs camera-based beam profile methods are basically related to the resolution and accuracy of irradiance detection. Michaud et al. [29] used a laboratory grade integrating sphere spectrometer system to measure the irradiation and emission spectra of LCUs. Combined with a beam profiler camera they recorded the localized irradiance across the face of the light tip. The irradiation calibrated beam profile was then divided into 45 squares of $1 \mathrm{~mm}^{2}$ each, thus being able to give more detailed beam analysis than it was possible with the method in the present paper. The beam inhomogeneity was additionally confirmed by micro hardness analysis [35].

Although the camera-based method can show higher resolution in $\mathrm{mm}^{2}$ than the spectrometerbased method, the quantitative measurement of the irradiance using the spectrometer-based method seems to be more accurate, because the spectrometer-based method captures light directly from the light output tip, which is not the case for camera-based methods. Camera-based beam profilers are rarely able to give a direct measurement of the total irradiance of an LCU light beam. First, the LCU light beam passes through a long chain of attenuation so that the camera-sensor does not see the total power of the beam directly. Since this attenuation is put in place so as to get the energy down to the level of the camera sensor, it is not practical to calibrate each element of attenuation. Thus, the irradiance values that get into the camera are relative to the total power of the LCU light beam. Secondly, cameras do not have uniform wavelength absorption [36]. Therefore, they would have a different calibration factor for every wavelength of the LCU that is used. It would be impractical to attempt to calibrate the camera as a function of wavelength. So, after correcting for the power loss, the total irradiance energy measured by the spectrometer can then be entered into the software of the beam analysis instruments. From then on, the camera can give a readout of the total power or energy across the entire two-dimensional light beam distribution.

For the clinical application, the findings of the present study mean that even with a properly positioned LCU, peripheral areas would get much less irradiation. Even small positioning deviations would aggravate this fact, e.g. looking at Fig. 4 one can see that a $1.5 \mathrm{~mm}$ positioning deviation in the "WEST" direction would yield approximately $50 \%$ of the maximal possible irradiation. At a distance of $2.5 \mathrm{~mm}$ this effect is slightly less pronounced. As a clinical relevance of this study, it is important for the clinicians to understand that there are a lot of broad spectrum LCUs on the market, but not all of them might be really effective. And, it is important to be aware of the implications of bad quality broad spectrum LCUs on the quality of RBCs and thus on dental practice.

\section{Conclusions}

The analyzed LCU has an inhomogeneous beam profile, being the most intensive in the center and diminishing substantially towards the periphery.

The spectrometer-based method used was able to characterize an LCU which may be helpful among other parameters to make a selection for a specific LCU for clinical use.

\section{Author contributions}

JFR: Idea, experimental design, wrote the manuscript. MGR: Performed standard camera-based beam profiles, contributed extensively to introduction and discussion. CS: Performed data analysis, proofread the manuscript. MMK: Performed spectrometer experiment. DCRSdeO: Contributed extensively to introduction and discussion.

\section{Acknowledgments}

DO is a Post-Doctoral Researcher at São Paulo Research Foundation - FAPESP (grant \#2016/058233 and \#2017/22161-7) and MR is a PhD Researcher at São Paulo Research Foundation - FAPESP (grant \#2016/06019-3 and \#2017/22195-9). 


\section{References}

1. Rueggeberg FA. State-of-the-art: dental photocuring-review. Dental Materials 2011;27(1):39-52. doi: 10.1016/j. dental.2010.10.021.

[PubMed] Google Scholar(186) Scopus(103)

2. Rueggeberg FA, Caughman WF, Curtis JW, Davies HC Factors affecting cure at depths within light-activated resin composites. Am J Dent 1993;6(2):91-95

[PubMed] Google Scholar(312) Scopus(166)

3. Rueggeberg FA, Chaghman WF, Curtis JW. Effect of light intensity and exposure duration on the cure of resin composite. Oper Dent. 1994;19(1):26-32.

[PubMed] Google Scholar(661) Scopus(361)

4. Price RB, Felix CM, Whalen JM. Factors affecting the energy delivered to simulated call I and class V preparations. J Can Dent Assoc. 2010;76:a94.

[Full text links] [PubMed] Google Scholar(48) Scopus(30)

5. Price RB, Strassler HE, Price HL, Seth S, Lee CJ. The effectiveness of using a patient simulator to teach lightcuring skills. J Am Dent Assoc. 2014;145(1):23-43. doi: 10.14219/jada.2013.17.

[Full text links] [PubMed] Google Scholar (15) Scopus(12)

6. Meyer GR, Ernst CP, Willershausen B. Decrease in power output of new light-emitting diode (LED) curing devices with increasing distance to filling surface. J Adhes Dent. 2002;4(3):197-204.

[PubMed] Google Scholar (75) Scopus(28)

7. Mutluay MM, Rueggeberg FA, Price RB. Effect of using proper light curing techniques on energy delivered to a Class 1 restoration. Quintessence Int. 2014; 45(7):549-556. doi: 10.3290/j.qi.a31959.

[Full text links] [PubMed] Google Scholar(14) Scopus(12)

8. André CB, Nima G, Sebold M, Giannini M, Price RB. Stability of the light output, oral cavity tip accessibility in posterior region and emission spectrum of light-curing units. Oper Dent. 2018 Apr 9. doi: 10.2341/17-033-L

[Full text links] [PubMed] Google Scholar(0)

9. Palin WM, Leprince JG, Hadis MA. Shining a light on high volume photocurable materials. Dent Mater. 2018;34(5):695710. doi: 10.1016/j.dental.2018.02.009 [Full text links] [PubMed] Google Scholar(1) Scopus(0)

10. Roulet JF, Price R. Light Curing - Guidelines for Practitioners. A consensus Conference Statement from the 2014 Symposium on Light Curing in Dentistry Held at Dalhousie University Halifax, Canada. J Adhes Dent. 2014;16(4):303-304. doi: 10.3290/j.jad.a32610.

[Full text links] [PubMed] Google Scholar(11)

11. Platt JA, Price RB. Light curing explored in Halifax. Oper Dent 2014;39(6):561-563.

[Full text links] [PubMed] Google Scholar(7) Scopus(4)

12. Watts DC. Let there be more light! Dent Mater. 2015;31(4):315-316. doi: 10.1016/j.dental.2015.03.001 [Full text links] [PubMed] Google Scholar(3)

13. Al Shaafi MM, Maawadh AM, Al Qahtani MQ. Evaluation of light intensity output of QTH and LED curing devices in various governmental health institutions. Oper Dent. 2011; 36(4):356-361. doi: 10.2341/10-247-O

[Full text links] [PubMed] Google Scholar(28) Scopus(17)

14. Maghaireh GA, Alzraikat $H$, Taha NA. Assessing the irradiance delivered from light-curing units in private dental offices in Jordan. J Am Dent Assoc. 2013;144(8):922-927.

[Full text links] [PubMed] Google Scholar(23) Scopus(15)

15. Ernst CP, Busemann I, Kern T, Willershausen B. [Field test for the light emission performance of polymerization equipment in 301 dental practices] Dtsch Zahnärztl Z 2006:61(9):466-471. [German]

Google Scholar(30)

16. Ernst CP, Price RB, Callaway A, et al. Visible light curing devices - Irradiance and use in 302 German dental offices. $J$ Adhes Dent. 2018;20(1):41-55. doi: 10.3290/j.jad.a39881. [Full text links] [PubMed] Google Scholar (0) Scopus(0)

17. Hirt T. Ivocerin -a milestone in composite technology. Report No. 19. Schaan, Liechtenstein: Ivoclar Vivadent AG; 2013.

18. McGowanT. Working knowledge: halogen lights. Sci AM 1966;275:92.

19. Mills RW, Jandt KD, Ashworth SH. Dental composite depth of cure with halogen and blue light emitting diodetechnology.
Br Dent J. 1999;186(8):388-391.

[PubMed] Google Scholar (476) Scopus(222)

20. Jandt KD, Mills RW. A brief history of LED

photopolymerization. Dent Mater. 2013;29(6):605-617. doi: 10.1016/j.dental.2013.02.003.

[Full text links] [PubMed] Google Scholar(115) Scopus(64)

21. Moseley H, Strang R, Stephen KW. An assessment of visiblelight polymerization sources.J Oral Rehabil 1986; 13(3):215224.

[Full text links] [PubMed] Google Scholar(58)

22. Arikawa $\mathrm{H}$, Kanie T, Fuji $\mathrm{K}$, Takahshi $\mathrm{H}$, Ban S. Effect of inhomogeneity of light from light curing units on the surface hardness of composite resin. Dent Mater J. 2008;27(1):21-28. [Full text links] [PubMed] Google Scholar(59) Scopus(28)

23. Price RBT, Labrie D, Rueggeberg FA, Felix CM. Irradiance differences in the violet $(405 \mathrm{~nm})$ and blue $(460 \mathrm{~nm})$ spectral ranges among dental light curing units. J Esthet Restor Dent. 2010;22(6):363-377. doi: 10.1111/j.1708-8240.2010.00368.x. [Full text links] [PubMed] Google Scholar (61) Scopus(42)

24. Price RB, Ferracane JL, Shortall AC. Light-curing units: a review of what we need to know. J Dent Res. 2015;94(9):1179-1186. doi: 10.1177/0022034515594786 [Full text links] [PubMed] Google Scholar(45) Scopus(22)

25. Megremis S, Ong V, Lukic H, Shepelak H. An ADA Laboratory Evaluation of Light-Emitting Diode Curing Lights. In ADA Professional Product Review. Ed. Sarret D. 2014; 9 (4), ADA Chicago II, USA 2014 Google Scholar(2)

26. Megremis S, Ong V, Lukic $\mathrm{H}$, Shepelak H. An ADA laboratory evaluation of light-emitting diode curing lights. J Am Dent Assoc. 2014;145(11):1164-1166. doi: 10.14219/jada.2014.97. [Full text links] [PubMed] Google Scholar(2)

27. Shortall AC, Felix CJ, Watts DC. Robust spectrometer-based methods for characterizing radiant exitance of dental LED light curing units. Dent Mater. 2015;31(4):339-350. doi: 10.1016/j.dental.2015.02.012

[Full text links] [PubMed] Google Scholar(11) Scopus(9)

28. Price RB, Rueggeberg FA, Labrie D, Felix C. Irradiance uniformity and distribution from dental light curing units. J Esthet Restor Dent. 2010;22(2):86-101. DOI 10.1111/j.17088240.2010.00319.x.

[Full text links] [PubMed] Google Scholar (55) Scopus(37)

29. Michaud PL, Price RBT, Labrie D, Rueggeberg FA, Sullivan B. Localized irradiance distribution found in dental light curing units. J Dent. 2014;42(2):129-139. doi: 10.1016/j. jdent.2013.11.014.

[Full text links] [PubMed] Google Scholar(51) Scopus(34)

30. Rocha MR, de Oliveira D, Correa IC, Correr-Sobrinho L, Sinhoreti M. Light-emitting diode beam and spectral output influence on the degree of conversion of bulk fill composites. Oper Dent. 2017;42(4):418-427. doi: 10.2341/16-164-L [Full text links] [PubMed] Google Scholar(3) Scopus(0)

31. De Oliveira D, Rocha MG, Correa IC, et al. The effect of combining photoinitiator systems on the color and curing profile of resin-based composites. Dent Mater. 2016, 32(10):1209-1217. DOI: 10.1016/j.dental.2016.06.010 [Full text links] [PubMed] Google Scholar(8) Scopus(5)

32. Schindelin J, Arganda-Carreras I, Frise E. et al. Fiji: an opensource platform for biological-image analysis. Nat Methods. 2012;9(7):676-682. doi: 10.1038/nmeth.2019.

[Full text links] [Free PMC Article] [PubMed] Google Scholar(8751) Scopus(6622)

33. Harlow JE, Sullivan B, Shortall AFC, Labrie D, Price RB. Characterizing the output settings of dental curing light. $J$ Dent. 2016;44:20-26. doi: 10.1016/j.jdent.2015.10.019. [Full text links] [PubMed] Google Scholar(16) Scopus(10)

34. Price R Strassler H, Price HL, Seth S, Lee CL. The effectiveness of using a patient simulator to teach light-curing skills. J Am Dent Assoc. 2014;145(1):32-43. doi: 10.14219/jada.2013.17. [Full text links] [PubMed] Google Scholar(15) Scopus(12)

35. Price RBT, Labrie D, Rueggeberg FA, et al. Correlation between the beam profile from a curing light and the microhardness of four resins. Dent Mater. 2014;30(12):13451357.

[Full text links] [PubMed] Google Scholar(40) Scopus(27)

36. Holst GC. CCD arrays, cameras, and displays. 2nd ed. Winter Park (FL): JCD Publishing; 1998. Google Scholar(937). 


\section{Jean-François ROULET}

DDS, DMD, PhD, Dr hc, Prof hc, Professor, Chair

Department of Restorative Dental Sciences

College of Dentistry, University of Florida

Gainesville, FL, USA

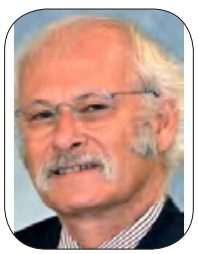

Jean-François Roulet, DDS, Dr med dent, $\mathrm{Dr}$ hc, PhD, is the former chair and current professor of the Department of Restorative Dental Sciences at the University of Florida. Professor Roulet is author/coauthor of more than 180 papers, edited/contributed to 27 textbooks and mentored more than 150 theses. He is a renowned international lecturer with over 800 appearances to date. Dr. Roulet is a member of many professional organizations, has won numerous awards, and holds four patents. He is editor of the Prophylaxe Impuls and Stomatology Edu Journal. His areas of interest include minimally invasive dentistry, dental materials (ie, composites and ceramics), adhesive dentistry, esthetic dentistry, and application concepts in preventive dentistry.

\section{Ouestions}

\section{A beam profile is:}

$\square$ a. The change if irradiance as a function of the distance from the light curing unit light outputting window;

$\square$ b. The 2D irradiance intensity plot of a light beam at a given location along the light beam output window;

ac. Identical for all light curing units;

$\square$ d. More homogeneous for broad band light curing units.

\section{Which factor highly influencing the quality of a light cured resin composite is} controlled by the dentist only?

$\square$ a. The composition of the resin based composite;

b. Resin composite residues stuck to the light curing units light output window:

$\square$ c. The geometry of the fiber bundle rod or the lens;

d. The correct positioning of the LCU on top of the RBC.

\section{The study used the following method to characterize the light curing unit:}

\section{a. An Ulbricht sphere;}

b. Micro hardness;

Dc. A spectrometer and a camera based beam profile method;

$\square$ d. Degree of conversion of the resin based composite.

\section{Which was the main outcome of the study?}

a. No inhomogeneity of the beam profile could be found;

b. Both methods showed very similar inhomogeneities of the beam profile;

ac. The beam profile inhomogeneity was the same regardless of the measuring distance;

$\square$ d. The irradiance was higher at the periphery of the beam profile.

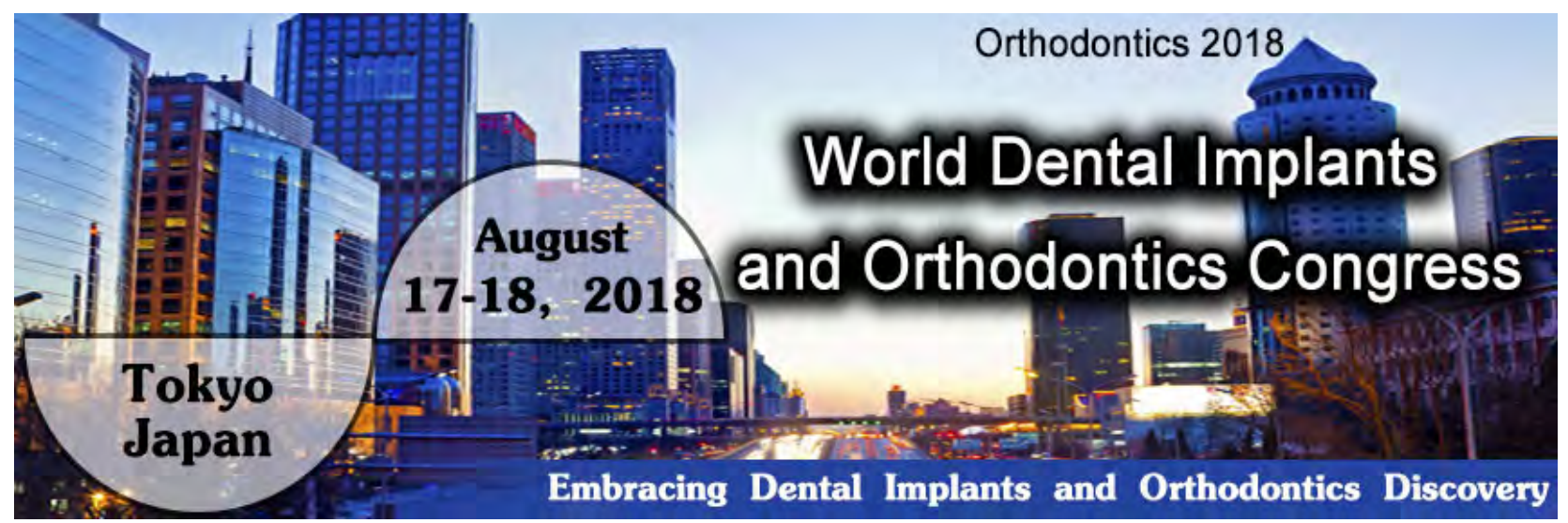

https://orthodontics.conferenceseries.com/ 


\title{
COMPARATIVE STUDY REGARDING THE EFFECT OF DIFFERENT FINISHING AND POLISHING SYSTEMS ON A BULK-FILL COMPOSITE RESIN SURFACE

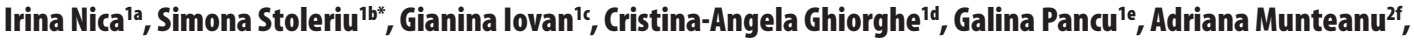 Sorin Andrian ${ }^{19}$
}

'Department of Odontology - Periodontology and Fixed Prosthodontics, Faculty of Dental Medicine, "Grigore T. Popa” University of Medicine and Pharmacy, Jassy, Romania

2Department of Machine Tools, Faculty of Machine Manufacturing and Industrial Management, "Gheorghe Asachi"Technical University, Jassy, Romania

\author{
${ }^{a} D D S$, PhD, Assistant Professor \\ b,c,fDDS, PhD, Associated Professor \\ d,eDDS, PhD, Lecturer \\ ${ }^{9} \mathrm{DDS}$, PhD, Professor
}

ABSTRACT

DOI: 10.25241/stomaeduj.2018.5(2).art.2

Introduction: One of the main objectives of composite restorations procedure is to obtain a smooth surface for aesthetic reasons and for oral health.

The aim of this study was to assess the surface morphology of a bulk fill composite material after finishing and polishing with three different finishing and polishing systems.

Materials and methods: Filtek Bulk Fill Posterior composite resin was chosen for this study (3M ESPE St. Paul, MN, USA). Twenty cylindrical samples $5 \mathrm{~mm}$ in diameter and $2 \mathrm{~mm}$ thick were made using plastic molds. They were randomly and equally assigned to four groups. In group 1 (control) the samples were not subjected to finishing and polishing procedure. In study groups 2-4, the samples were finished using two tungsten carbide burs and then polished using one step Occlubrush system (KerrHawe SA, Switzerland) - group 2, with the two step Sof-Lex system (3M ESPE) - group 3, and with the multi-step Super Snap system (Shofu, Inc. Kyoto, Japan) - group 4. The surface characteristics of the samples were quantitatively analyzed using profilometry and qualitatively evaluated by scanning electron microscopy. The Kolmogorov-Smirnov normality test was used to determine the distribution of data in groups. ANOVA and Tukey post hoc statistical tests were used to compare the results in groups.

Results: Finishing with tungsten carbide burs and two-steps Sof-Lex polishing system and one-step polishing system Occlubrush determined, higher roughness when comparing to multi-step Super Snap system.

Conclusion: The surface characteristics of the studied composite resin were influenced by the type of finishing and polishing system used.

Keywords: bulk-fill composite, finishing and polishing systems, profilometry, SEM.

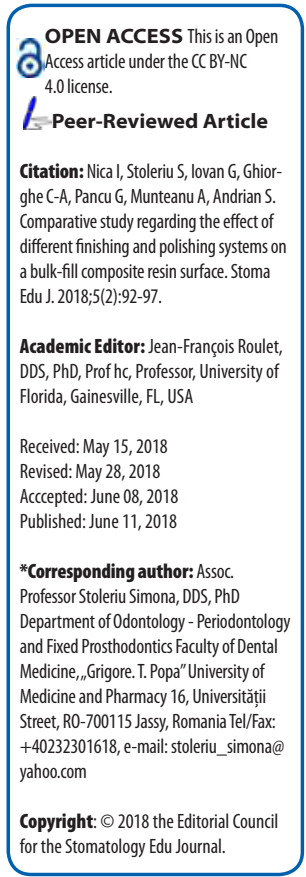

\section{Introduction}

Finishing and polishing are mandatory steps in direct restoration using composite resins. Obtaining a smooth surface has always been one of the main objectives of composite restorations, not only for aesthetic reasons but also for maintaining oral health [1].

It is considered that the surface roughness that leads to bacterial plaque retention is $0.2 \mu \mathrm{m}$ [2]. Surface roughness higher than this value makes the adherence of bacteria from the oral environment impossible to prevent. In time, biofilm accumulation is responsible for the decreased wear resistance of the restoration, increased risk of caries adjacent to restoration and periodontal inflammation. Surface roughness also influences the retention rate of extrinsic pigments and the aesthetic aspect of the restoration [3-5].

A wide range of instruments can be used to finish and polish direct restoration, such as carbide or diamond finishing burs, rubber based abrasives, aluminium oxide particle discs, abrasive strips and polishing pastes. The action of each instrument determines different values of roughness by the degree of flexibility of the substrate on which the abrasive powder is impregnated, by the hardness of the abrasive powder and by the diameter of the particles from which it is made and all these in relation to the structure of the composite material [6-8]. Aim The purpose of the present study was to evaluate the surface characteristics of a bulk fill composite resin used for direct restoration when different types of finishing and polishing systems were used. The surface microstructure was qualitatively evaluated by scanning electron microscopy (SEM) and quantitatively assessed by surface roughness determination using profilometry.

\section{Materials and Methods}

The material used in the present study was Filtek Bulk Fill Posterior Restorative (3M ESPE, St. Paul, MN, USA). Lot: N720858, shade A3. It was designed to be easily and quickly applied in layers of $5 \mathrm{~mm}$ thickness, and it can remain exposed to occlusal forces.

The organic matrix of the Filtek Bulk Fill Posterior Restorative composite contains two new methacrylic monomers, which act synergistically to reduce the polymerization shrinkage. One of the monomers is a high molecular weight aromatic dimethacrylate (AUDM), which modulates the volumetric contraction. The second innovative monomer is actually a class of 
compounds called adhesion-fragmentation monomers (AFM) that contributes to the release of polymerization stress while maintaining the physical properties of the newly created polymer chains. The organic component also contains DDDMA (1,12-dodecanediol dimethacrylate) which provides low resin viscosity, decreasing exothermic reactions and polymerization shrinkage, and UDMA (urethane dimethacrylate), an increased molecular weight monomer, that reduces resin viscosity and polymerization shrinkage.

The inorganic component of Filtek Bulk Fill Posterior Restorative consists in a combination of nonagglomerated/non-aggregated silica particles of 20 nm, non-agglomerated/non-aggregated zirconia particles with sizes ranging from 4 to $11 \mathrm{~nm}$, respectively zirconia/silica clusters (containing $20 \mathrm{~nm}$ silica particles and 4 to $11 \mathrm{~nm}$ zirconia particles).

The inorganic component also includes ytterbium trifluoride aggregate particles of $100 \mathrm{~nm}$ (YbF3), which have the role of increasing radiopacity of the material. The total inorganic phase loading is about $76.5 \%$ (by weight), equivalent to $58.4 \%$ (by volume). Details about composite resins type, producer and chemical composition are presented in Table 1.

Twenty cylindrical samples $5 \mathrm{~mm}$ in diameter and $2 \mathrm{~mm}$ thick were made using plastic moulds The conformers were placed in tight contact with a celluloid matrix between two glass plates, in order to obtain a smooth, flat and a surface free of pores. The samples were lightcured for $40 \mathrm{~s}$ on both sides through glass plate to ensure complete polymerization of the material, using a light emitting diode light curing device (Optilight LD MAX -Gnatus) heaving a wavelength of $470 \mathrm{~nm}$ to 480 $\mathrm{nm}$, a maximum power of $600 \mathrm{~mW} / \mathrm{cm}^{2}$ and providing a polymerization depth of up to $3 \mathrm{~mm}$. After removing samples from moulds they were randomly divided into 4 groups. Samples from group 1 (control), were not finished or polished and the samples in groups 2-4, were finished and polished using three different systems.

In group 2, samples were firstly contoured and finished using tungsten carbide burs from Komet Dental/Gebr Brasseler $\mathrm{GmbH} \& \mathrm{Co}$. KG, Germany in the following order: for the coarse finishing step (cut-off) the H135Q bur, batch 906561 was used and for ultra-fine finishing (contouring) the H135UF bur, batch 903481 (ISO 500314166031014) was used. Each bur was used for 30 seconds, at 20,000 rpm and under continuous water cooling. Burs were driven in one direction, clockwise. Subsequent polishing was performed with a one-step polishing system Occlubrush (KerrHawe SA, Switzerland) made of polycarbonate fibers impregnated with silicon carbide particles. The small cup brushes were used at 5000 rpm, for 30 seconds and without polishing paste.

In group 3, samples were contoured and finished using the $\mathrm{H} 135 \mathrm{Q}$ and H135UF carbide burs (Komet Dental/Gebr Brasseler GmbH \& Co. KG, Germany). The polishing was done with a two-step polishing system Sof-Lex (3M ESPE). This system is made up of disposable spiral wheels for finishing (the beige one) and polishing (the white one). The lamellar discs are made of a thermoplastic elastomer impregnated with aluminium oxide particles. Each lamellar disk was used once for each sample, for 30 seconds, without paste or
I Table 1. Details about tested material

\begin{tabular}{|c|c|c|c|}
\hline \multirow{3}{*}{$\begin{array}{r}\text { Material/ } \\
\text { Manufacturer/ } \\
\text { Type/ } \\
\text { Batch No./ } \\
\text { Shade }\end{array}$} & \multirow{3}{*}{ Matrix } & \multicolumn{2}{|c|}{ Chemical composition } \\
\hline & & \multicolumn{2}{|c|}{ Filler Load: 76.5 wt\% / 58.4 vol\% } \\
\hline & & Type & Size \\
\hline $\begin{array}{r}\text { Filtek Bulk } \\
\text { Fill Universal } \\
\text { Restorative }\end{array}$ & $\begin{array}{r}\text { bis-GMA, } \\
\text { AUDM, }\end{array}$ & $\begin{array}{r}\text { Non-agglomerated/ } \\
\text { non-aggregated silica } \\
\text { particles }\end{array}$ & $\begin{array}{r}20 \\
\mathrm{~nm}\end{array}$ \\
\hline $\begin{array}{r}\text { 3MESPE, } \\
\text { St.Paul, MN, } \\
\text { USA }\end{array}$ & $\begin{array}{r}\text { AFM, } \\
\text { DDDMA } \\
\text { UDMA, }\end{array}$ & $\begin{array}{r}\text { Non-agglomerated/ } \\
\text { non-aggregated zirconia } \\
\text { particles }\end{array}$ & $\begin{array}{r}4-11 \\
\mathrm{~nm}\end{array}$ \\
\hline N720858/ A3 & $\begin{array}{r}\text { TEGDMA, } \\
\text { bis- } \\
\text { EMA(6) }\end{array}$ & $\begin{array}{r}\text { Clusters of aggregated } \\
\text { silica and zirconia particles } \\
\text { Ytterbium trifluoride } \\
\text { aggregate particles }\end{array}$ & $\begin{array}{l}100 \\
\mathrm{~nm}\end{array}$ \\
\hline
\end{tabular}

Bis-GMA: Bisphenol A diglycidyl ether dimethacrylate; AUDM: aromatic dimethacrylate; AFM: adhesion-fragmentation monomers; DDDMA: 1,12-dodecanediol dimethacrylate; UDMA: urethane dimethacrylate; TEGDMA: Triethyleneglycoldimethacrylate; bis EMA(6): ethoxylated bisphenol-A dimethacrylate.

water cooling, at speed of 20,000 r.p.m. according to the manufacturer's specifications.

In group 4, samples were contoured and finished using the H135Q and H135UF burs (Komet Dental/ Gebr Brasseler GmbH \& Co. KG, Germany). Subsequent polishing was performed with the multi-step Super Snap System (Shofu, Inc. Kyoto, Japan). This system consists of discs for contouring, finishing, polishing and superpolishing. The discs are manufactured without a metallic ring, do not expose the mandrel to the active surface, and they are impregnated with aluminium oxide powder of different grain size. For the present study, the purple finishing discs, the green polish and the pink ones for super-polish were used successively. Each abrasive disc was used once for each sample, without water spraying, without paste, for 30 seconds and the hand-piece was used at a speed of 10,000-20,000 rpm.

Finally, the samples were cleaned from the debris by washing with distilled water and dried with air. Subsequently, they were subjected to qualitative surface evaluation using the scanning electron microscope VEGA II LSH TESCAN (Czech Republic) and to quantitative profilometric analysis using a profilometer Taylor Hobson-Surtronic 25 (Ametek Inc, Berwyn, PA, USA). Ten traces were registered in different areas with a tip load of $0.75 \mathrm{mN}$, a tip diameter of $10 \mu \mathrm{m}$, a trace length of $0.25 \mathrm{~mm}$, a scanning speed of $0.5 \mathrm{~mm} / \mathrm{s}$ and a cut-off length of $0.8 \mu \mathrm{m}$.

The roughness parameters were calculated and the mean arithmetic deviation, $\mathrm{Ra}$, of the assessed profile was used. The Kolmogorov-Smirnov normality test was used to determine the distribution of data in groups. ANOVA and Tukey post hoc statistical tests were used to compare the results in groups.

\section{Results}

Some SEM surface images at different magnification with morphological aspects of Filtek Bulk Fill composite resin samples in groups 1-4 are presented in Fig. 1. In group 1 - Fig. 1a) (control samples), very rare micro-voids may be observed in small magnification $(500 \times)$, which can be inferred as arising from the sample preparation technique, 


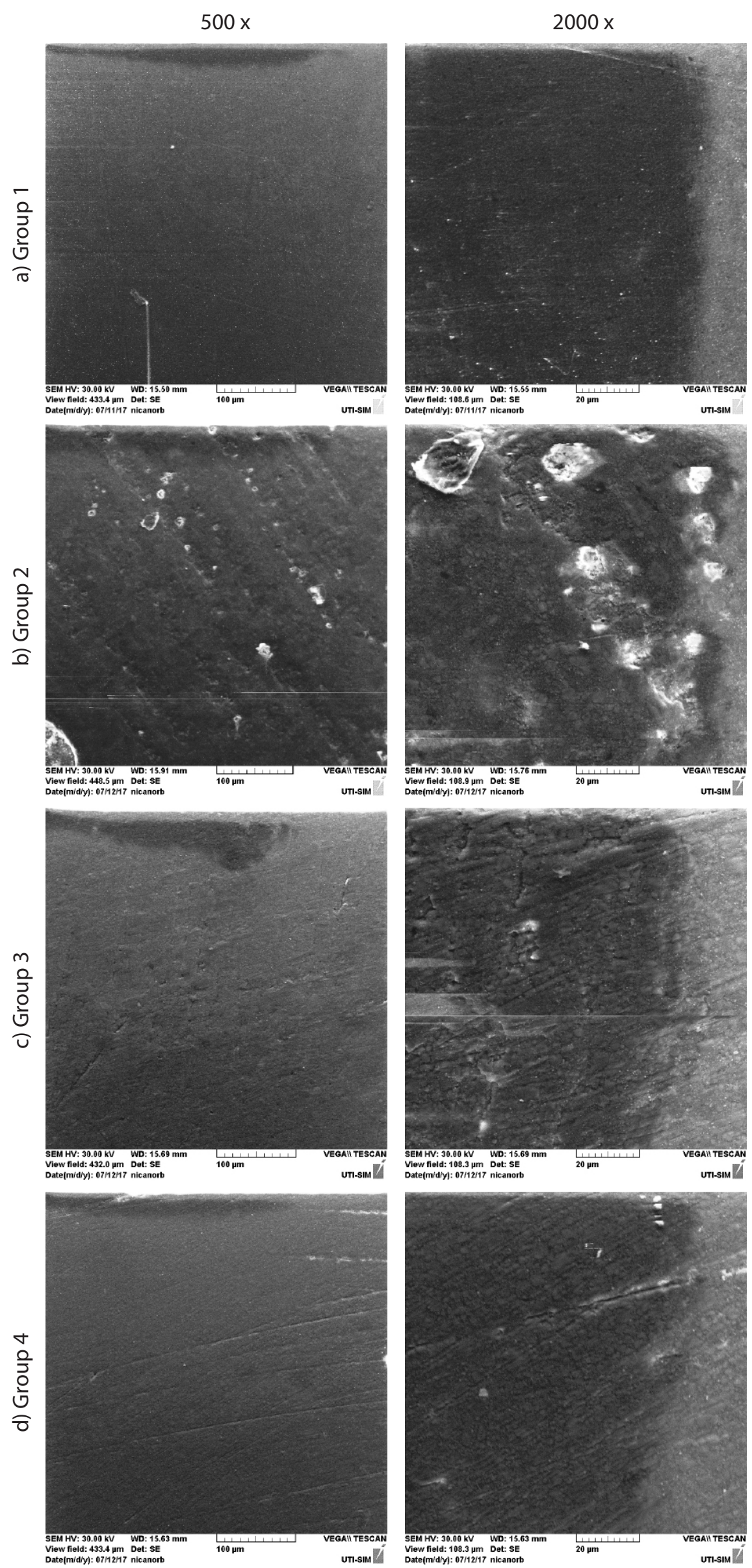

I Figure 1.SEM surface images of Filtek Bulk Fill composite resin at different magnification: a) control group, b-d) after finishing with the three finishing and polishing systems. 


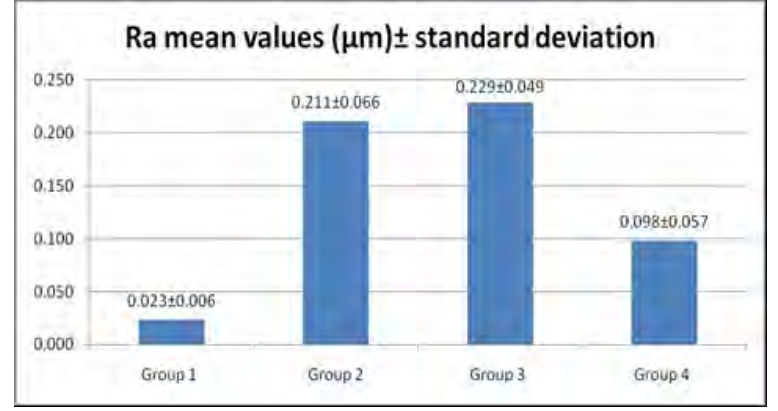

I Figure 2. Mean values of Ra parameter of Filtek Bulk Fill in control group and after finishing and polishing.

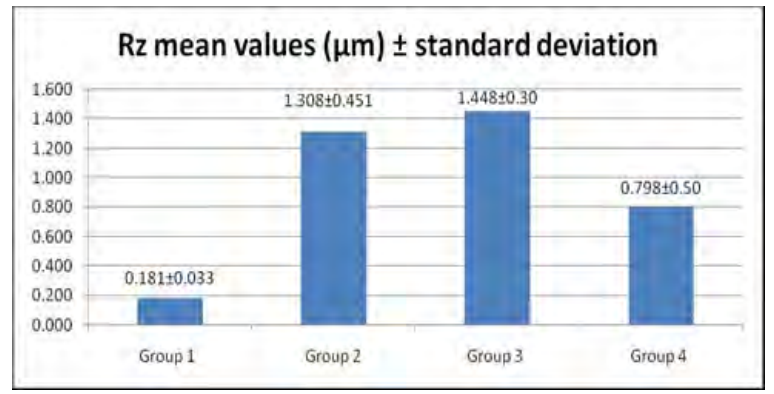

I Figure 3. Mean values of Rz parameter of Filtek Bulk Fill in control group and after finishing and polishing.

I Table 2. The Kolmogorov-Smirnov normality test result. One-Sample Kolmogorov-Smirnov Test

\begin{tabular}{|c|c|c|}
\hline & & method \\
\hline$N$ & & 41 \\
\hline \multirow[t]{2}{*}{ Normal Parameters ${ }^{a, b}$} & Mean & .14032 \\
\hline & Std. Deviation & .096316 \\
\hline \multirow[t]{3}{*}{ Most Extreme Differences } & Absolute & .159 \\
\hline & Positive & .159 \\
\hline & Negative & -.103 \\
\hline Kolmogorov-Smirnov Z & & 1.019 \\
\hline Asymp. Sig. (2-tailed) & & .250 \\
\hline
\end{tabular}

I Table 3. ANOVA statistical test result.

ANOVA

method
\begin{tabular}{|l|r|r|r|r|r|}
\hline & \multicolumn{1}{c|}{$\begin{array}{c}\text { Sum of } \\
\text { Squares }\end{array}$} & \multicolumn{1}{c|}{ df } & Mean Square & F & Sig. \\
\hline Between Groups & .276 & 3 & .092 & 35,949 & 000 \\
Within Groups & .095 & 37 & .003 & & \\
Total & .371 & 40 & & & \\
\hline
\end{tabular}

I Table 4. Tukey post hoc statistical test result. Post Hoc Tests

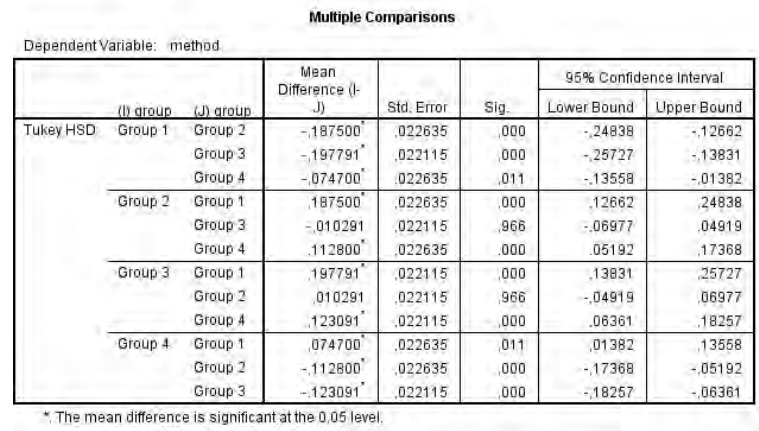

rather than from the polymerization shrinkage. At this magnification, the surface of control samples appears to be much smoother compared to the other samples. At larger magnifications $(2000 \times)$ very small particles can be identified, not aggregated, distributed among larger particles of silica and zirconia. The appearance of the surface seems compact, revealing a close adhesion between the organic matrix and the inorganic load.

For group 2 - Fig. 1b), the microstructure presents many parallel micro-channels 1 micrometer wide and a 10 micrometers mean distances between them. It is observed that the very fine particles on the surface and matrix elements were removed by abrasion, leaving large clusters with the diameter up to $5 \mu \mathrm{m}$ to be visible. Similar aspects are also observed in group 3 - Fig. 1c), but the micro-channels formed appear more accentuated and closer when compared to group 2. In group 4, the analyzed surface microstructure - Fig. 1d) indicates similar aspects, but the micro-channels are finer and rarer when compared to the samples from previous groups.

The mean $\mathrm{Ra}$ and $\mathrm{Rz}$ values obtained by quantitative assessment of samples surface using profilometry are represented in Fig. 2 and Fig. 3, respectively. The lowest $\mathrm{Ra}(0.023 \mu \mathrm{m})$ and $\mathrm{Rz}(0.181 \mu \mathrm{m})$ values were obtained in group 1. In group 2, increased $R a$ and $R z$ values were found (Ra mean value of $0.211 \mu \mathrm{m}$ and mean $\mathrm{Rz}$ value of $1.308 \mu \mathrm{m})$. In group 3 the same increase in the Ra and $R z$ mean values was observed ( $R a$ of $0.229 \mu \mathrm{m}$ and Rz of $1.448 \mu \mathrm{m})$. In group 4 the mean $\operatorname{Ra}(0.098 \mu \mathrm{m})$ and $\mathrm{Rz}(0.798 \mu \mathrm{m})$ values were much lower when compared to groups 2 and 3 , but higher than the control samples. The result of the Kolmogorov-Smirnov normality test showed that in all groups the data were normal distributed ( $p=0.250>0.05$ ) (Table 2). In order to compare the results in groups, ANOVA and Tukey post hoc statistical tests were used (Table 3 and 4, respectively).

Significant results were obtained when comparing $\mathrm{Ra}$ values in groups 2,3 , and 4 to group 1 ( $p<0.05$, Table 4). Also, statistically significant results were obtained when comparing the surface roughness in group 2 to group 4 and in group 3 to group 4. The results in group 2 were not statistically significant when compared to group 3 ( $p>0.05$, Table 4$)$.

\section{Discussion}

The type of inorganic filler of the material can influence the handling characteristic and the final surface aspect after finishing and polishing procedure. Some in vitro studies revealed that a number of other factors may influence the surface condition of the material, such as the type of finishing and polishing system: in one step or several steps $[9,10]$. It is a lack of consensual opinion in the literature regarding the effect of one step or multi-steps polishing system on composite resins surface roughness. It has been demonstrated that multi-step systems determined smoother surfaces than two-step systems or one-step systems [11]. On the other hand, some other studies showed that there are no significant differences between one-step and multi-step systems [12].

In the present study, the surface roughness of control samples was lower when compared to the results obtained for each of the three finishing and polishing systems used. These results are in agreement with a series of studies which have shown that the smoothest composite resin surface is obtained when the material is light-cured in tight contact with a celluloid matrix [1315]. The superficial layer, polymerized in contact with 
the celluloid matrix has a higher organic content than the underlying layer [16-18] and the removal of this layer by finishing and polishing procedure will increase the surface resistance of the material $[19,20]$. However, the anatomical contour of the restoration is rarely achieved only by the use of the celluloid matrix [21,22], so most of the time it is necessary to use the finishing and polishing instruments to remove the material in excess and to obtain the shape and the appearance of the restoration closer to the natural tooth.

In order to be effective, a finishing system has to contain abrasive particles with higher hardness than the inorganic filler particles of the composite. Otherwise, during the finishing and polishing steps, the resin-rich superficial layer (which has poor physical and mechanical properties) will be removed, and the filler particles will remain into bold relief on the surface layer [23,24]. Composites containing small filler particles will provide after finishing and polishing a smoother surface than the ones containing larger-sized filler particles $[25,26]$.

It was demonstrated that a composite surface roughness higher than $0.2 \mu \mathrm{m}$ will prone the composite surface to bacterial plaque retention, increased risk for secondary caries onset and for periodontal inflammation, and will affect the aesthetic aspect and the longevity of the restoration [27]. Some studies have shown that many of the finishing and polishing systems on the market lead to a smooth surface, with mean Ra values varying from $0.02 \mu \mathrm{m}$ to $0.56 \mu \mathrm{m}$ [28, 29]. In our study using tungsten carbide burs with the one-step polishing system Occlubrush and tungsten carbide burs with the two-step Sof-Lex finishing system determined the Ra mean value to slightly increase over $0.2 \mu \mathrm{m}$. When using tungsten carbide burs and the multi-step Super Snap system, the mean Ra value was lower than $0.2 \mu \mathrm{m}$. We can assume that the effect of the finishing and polishing protocol used in this study had a notable clinical significance.

The complex surface structure of a composite resin cannot be fully characterized only by using profilometry. A clear prediction of clinical performance of a restorative material can be made by correlating the roughness parameters calculated by the profile geometry with the morphological surface analysis by scanning electron microscopy, which allows assessing the destructive potential of different finishing and polishing systems $[30,31]$. Since the quality of the final restoration surface is influenced by the type of the instrument used for finishing and polishing and also by the material structure, choosing the most suitable instrument for a specific material seems to become of great clinical importance.

\section{Conclusion}

1. For Filtek Bulk Fill Posterior (3M ESPE), the smoothest surface was obtained when the material was placed in direct contact with the celluloid matrix.

2. The use of tungsten carbide burs followed by multistep Super Snap finishing system determined a lower surface roughness than with the other polishing systems. 3. Finishing with tungsten carbide burs and two-steps Sof-Lex polishing system and one-step polishing system Occlubrush determined, significantly higher surface roughness than t multi-step Super Snap system.

4. The surface characteristics of the studied composite resin were influenced by the type of finishing and polishing system used.

\section{Author contributions}

Equal contribution to the paper.

\section{Acknowledgement}

Not applicable. The study was self-funded.

\section{References}

1. Raj R, Gupta R. In vitro evaluation of the effect of two finishing and polishing systems on four esthetic restorative materials. J Conserv Dent. 2013;16(6):564-567. doi: 10.4103/0972-0707.120946. [Full text links] [Free PMC Article] [PubMed] Google Scholar(20) Scopus(10)

2. Yap AU, Yap SH, Teo CK, Ng J. Comparison of surface finish of new aesthetic restorative materials. Oper Dent. 2004;29(1):100-104. [PubMed] Google Scholar(110) Scopus(47)

3. Stoleriu S, lovan G, Pancu G, Nica I, Andrian S. Study concerning the influence of the finishing and polishing systems on the surface state of various types of composite resins. Rom J Oral Rehab. 2013;5(3):78-83 Google Scholar(2)

4. Erdemir U, Sancakli HS, Yildiz E. The effect of one-step and multi-step polishing systems on the surface roughness and microhardness of novel resin composites. Eur J Dent. 2012;6(2):198-205.

[Free PMC Article] [PubMed] Google Scholar(41) Scopus(17)

5. Nica I, Stoleriu S, lovan G, Pancu G, Andrian S. Fractal analysis of some restorative Nano-filled composite materials microstructure. Stoma Edu J. 2015;2(1):36-43. Google Scholar(2)

6. Takanashi E, Kishikawa R, Ikeda M, et al. Influence of abrasive particle size on surface properties of flowable composites. Dent Mater J. 2008;27(6):780-786.

[Full text links] [PubMed] Google Scholar(24) Scopus(16)

7. Yazici AR, Muftu A. Three dimensional surface profile analysis of different types of flowable restorative resins following different finishing protocols. J Contemp Dent Pract. 2007;8(5):1-11. [PubMed] Google Scholar(20) Scopus(9)

8. Attar N. The effect of finishing and polishing procedures on the surface roughness of composite resin materials. J Contemp Dent Pract. 2007:8(1):27-35.

[PubMed] Google Scholar(119) Scopus(51)

9. Jefferies SR. Abrasive finishing and polishing in restorative dentistry: a state of art review. Dent Clin North Am. 2007;51(2):379-397, ix. doi: 10.1016/j.cden.2006.12.002 [Full text links] [PubMed] Google Scholar(135) Scopus(51)

10. Efreifej NS, Oweis YG, Eliades G. The effect of polishing technique on 3-D surface roughness and gloss of dental restorative resin composites. Oper Dent. 2013;38(1):9-20.

[Full text links] [PubMed] Google Scholar(26) Scopus(15)

11. Jung M, Sehr K, Klimek J. Surface texture of four nanofilled and one hybrid composite after finishing. Oper Dent. 2007;32(1):4552. doi: 10.2341/06-9.

[Full text links] [PubMed] Google Scholar(107) Scopus(48)

12. Yap AU, Mok BY. Surface finish of a new hybrid aesthetic restorative material. Oper Dent. 2002;27(2):161-166. [PubMed] Google Scholar(75) Scopus(45)

13. Sarac D, Sarac YS, Kulunk S, Ural C, KulunkT. The effect of polishing techniques on the surface roughness and color change of composite resins. J Prosthet Dent. 2006;96(1):33-40. doi: 10.1016/j. prosdent.2006.04.012

[Full text links] [PubMed] Google Scholar(173) Scopus(67)

14. Uctasli MB, Bala O, Gull A. Surface roughness of flowable and packable composite resin materials after finishing with abrasive disc. J Oral Rehabil. 2004;31(12):1197-2002. doi:10.1111/j.13652842.2004.01341.x

[Full text links] [PubMed] Google Scholar(54) Scopus(24)

15. EndoT, Finger WJ, Kanehira M, Utterodt A, Komatsu M. Surface texture and roughness of polished nanofill and nanohybrid resin composites. Dent Mater J. 2010;29(2):213-223. [Full text links] [PubMed] Google Scholar(82) Scopus(34)

16. Grădinaru I, Ignat L, Dascălu CG, Soroaga LV, Antohe ME. Studies regarding the architectural design of various composites and nanofibres used in dental medicine. Rev Chim.(Bucharest). 2018;69(2):328-331. Google Scholar(0) Scopus(0) 
17. Joniot SB, Gregoire GL, Auther AM, Roques YM. Threedimensional optical perfilometry analysis of surface states obtained after finishing sequences for three composite resins. Oper Dent. 2000;25(4):311-315.

[PubMed] Google Scholar(87)

18. Pettini F, Corsalini M, Savino MG, et al. Roughness analysis on composite materials (Microfilled, Nanofilled and Silorane) after different finishing and polishing procedures. Open Dent J. 2015;9:357-367. doi: 10.2174/1874210601509010357. eCollection 2015.

[Free PMC Article] [PubMed] Google Scholar(7) Scopus(3)

19. Chinelatti MA, Thomazatti Chimello D, Pereira Ramos R, PalmaDibb RG. Evaluation of the surface hardness of composite resins before and after polishing at different times. J Appl Oral Sci. 2006;14(3):188-192.

[Full text links] [Free PMC Article] [PubMed] Google Scholar(25) Scopus(11)

20. Kumari CM, Bhat KM, Bansal R. Evaluation of surface roughness of different restorative composites after polishing using atomic force microscopy.J Conserv Dent. 2016;19(1):56-62.

[Full text links] [PubMed] Google Scholar(7) Scopus(7)

21. Venturini D, Cenci MS, Demarco FF, Camacho GB, Powers JM. Effect of polishing techniques and time on surface roughness, hardness and microleakage of resin composite restorations. Ope Dent 2006:31(1):11-17. doi: 10.2341/04-155

[Full text links] [PubMed] Google Scholar(116) Scopus(51)

22. Bittencourt Berger S, Muniz Palialol AR, Cavalli V, Giannini M. Surface roughness and staining susceptibility of composite resins after finishing and polishing. J Esthet Restor Dent. 2011;23(1):34-

43. doi: 10.1111/j.1708-8240.2010.00376.x.

[Full text links] [PubMed] Google Scholar(57)

23. Balan A, Sandu AV, Stoleriu S, Pintiliciuc VS, Toma V. Effect of different finishing and polishing systems on the surface roughness of composite resins. Rev Mat Plast. 2015;52(1):55-57. Google Scholar(4) Scopus(10)
24. Schmidlin PR, Göhring TN. Finishing tooth-colored restorations in vitro: an index of surface alteration and finish-line destruction. Oper Dent. 2004;29(1):80-86.

[PubMed] Google Scholar(30) Scopus(15)

25. Baciu ER, Ben Amor H, Calamaz D, Baciu M, Grădinaru I. Study regarding the profile of finished surfaces of some direct composite resins. Rom J Oral Rehab. 2016;8(3):19-25. Google Scholar(0)

26. Patel B, Chhabra N, Jain D. Effect of different polishing systems on the surface roughness of nano-hybrid composites. J Conserv Dent. 2016;19(1):37-40. doi: 10.4103/0972-0707.173192. [Full text links] [Free PMC Article] [PubMed] Google Scholar(4) Scopus(3)

27. Kakaboura A, Fragouli M, Rahiotis C, Silikas N.Evaluation of surface characteristics of dental composites using profilometry, scanning electron, atomic force microscopy and gloss-meter. J Mater Sci Mater Med. 2007;18(1):155-163. doi: 10.1007/s10856-006-0675-8 [Full text links] [PubMed] Google Scholar(162) Scopus(86)

28. Baroudi K, Rodrigues JC. Flowable resin composites: a systematic review and clinical considerations. J Clin Diagn Res. 2015;9(6):ZE18-24. doi: 10.7860/JCDR/2015/12294.6129. [Free PMC Article] [PubMed] Google Scholar(28) Scopus(6)

29. Baseren M. Surface roughness of nanofill and nanohybrid composite resin and ormocer-based tooth-colored restorative materials after several finishing and polishing procedures. J Biomater Appl. 2004;19(2):121-134. doi: 10.1177/0885328204044011

[Full text links] [PubMed] Google Scholar(144) Scopus(69)

30. Ergücü Z, Türkün LS. Surface roughness of novel resin composites polished with one-step systems. Oper Dent. 2007:32(2):185-192 doi: 10.2341/06-56

[Full text links] [PubMed] Google Scholar(107) Scopus(51)

31. Uctasli MB, Arisu HD, Omürlü $\mathrm{H}$, et al. The effect of different finishing and polishing systems on the surface roughness of different composite restorative materials. J Contemp Dent Pract. 2007;8(2):89-96.

[PubMed] Google Scholar(57) Scopus(18)

\section{Irina NICA}

DMD, MSc, PhD, Assistant Professor

Department of Odontology - Periodontology and Fixed Prosthodontics Faculty of Dental Medicine, "Grigore T. Popa" University of Medicine and Pharmacy

Jassy, Romania

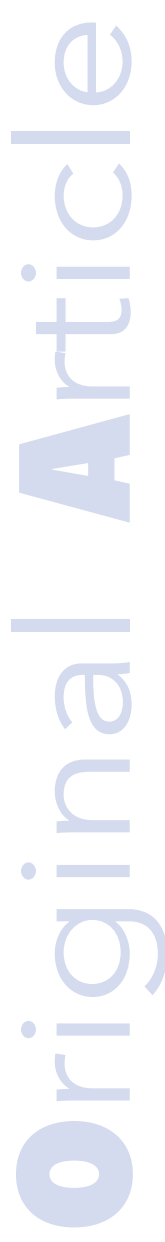

Doctor Irina Nica is Assistant Professor of Cariology and Operative Dentistry at the Faculty of Dental Medicine, "Gr. T. Popa" University of Medicine and Pharmacy Jassy, Romania. She graduated from the Faculty of Stomatology of the "Gr. T. Popa" University of Medicine and Pharmacy, Jassy (2001). She is a Board Certified Physician in the specialty "General Stomatology" (2005). In 2012 she obtained her PhD title in medical sciences with a thesis entitled"Theoretical and experimental contributions to nanomaterials usage in dental medicine". Her main research field is Restorative Dentistry.

\section{A smooth surface of the composite restoration is very important for:}

$\square$ a. Preventing biofilm accumulation;

b. Maintaining oral health;

bc. Preventing external staining;

d. All the previous answers are correct.

\section{The two steps polishing system used in the present study was:}

口a. Tungsten Carbide Burs H135Q and H135UF (Komet Dental/Gebr Brasseler GmbH \& Co. KG, Germany); b. Occlubrush system (KerrHawe SA, Switzerland);

口c. Sof-Lex system (3M ESPE);

d. Super Snap system (Shofu, Inc. Kyoto, Japan).

\section{The action of the instrument used for finishing and polishing determines different values of roughness parameters by:}

a. The hardness of the abrasive powder;

b. The diameter of the particles from which it is made;

c. The flexibility of the substrate on which the abrasive powder is impregnated;

$\square$ d. All the previous answers are correct.

\section{The surface microstructure of Filtek Bulk Fill composite was evaluated:}

a. Qualitatively by AFM (Atomic Force Microscopy);

b. Quantitatively by Profilometry;

口c. Qualitatively by MO (Optical Microscopy);

ad. Quantitatively by SEM (Scanning Electron Microscopy). 


\title{
SOFT-TISSUE FACIAL ASYMMETRY BEFORE AND AFTER ORTHOGNATHIC SURGERY: APPLICATION OF A NEW 3D PROTOCOL

\author{
Filippo Da Pozzoㄹ,2a, Francesca M.E. Rusconi ${ }^{1 b}$, Giada Anna Beltramini²c, Daniele M. Gibelli' ${ }^{1 d}$, Valentina Pucciarelli1e, \\ Aldo Bruno Giannì ${ }^{2,3 f}$, Chiarella Sforza ${ }^{1 g}$
}

\author{
'LAFAS, Laboratory of Functional Anatomy of the Stomatognathic System, Department of Biomedical Sciences for Health, Università degli Studi di Milano, \\ Milan, Italy \\ 2Maxillofacial and Dental Unit, Fondazione IRCCS Ca' Granda Ospedale Maggiore Policlinico di Milano, Milan Italy \\ ${ }^{3}$ Department of Biomedical, Surgical and Dental Sciences, University of Milan, Milan Italy
}

\author{
${ }^{\mathrm{a} M D}$ \\ ${ }^{\mathrm{b} D D S}$ \\ MDD, PhD \\ dMD, PhD, ORCID 0000-0002-9591-1047 \\ eMBiothec, PhD, ORCID 0000-0002-9165-133X \\ ${ }^{\mathrm{I}} \mathrm{MD}, \mathrm{PhD}$ \\ ${ }_{9}^{9} \mathrm{MD}, \mathrm{PhD}$, ORCID 0000-0001-6532-6464
}

\begin{abstract}
Introduction: Skeletal Class III patients often present a major facial asymmetry. In the current investigation, a quantitative method to assess 3D facial asymmetry was applied to an orthognathic surgery patient to quantify possible postsurgical modifications.

Methodology: Soft-tissue facial scans of a 20-year-old man with skeletal Class III, candidate to orthognathic surgery, were collected in the pre-surgery stage and 6, 12, 24 months post-surgery with a stereophotogrammetric system. Soft tissue asymmetry was calculated in the facial thirds according to a published protocol (J Craniomaxillofac Surg 2017;45(1):76-81), and the relevant time-related modifications described. The results were also compared to normal values from a group of 23 control subjects ( 10 men, 13 women, mean age 26) by using z-scores.

Results: The longitudinal analysis of the soft-tissue facial asymmetry showed a marked difference in the analysed time points: orthognathic surgery did reduce facial symmetry in the present patient. The comparison between the patient and the control subjects by using z-scores highlighted a clear difference in all-time points: the patient with facial dysmorphia had a higher degree of asymmetry than healthy subjects.

Conclusion: The measurements of soft-tissue facial asymmetry using 3D optical digitisers can provide clinically useful information. The graphical representation of results can help in the patient's understanding of the treatment phases, thus increasing compliance.

Keywords: face, soft tissues, orthognathic surgery, symmetry.

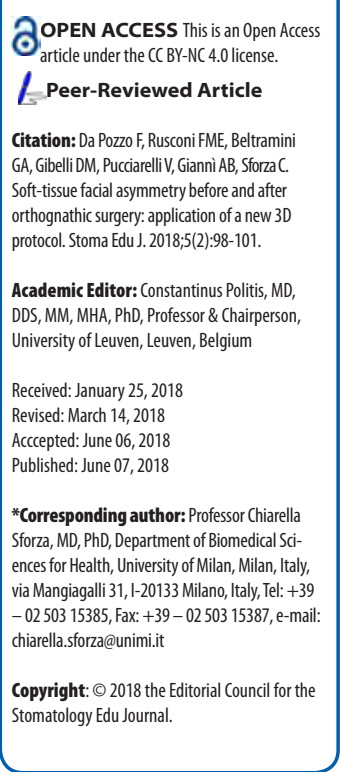

\section{Introduction}

Facial dysmorphoses are not common in the western world. According to US studies, dentoskeletal Class III patients can be found in $0.6 \%$ of the general population, a much smallervalue than that reported for dentoskeletal Class II patients, which is around 10\% [1].

Nonetheless, Class III patients often present more complex situations than Class II ones, with a much more altered facial function and aesthetics, and the percentage of patients undergoing surgical interventions is approximately 6-7 times larger in Class III than in Class II subjects (about 33\% vs. 5\%) [1]. Apart from the restoration of a sound functionality and a normal occlusion, aesthetics and facial symmetry are among the most important aspects in modern orthognathic surgery [2]. The successful attainment of an aesthetically acceptable result starts from correct skeletal and dental positions [3-5], but it needs a thorough evaluation of the facial soft tissues $[1,2]$. The external appearance of the face is also the key point for a fruitful dialogue among the surgeons, the orthodontists and the patients, allowing the best compliance especially for treatments that require several interventions, and that need a middle term follow up to show their final results [6,7].

Current technology offers a wide range of computerized optical scanners that can be used to assess facial soft tissues not invasively, providing a 3D, quantitative reproduction of the patients'characteristics [8]. The digital images can be evaluated longitudinally to appreciate the effects of the various phases of the treatment [6] and can be compared to those obtained from normal subjects of comparable age, sex and ethnicity.

Indeed, the need for reference values is important, as a slight facial asymmetry is also present in healthy subjects [9-11], and even the best surgical and orthodontical approaches cannot restore a perfectly symmetrical appearance. In the present study, we evaluated the soft tissue facial asymmetry of a patient undergoing a combined surgical-orthodontic treatment to correct a Class III dento-skeletal malocclusion. 3D 
morphometric measurements were performed on digital stereophotogrammetric images, and facial soft tissue asymmetry quantified. Data were obtained longitudinally and compared to those obtained in healthy, control subjects.

\section{Materials and methods}

The facial soft tissues of a 20-year-old man were imaged by using the VECTRA M3 3D Imaging System (Canfield Scientific, Fairfield, NJ, USA). The instrument is a stereophotogrammetric unit made up of three pods. In each pod, there are two cameras that photograph the subject's face from different points of view (Fig. 1). A previous calibration permits to obtain the metrical data of the facial surface (from ear to ear, from trichion to neck) in a few milliseconds. Files can be exported and elaborated with proprietary and custom software. In particular, the Mirror ${ }^{\circledast}$ Vectra Software (Canfield Scientific, Fairfield, NJ, USA) was used in the present investigation [4].

The patient had a diagnosis of skeletal Class III dysmorphism and was a candidate for a surgical intervention of bimaxillary osteotomy. The patient was analysed in 4 different stages (preoperative, at the end of orthodontic treatment, and postoperatively 6, 12 and 24 months after surgery). On each occasion, he was imaged while seating with a natural relaxed expression (closed lips, teeth in slight contact).

A group of 23 subjects were selected from the Laboratory archive to form the control group ( 13 females and 10 males, mean age 26, SD 6.8 years); they all had a diagnosis of dentoskeletal Class I and no history of traumas or alterations in the facial bones. Acquisitions were obtained after the patients' written informed consent and did not involve any invasive, painful or dangerous procedure. All procedures were performed as previously described in the literature $[12,13]$. In brief, on each facial image, a set of 50 anthropometric landmarks were identified and digitized. Afterwards, following the protocol validated by Codari et al. [3], the anterior part of the face was delimitated by the following 10 landmarks: trichion (tr); right and left frontotemporal ( $\mathrm{ft}$ ); right and left zygion (zy); right and left tragion (t); right and left gonion (go); gnathion (gn) (Fig. 2).

Each half-face was split into three thirds (upper, middle and lower part); the mid facial plane of maximum symmetry was automatically obtained, and the two facial halves superimposed. The software automatically calculated the Root Mean Square (RMS) distance values among the two facial halves separately for each facial third, thus providing a set of symmetry values. The lower the value, the higher the symmetry. Ideally, very symmetrical areas should have an RMS value of 0 .

To assess the longitudinal modifications, the preoperative image was superimposed on those obtained at 6, 12 and 24 months after the intervention, and RMS values obtained. The software also produced colorimetric maps which highlight the modifications in an intuitive way.

The same procedures were followed for the subjects of the control group, and descriptive statistics (mean, SD) were obtained for regional facial asymmetry and used to calculate $z$-scores (Patient value minus reference mean value divided by reference SD). The smaller the $z$-score, the similar the patient is to the control group. IRB Approval

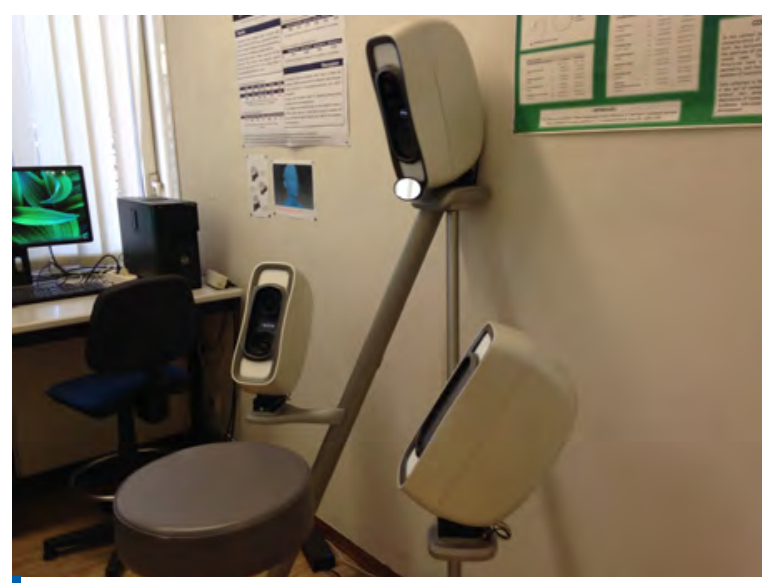

Figure 1.VECTRAM3 3D Imaging System (Canfield Scientific, Fairfield, NJ, USA): the three pods that surround the subject can be seen.

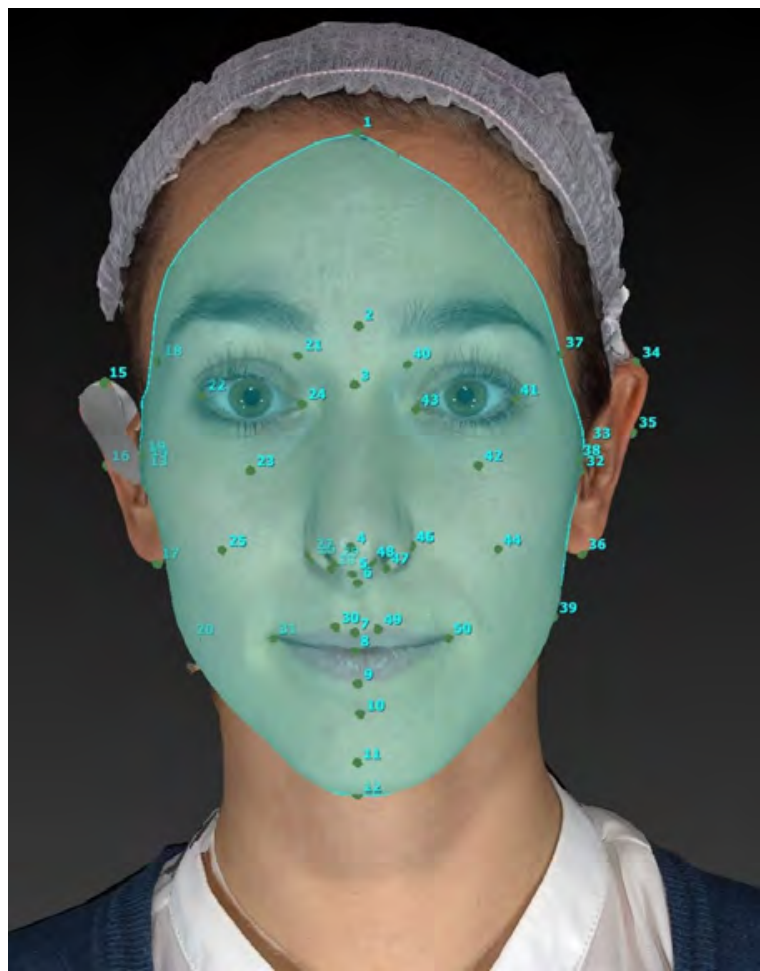

Figure 2. Landmarks used for symmetry analysis. (Written consent for the publication of this image was obtained).

The work described was carried out in accordance with The Code of Ethics of the World Medical Association (Declaration of Helsinki). Informed consent was obtained from all patients, and their privacy rights observed. Ethical approval was given by University ethics review board.

\section{Results}

Table 1 illustrates the time-related variations in facial asymmetry in the analysed patient. A trend of improvement in his facial symmetry was observed during the follow-up examinations.

With regards to the lower third of the face, the RMS value obtained from the overlap of the pre-surgical images of the two hemifaces was $1.2 \mathrm{~mm}$; this value decreased in the subsequent acquisitions made after 6, 12 and 24 months. A reduction in the RMS values was also found in the middle and upper facial thirds.

When the facial asymmetry of the patient was compared to that of healthy, reference subjects using z-scores, a trend of improvement was seen after surgery (Fig. 3). The 
Table 1. Time-related variations in facial asymmetry in the analysed patient $(\mathrm{mm})$. The larger the value, the more asymmetrical the patient.

\begin{tabular}{rcccc}
\hline & RMS PRE & $\begin{array}{r}\text { RMS 6 } \\
\text { months }\end{array}$ & $\begin{array}{r}\text { RMS 12 } \\
\text { months }\end{array}$ & $\begin{array}{c}\text { RMS 24 } \\
\text { months }\end{array}$ \\
\hline $\begin{array}{r}\text { Upper third } \\
\text { (forehead) }\end{array}$ & 0.887 & 0.753 & 0.831 & 0.876 \\
$\begin{array}{r}\text { Middle third } \\
\text { (maxilla) }\end{array}$ & 1.300 & 0.640 & 0.691 & 0.813 \\
$\begin{array}{r}\text { Lower third } \\
\text { (mandible) }\end{array}$ & 1.213 & 0.699 & 0.699 & 0.974 \\
\hline
\end{tabular}

Z-score comparison pre and post $24 \mathrm{~m}$

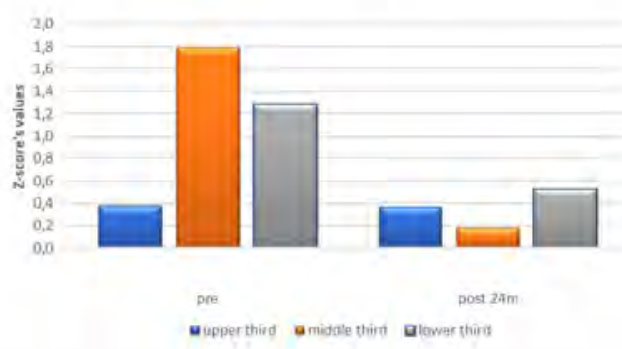

I Figure 3. Z-scores of the analysed patient during the 24-months follow up.

z-score value calculated in pre-surgical acquisitions was 1.28 SD for the lower third, 1.79 SD for the middle third and 0.38 SD for the upper third; 24 months after surgery the $z$-score was 0.52 SD for the lower third, 0.18 SD for the middle and 0.37 SD for the upper one.

To better assess the localised facial asymmetry, Fig. 4 presents the asymmetry divided in the upper, middle and lower parts of the face in the analysed patient. The pre-surgical image is compared to that obtained at the 24 months follow up. The software produces a colorimetric map which highlights the variations in an intuitive manner. The major differences are represented in red and in blue, respectively by default and in excess. The unvaried areas are coloured in green. As expected the degree of asymmetry is reduced in every third of the face and the best results are seen in the lower third.

\section{Discussion}

In the current investigation, we performed a longitudinal evaluation of soft-tissue facial asymmetry in a patient candidate for bimaxillary surgery for a skeletal Class III malocclusion. The method used a set of stereophotogrammetric facial scans, and it allowed a complete picture of the modifications of the patients' soft tissues: orthodontists and surgeons are thus provided with an extra tool to plan and monitor the clinical outcome. An additional advantage is the patient-friendly depiction of the results which can enhance the patient's comprehension of the various treatment phases, with increased compliance [6].

The acquisitions were made with a middle term follow up, starting in the preoperative (post orthodontic) phase, and subsequently 6, 12 and 24 months after surgery. The 24-months stage allowed stable facial images of the patients to be obtained, without the transient effects of surgery on soft tissues edema and the post-surgical orthodontic treatment $[1,14]$. Indeed, despite the variety of studies on 3D facial asymmetry after bimaxillary orthognathic surgery, few were longitudinal and lasted

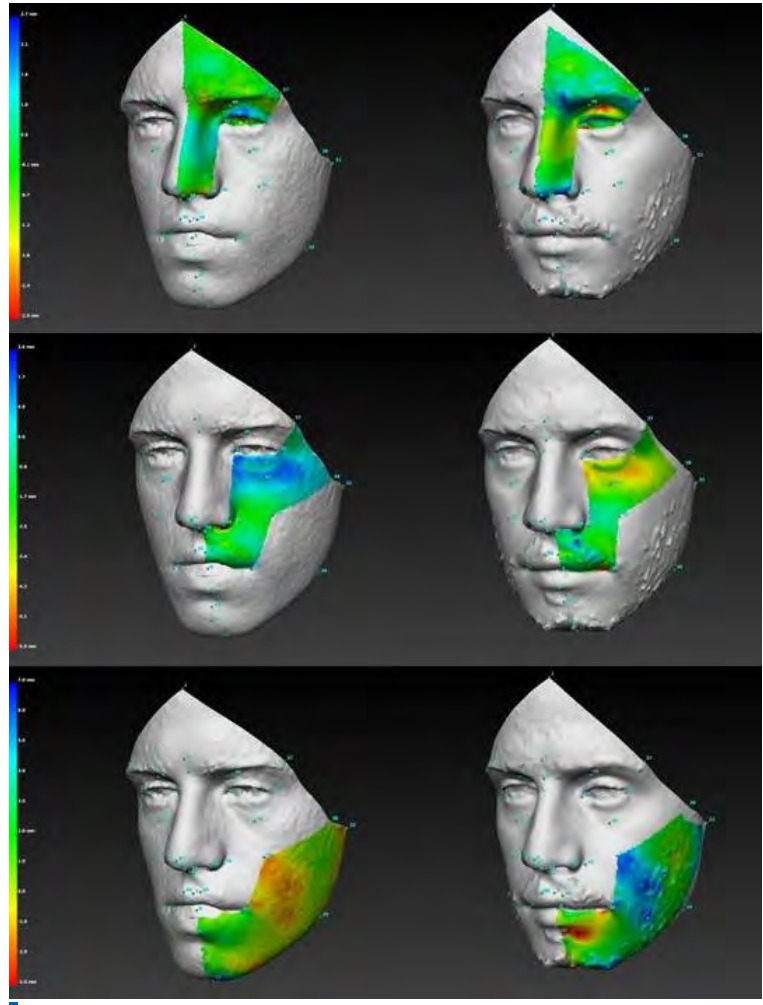

Figure 4. Localised asymmetry in the upper, middle and lower parts of the face in the analysed patient. The pre-surgical image is compared to that obtained at the 24 months follow up..

more than 6 months [15].

Generally, patients with skeletal dysmorphia are more asymmetrical than healthy subjects without malocclusions $[9,16]$, as shown in the current analysis that allowed to localize those parts of the face showing a higher degree of left-right imbalance. The present method can, therefore, be coupled with the conventional analyses of facial esthetics [17], thus increasing the quantitative description of the patient, and helping in treatment planning and monitoring of follow up.

\section{Conclusion}

The measurements of soft-tissue facial asymmetry using 3D optical digitisers can provide clinically useful information. The graphical representation of results can help in the patient's understanding of the treatment phases, thus increasing compliance.

\section{Author Contributions}

FP: Conception and design of the study; Acquisition of data; Analysis and interpretation of data collected; Drafting of the article; Final approval. FMER: Acquisition of data; Analysis and interpretation of data collected; Drafting of the article; Final approval. GAB: Acquisition of data; Analysis and interpretation of data collected; Drafting of the article; Final approval. DMG: Acquisition of data; Analysis and interpretation of data collected; Drafting of the article; Final approval. VP: Analysis and interpretation of data collected; Drafting of the article; Final approval. ABG: Conception and design of the study; Analysis and interpretation of data collected; Critical revision of article; Final approval. CS: Conception and design of the study; Analysis and interpretation of data collected; Critical revision of article; Final approval. 


\section{Acknowledgments}

The authors have no conflicts of interest.

This research did not receive any specific grant from funding agencies in the public, commercial, or not-forprofit sectors. The authors declare that the research was conducted in the absence of any commercial or financial relationship that could be construed as a potential conflict of interest.

\section{References}

1. Proffit WR, White RP, Sarver DM. Contemporary treatment of dentofacial deformity. 15th ed. St. Louis, Mo: Mosby. Chicago 2003.

Google Scholar(412)

2. Cullati F, Mapelli A, Beltramini G, et al. Surface electromyography before and after orthognathic surgery and condylectomy in active laterognathia: a case report. Eur J Paediatr Dent. 2017;18(2):131-138. doi: 10.23804/ejpd.2017.18.02.08 [Full text links] [PubMed] Google Scholar(0) Scopus(0)

3. Chew MT. Spectrum and management of dentofacial deformities in a multiethnic Asian population. Angle Orthod. 2006;76(5):806809. doi: 10.1043/0003-3219(2006)076[0806:SAMODD]2.0.CO;2 [Full text links] [PubMed] Google Scholar(52) Scopus(24)

4. Gibelli DM, Pucciarelli V, Pisoni L, et al. Quantification of dental movements in orthodontic follow-up: a novel approach based on registration of 3D models of dental casts. Stoma Edu J. 2017:4(1):53-59 doi: 10.25241/stomaeduj.2017.4(1).art.5.

5. Shaheen $\mathrm{E}$, Politis $C$. The use of $3 \mathrm{D}$ virtual planning and 3D printing for the treatment of facial asymmetry: a case report. Stoma Edu J. 2016;3(3-4):156-161. doi: 10.25241/ stomaeduj.2016.3(3-4).art.4.

Google Scholar(1)

6. Pucciarelli V, Tarabbia F, Codari M, et al. Stereophotogrammetric evaluation of labial symmetry after surgical treatment of a lymphatic malformation. J Craniofac Surg. 2017;28(4):e355-e358. doi: 10.1097/SCS.0000000000003601.

[Full text links] [PubMed] Google Scholar(1) Scopus(2)

7. Segna E, Pucciarelli V, Beltramini GA, et al. Parry Romberg Syndrome and linear facial scleroderma: management in pediatric population. J Biol Regul Homeost Agents. 2017;31(2 Suppl 1):131-138

[PubMed] Google Scholar(2) Scopus(0)

8. Sforza C, de Menezes M, Ferrario V. Soft- and hard-tissue facial anthropometry in three dimensions: what's new. J Anthropol Sci. 2013:91:159-184. doi:10.4436/jass.91007.

[Full text links] [PubMed] Google Scholar(45) Scopus(27)

9. Cheong YW, Lo L. Facial asymmetry: etiology, evaluation, and management. Chang Gung Med J. 2011;34(4):341-351. [PubMed] Google Scholar(109) Scopus(50)

10. Ferrario VF, Sforza C, Dellavia C, et al A quantitative threedimensional assessment of soft tissue facial asymmetry of cleft lip and palate adult patients. J Craniofac Surg. 2003;14(5):739-746. [Full text links] [PubMed] Google Scholar(49) Scopus(37)

11. Sforza C, Laino A, D'Alessio R, et al. Soft-tissue facial characteristics of attractive Italian women as compared to normal women. Angle Orthod. 2009;79(1):17-23. doi: 10.2319/122707-605.1. [Full text links] [PubMed] Google Scholar(49) Scopus(26)

12. Codari M, Pucciarelli V, Stangoni F, et al. Facial thirds-based evaluation of facial asymmetry using stereophotogrammetric devices: Application to facial palsy subjects. J Craniomaxillofac Surg. 2017;45(1):76-81. doi: 10.1016/j.jcms.2016.11.003. [Full text links] [Free full text] [PubMed] Google Scholar(11)

13. De Menezes M, Rosati R, Ferrario VF, et al. Accuracy and reproducibility of a 3-dimensional stereophotogrammetric imaging system. J Oral Maxillofac Surg.2010;68(9):2129-2135. doi: 10.1016/j.joms.2009.09.036.

[Full text links] [PubMed] Google Scholar(91) Scopus(58)

14. Aydemir $\mathrm{H}$, Efendiyeva $\mathrm{R}$, Karasu $\mathrm{H}$, Toygar-Memikoğlu U. Evaluation of long- term soft tissue changes after bimaxillary orthognathic surgery in Class III patients. Angle Orthod. 2015;85(4):631-637. doi: 10.2319/062214-449.1. [Full text links] [PubMed] Google Scholar(4) Scopus(3)

15. Kobayashi T, Ueda K, Honma K, et al. Three-dimensional analysis of facial morphology before and after orthognathic surgery. J Craniomaxillofacial Surg. 1990;18(2):68-73.

[Full text links] [PubMed] Google Scholar(51) Scopus(25)

16. Chew MT. Spectrum and management of dentofacial deformities in a multiethnic Asian population. Angle Orthod. 2006;76(5):806809. doi: 10.1043/0003-3219(2006)076[0806:SAMODD]2.0.CO;2 [Full text links] [PubMed] Google Scholar(52) Scopus(24)

17. Rossetti A, De Menezes M, Rosati R, Ferrario VF, Sforza C. The role of the golden proportion in the evaluation of facial esthetics. Angle Orthod. 2013:83(5):801-808. doi: 10.2319/111812-883.1. [Full text links] [PubMed] Google Scholar(33) Scopus(13)

\section{Filippo DA POZZO}

LAFAS, Laboratory of Functional Anatomy of the Stomatognathic System Department of Biomedical Sciences for Health, University of Milan via Mangiagalli 31, I-20133 Milano, Italy

Filippo Da Pozzo, MD, graduated in 2017 with the highest grades in Medicine and Surgery at the University of Milan. Since 2015 he has been attending the university department of Oral and Maxillofacial surgery at the polyclinic hospital Fondazione IRCCS Ca' Granda in Milan. He is currently a member of the research staff in the Laboratory of Functional Anatomy of the Stomatognathic System - LAFAS, Department of Biomedical Sciences for Health at the University of Milan, Milan, Italy. His fields of research are the morphological and metrical assessment of anatomical characteristics of craniofacial structures, including their modifications with pathology and treatment.

\section{0uestions}

\section{Which instruments can be used to measure soft tissue facial asymmetry?}

$\square$ a. Bite wing radiographs;

b. Lateral plane teleradiographs;

ac. Stereophotogrammetric units;

d. Conventional orthopantomographs.

\section{How was facial asymmetry measured?}

a. Using Root Mean Square distances among images;

b. Using surface electromyography;

b. Superimposing facial photos to Computerized Tomography reconstructions;

d. Measuring the distances between selected skeletal landmarks.
3. In the current study we investigated

$\square$ a. Three-dimensional modifications in dental arch diameters;

b. The effect of operator experience in making facial measurements;

ac. The use of Computerized Tomography to measure facial asymmetry;

$\square d$. A new protocol to assess localized soft-tissue facial asymmetry.

4. In the current investigation, we found that:

$\square$ a. Soft-tissue facial asymmetry increased after dental extraction;

ab. Skeletal facial asymmetry decreased after implant placement;

$\square$ c. Soft-tissue facial asymmetry decreased after orthognathic surgery;

$\square d$. Dental arch asymmetry increased after functional orthodontic treatment. 


\section{BONDING ORTHODONTIC RESIN CEMENT TOZIRCONIUM OXIDE UNDER ORTHODONTICS LOAD AND THERMOCYCLING EFFECT \\ Hind S. Hussein ${ }^{1 \mathrm{a}}$, Nader Abdulhameed ${ }^{1 \mathrm{~b}}$, Chiayi Shenc, Calogero Dolce ${ }^{2 \mathrm{~d}}$, Jean-François Roulet ${ }^{1 \mathrm{e}^{*}}$}

'Department of Restorative Dental Sciences, College of Dentistry, University of Florida

${ }^{2}$ Department of Orthodontics, College of Dentistry, University of Florida

a,BDS, Courtesy Clinical Assistant Professor

${ }^{\mathrm{b} B D S}, \mathrm{MS}$, PhD Student, Clinical Assistant Professor

PhD, Associate Professor

${ }^{\mathrm{D} D D S}$, PhD, Professor

eDr med dent, Drhc, Professor, Director of Center for Dental Biomaterials

Purpose: Evaluate the microshear bond strength ( $\mu \mathrm{SBS})$ of orthodontic resin cement to monolithic zirconium oxide ceramic (MZ) under orthodontic load (OL) and thermocycling (TC) effect.

Materials and Methods: Glazed MZ blocks (Zenostar, Ivoclar Vivadent) were tested after air abrasion with 30- $\mu$ m silica coated aluminum oxide $\left(\mathrm{Al}_{2} \mathrm{O}_{3}\right)$ particles (CoJet, 3M ESPE). The specimens were randomly divided into 4 groups $(n=15): G 1$, OL with TC; $G 2$, OL without TC; G3 no OL with TC; and G4, no OL, no TC (control). Orthodontic cement cylinders (Heliosit Orthodontic, Ivoclar Vivadent) were bonded to the primed samples (Monobond Plus, Ivoclar Vivadent) using the Ultradent SBS system and light cured (SmartLite Max, Dentsply Sirona, $\left.1400 \mathrm{~mW} / \mathrm{cm}^{2}, 40 \mathrm{~s}\right) . \mathrm{G} 1$ and $\mathrm{G} 2$ were subjected to $70 \pm 15 \mathrm{~N}$ load perpendicular to the cylinder axis, $\mathrm{G} 1$ and $\mathrm{G} 3$ were thermo-cycled ( 5000 cycles $5-55^{\circ} \mathrm{C}, 90$ s/cycle). $\mathrm{G} 2$ and G4 were stored in distilled water at $37 \pm 1{ }^{\circ} \mathrm{C}$. The specimens were subjected to $\mu$ SBS test (crosshead speed $0.5 \mathrm{~mm} / \mathrm{min}$ ). Data were analyzed using two-way ANOVA, and one-way ANOVA and Tukey test (HSD).

Results: Two-way ANOVA for $\mu$ SBS values (MPa) showed significant $(p=0.0004)$ load effects, but not thermal effect $(p=0.2455)$ with significant load/thermocycling interactions $(p<$ $0.0001)$. The ranking of the single groups by Tukey test $(a=0.05)$ showed that $G 1$ exhibited the highest $\mu \mathrm{SBS}(8.4 \pm 2.8 \mathrm{MPa}), \mathrm{G} 4(6.3 \pm 1.1 \mathrm{MPa})$ and $\mathrm{G} 2(5.8 \pm 1.1 \mathrm{MPa})$ as a group was second, and $\mathrm{G} 2$ and $\mathrm{G} 3(4.7 \pm 1.1 \mathrm{MPa})$ as a group was the lowest.

Conclusion: G1, which is the closest to clinical reality, yielded the best results.

Keywords: orthodontics, dental materials, orthodontic resin cement, monolithic zirconium oxide ceramic, microshear bond strength test.

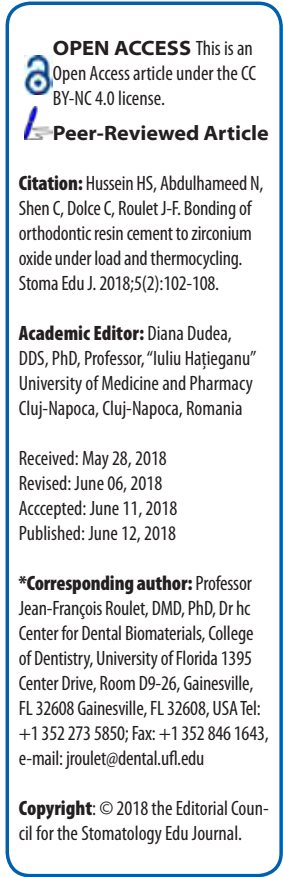

\section{Introduction}

Due to the patients' increased esthetic demands and the development of technology in dental materials, porcelain fused to metal (PFM) crowns and bridges are being replaced by glass based ceramic materials and monolithic Zirconium oxide (MZ) [1]; they are more esthetic, biocompatible, resistant to wear, show low thermal conductivity, and are color stable [2]. However, despite these advantages, the brittle nature of these materials restricts their use [3].

Therefore, there is a need for new materials which have the same esthetic properties as glass based all ceramic materials and a strong framework like PFM for fixed dental prosthesis (FDPs). The introduction of zirconium oxide fulfilled these requirements [4]. The advantages of zirconium oxide include high fracture resistance and high flexural strength (>1000 MPa), which allowed for thinner restorations. Furthermore the material can be stained which allows better esthetic results [5]. These properties make it a very good candidate for aesthetic FDPs. The tetragonal zirconia polycrystals (TZP), especially $3 \mathrm{~mol} \% \mathrm{Y}_{2} \mathrm{O}_{3}$ stabilized zirconia (3Y-TZP) has been used as a material for dental and medical restorations [6]. Previous studies have reported that the life expectancy of (3Y-TZP) zirconium oxide when compared to PFM FDPs for posterior indication, is shorter because of the delamination and chipping of veneering ceramic; to overcome this problem, the monolithic zirconium oxide (MZ) was introduced to the dental market $[1,2,4,7]$.

Full contour MZ FDPs are produced using CAD/CAM technologies. The restorations are milled from blocks which can be used either glazed or polished for better esthetic results [8]. Although polishing may provide sufficient esthetic appearance by decreasing the surface roughness, technicians like to glaze the $\mathrm{ZrO}_{2}$ surface to improve the esthetic properties. With this process, the glass will infiltrate the zirconium oxide [9]. Since the number of adult patients who have been seeking orthodontic treatment is increasing [9], it means that the orthodontist will sometimes apply orthodontic brackets on dental restorations rather than on enamel. In a clinical situation, the orthodontist may not know the composition of all the ceramic crowns. Since different ceramics require different bonding procedures and the lack of bonding protocols for 
these new materials, these situations may lead to early debonding of orthodontic brackets [4]. Furthermore, in orthodontics the goal is not a maximum bond strength, but one that is adequate to withstand orthodontic forces. Finally, the bond should be reversible i.e. it should be easy to remove brackets without damaging the enamel or the restored teeth.

Currently, there are several studies about the different surface conditioning protocols for orthodontic bonding to porcelain materials. They enhance the adhesion either by mechanical conditioning such as "roughness by airborne particle abrasion" or by chemical conditioning such as the use of hydrofluoric acid etch of glass-based ceramics to increase the bond strength and/or silane coupling agents or oxidic primers which change the wettability of the surface, or by combination of both mechanical and chemical surface treatments [10-12].

Although there is increased use for $\mathrm{MZ}$ crowns in dental practice, there is not enough information available about how to bond orthodontic brackets on MZ [13]. The most commonly method used to evaluate the performance of orthodontic bonding systems and the bonding technique is by measuring shear bond strength [14]. Doing this, one should consider the effect of orthodontic forces applied and the stress induced by water storage and thermocycling on the bond strength. This should be simulated in vitro as an accelerated ageing process [13]. In shear bond strength testing, the ideal direction of pull is parallel to the loading interface. It has been recognized that the direction of the debonding force will affect the results [15]. In clinical orthodontic practice, bonding the brackets and placement of arch wire might be done in the same visit. Hence, force could be applied to the bracket within the first hour after bonding and regardless of the relatively low magnitude of the force, it could have an adverse effect on the bond strength. It was reported that the polymerization of adhesives should quickly reach a minimum value to enable the adhesive to resist bonding failure when tying in initial arch wires [16].

The objective of this study was to evaluate the thermo cycling effect accompanied by orthodontic force on the micro shear bonding strength of orthodontic resin cement on glazed monolithic zirconium oxide surface conditioned by air abrasion with silica coated alumina particles.

The following null hypotheses were tested: 1) The thermo cycling (TC) does not influence the shear bond strength, 2) The orthodontic load does not influence the shear bond strength, and 3) The orthodontic load with TC does not influence the shear bond strength.

\section{Material and methods}

The types, brands, manufacturers and chemical composition of the material used in this study are listed in Table 1.

\subsection{Specimen Preparation}

One monolithic zirconium oxide (MZ) material was tested in this study (Zenostar, Ivoclar Vivadent, Schaan, Liechtenstein). The specimens were received in nonsintered blocks. They were cut into squares approximately $(9 \mathrm{~mm} \times 9 \mathrm{~mm} \times 4 \mathrm{~mm}$ ). They were
Table 1.Types, brands, manufacturers and chemical compositions of the material used in this study.

\begin{tabular}{|c|c|c|}
\hline $\begin{array}{l}\text { Type and } \\
\text { Brand }\end{array}$ & Manufacturer & Chemical composition \\
\hline Zenostar & $\begin{array}{l}\text { Wieland, Ivoclar } \\
\text { Vivadent }\end{array}$ & $\begin{array}{l}\text { Zirconium dioxide }\left(\mathrm{ZrO}_{2}+\mathrm{HfO}_{2}\right. \\
\left.+\mathrm{Y}_{2} \mathrm{O}_{3}\right)>99.0 \% \text {, yttrium oxide } \\
\left(\mathrm{Y}_{2} \mathrm{O}_{3}\right) 4.5 \leq 6.0 \% \\
\text { Hafnium oxide }\left(\mathrm{HfO}_{2}\right) \leq 5.0 \% \text {, } \\
\text { aluminum oxide }\left(\mathrm{Al}_{2} \mathrm{O}_{3}\right)+\text { other } \\
\text { oxides } \leq 1.0 \%\end{array}$ \\
\hline Glaze spray & $\begin{array}{l}\text { IPS e.max } \\
\text { Ceram }\end{array}$ & $\begin{array}{l}\text { Isobutane } 30-60 \% \text {, propan-2-ol } \\
25-40 \%\end{array}$ \\
\hline $\begin{array}{l}\text { Acratray } \\
\text { Acrylic Powder } \\
\text { (blue) }\end{array}$ & $\begin{array}{l}\text { Henry Schein; } \\
\text { Melville NY, } \\
\text { USA }\end{array}$ & $\begin{array}{l}\text { Poly Methyl methacrylate } \\
\text { (PMMA), calcium carbonate, } \\
\text { titanium dioxide, benzoyl } \\
\text { Peroxide }\end{array}$ \\
\hline $\begin{array}{l}\text { Acrylic Liquid } \\
\text { (Self cure) }\end{array}$ & Henry Schein & $\begin{array}{l}\text { Methyl methacrylate (MMA), } \\
\text { benzophenone, hydroquinone }\end{array}$ \\
\hline CoJet Sand & $\begin{array}{l}\text { 3M ESPE; St } \\
\text { Paul, MN, USA }\end{array}$ & $30-\mu \mathrm{ml}_{2} \mathrm{O}_{3} \mathrm{SiO}_{2}$ \\
\hline $\begin{array}{l}\text { Monobond } \\
\text { Plus }\end{array}$ & $\begin{array}{l}\text { Ivoclar } \\
\text { Vivadent; } \\
\text { Schaan, } \\
\text { Liechtenstein }\end{array}$ & $\begin{array}{l}\text { Ethanol, 3-trimethoxysilylpropyl } \\
\text { methacrylate, methacrylate } \\
\text { phosphoric acid ester, disulfide } \\
\text { methacrylate }\end{array}$ \\
\hline $\begin{array}{l}\text { Heliosit } \\
\text { Orthodontic } \\
\text { Adhesive }\end{array}$ & Ivoclar Vivadent & $\begin{array}{l}\text { Bis-GMA } 50-100 \% \\
\text { urethane dimethacrylate } 10 \\
<20 \% \\
1,10 \text {-decandiol dimethacrylate } \\
10<20 \%\end{array}$ \\
\hline $\begin{array}{l}\text { Orthodontic } \\
\text { wire }\end{array}$ & $\begin{array}{l}\text { ORTHO } \\
\text { TECHNOLOGY }\end{array}$ & SS Straight Lengths 0.14 . \\
\hline $\begin{array}{l}\text { Orthodontic } \\
\text { brackets }\end{array}$ & $\begin{array}{l}\text { Dentsply GAC } \\
\text { international, } \\
\text { INC Bohemia, } \\
\text { NY, USA }\end{array}$ & Stainless Steel. \\
\hline
\end{tabular}

then sintered in a furnace at $1530^{\circ} \mathrm{C}$ (Sintramat S1 High Temperature Furnace, Ivoclar Vivadent) with a heating rate of $8^{\circ} \mathrm{C} / \mathrm{min}$ and a holding time of two hours.

All the specimens were glazed with (IPS e.max Ceram glaze spray, Ivoclar Vivadent) according to the manufacturer's directions $\left(770^{\circ} \mathrm{C}\right)$. The glazing material was applied in an even layer on the specimen in the usual manner and then all the specimens were fired according to the manufacturer's direction in a furnace (Programat EP 5000, Ivoclar Vivadent). After completion of the firing process the samples were removed from the furnace and allowed to cool to room temperature in a place protected from draft.

All specimens were then embedded in autopolymerizing acrylic resin (powder and liquid, Acratray Blue, Henry Schein, Melville, NY, USA). First, the specimens were held in place on a smooth surface with a piece of two-sided adhesive tape. Then, powder and liquid of acrylic resin was mixed (1:3) and poured into the molds to produce cylinders measuring $2.5 \mathrm{~cm}$ in diameter and $2.3 \mathrm{~cm}$ in length (Ultradent Products, South Jordan, UT, USA). After autopolymerization started, the mold was placed in a container with cold water to decrease the polymerization temperature.

After polymerization, the cylinders were removed from the mold and the two-sided adhesive tape was removed. The specimen surfaces were then cleaned with ethanol (Table 1). The cylinders were ground with 120-grit silicon carbide abrasive paper under running water for about 1 min to ensure a parallel surface to the bottom surface of the clamp into which the cylinders were placed during 
bonding.

The specimens $(\mathrm{N}=60)$, were randomly divided in two subgroups. Half of the specimens with orthodontic load $(n=30)$ and the other half without orthodontic load ( $n$ $=30$ ). The orthodontic load and the non-orthodontic load specimens were further randomly divided into two subgroups: thermo cycling (TC) group and non-thermo cycling (non-TC) group ( $\mathrm{n}=15$ per group) (Fig. 1).

\subsection{Surface Conditioning Methods}

All the specimen's surfaces were conditioned using air abrasion with an intraoral air-abrasion device (Microetcher, Danville Engineering, San Ramon, CA, USA) with $30 \mu \mathrm{m}$ silica-coated $\mathrm{Al}_{2} \mathrm{O}_{3}$ (CoJet Sand, $3 \mathrm{M}$ ESPE, St Paul, MN, USA), perpendicular to the surface from approximately $10 \mathrm{~mm}$ for $20 \mathrm{~s}$ in circling motions at 2.8 bar. After air abrasion, the specimen surfaces were air blown to remove the remnants of the powder.

\subsection{Bonding Procedures}

Specimen surfaces were coated with a thin layer of Universal Primer (Monobond Plus, Ivoclar Vivadent) that was left for 60 seconds to allow it to react, and then the remaining excess was removed with a strong stream of air. Each specimen was fixed to a bonding clamp with a special mold (Ultradent Shear Bond Test, Ultradent Products, Inc., South Jordan, UT, USA) to assure flat substrate surfaces and to standardize the diameter (2.3 $\mathrm{mm}$ ) of the resin composite. Orthodontic resin (Heliosit Orthodontic, Ivoclar Vivadent) was applied to the surface using the bonding mold. Composite was applied in the mold and light cured (SmartLite Max, Dentsply Sirona, York, PA, USA, $1400 \mathrm{~mW} / \mathrm{cm}^{2}, 40 \mathrm{~s}$ ) (Fig. 2). All specimens were stored in distilled water at $37 \pm 1{ }^{\circ} \mathrm{C}$.

As next step, orthodontic brackets were bonded to the acrylic next to the embedded specimens of the load groups. The position was selected to apply a force of approximately $70 \pm 15 \mathrm{~g}(0.69 \pm 0.14 \mathrm{~N})$ with an orthodontic wire (SS 0.14) (Fig. 3) to the bonded composite cylinders. The force was measured by using a Dontrix gauge (TP Orthodontics, Inc., La Porte, IN, USA). The orthodontic load group and the non-orthodontic load group were further randomly divided into two subgroups ( $n=15)$ : the thermo cycling (TC) group and the non-TC group (Fig. 1). Before testing the microshear bond strength all the specimens of the TC group were thermocycled in a Chewing Simulator device (CS-4SD Mechatronic $\mathrm{GmbH}$, Feldkirchen, Westerham, Germany) for 5000 cycles between $5^{\circ} \mathrm{C}$ and $55^{\circ} \mathrm{C}$ with a dwell time of 30 seconds with the mechanical load component of the machine turned off. At the same time, all the specimens of the non-TC group were stored in distilled water at 37 $\pm 1^{\circ} \mathrm{C}$. The position of the brackets to be bonded to the resin block is marked on both sides of the composite/MZ sample. The specimens were subjected to $\mu S B S$ test using an universal machine (Instron 1125, Norwood, MA, USA, Fig. 4) (crosshead speed $0.5 \mathrm{~mm} / \mathrm{min}$ ).

\subsection{Statistical Analysis}

Means and standard deviations of the shear bond strength were calculated for all groups [9]. Microshear bond strength data (MPa) were submitted to a twoway ANOVA (SAS 9.4). Multiple comparisons were made using the Tukey's Studentized Range (HSD) Test ( $a=$

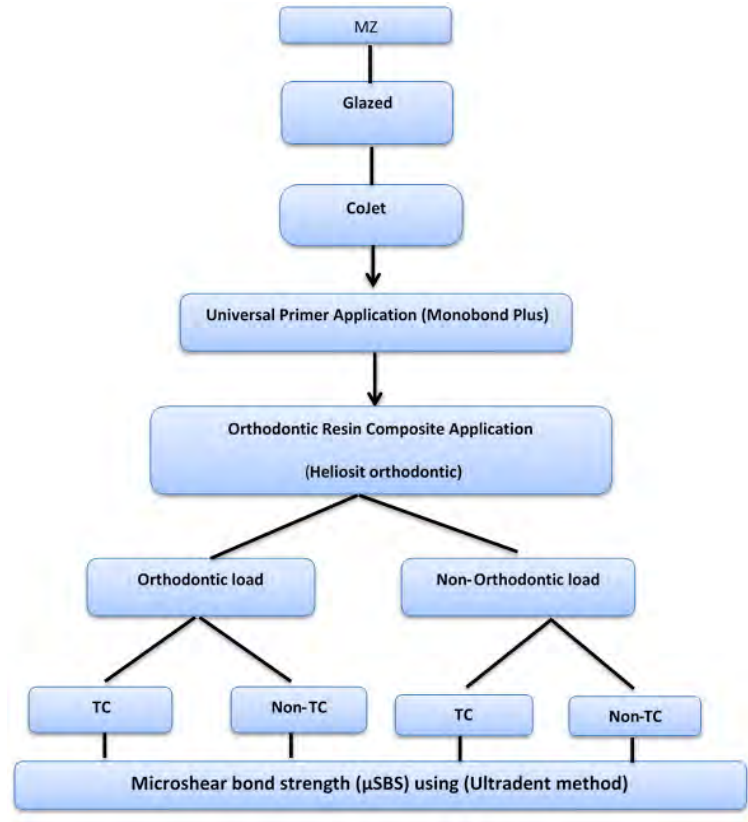

Figure 1. Experimental sequence, $M Z=$ Monolithic Zirconium oxide ceramic, $\mathrm{TC}=$ Thermocycling effect.

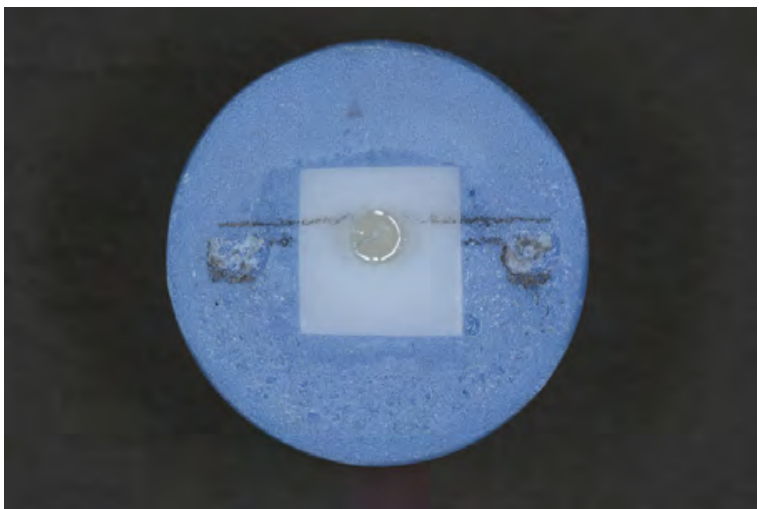

Figure 2. The Pencil line is tangent to the composite cylinder and it is 0.5 $\mathrm{mm}$ higher than the position of the bracket on the both side of $\mathrm{MZ}$, in order to provide $70 \pm 15 \mathrm{~g}(0.69 \pm 0.14 \mathrm{~N})$ load force by the orthodontic wire.

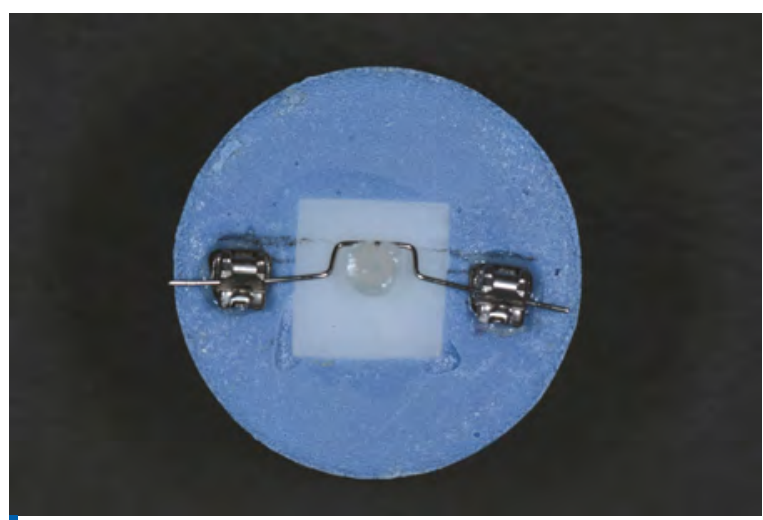

Figure 3. Top view showing the final design after adding orthodontic wire to composite cylinder.

0.05) for shear used to determine significant differences between the group dependent on the variable with and without application of load and/or TC.

\section{Results}

Two-way ANOVA for $\mu$ SBS values (MPa) showed highly significant $(p=0.0004)$ effects, however highly significant load/thermocycling interactions were found (Tab. 


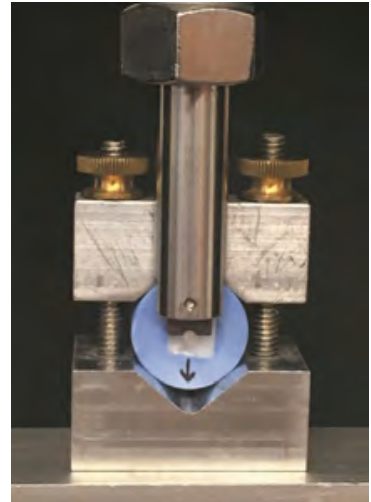

I Figure 4. Sample loaded in universal Instron machine.

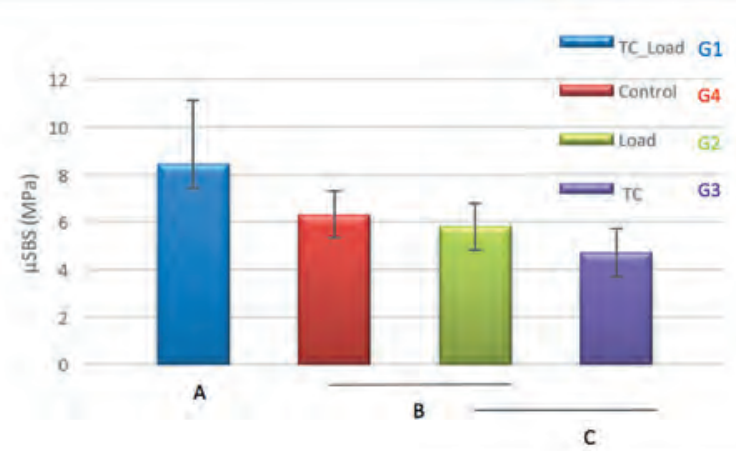

I Figure 5. Means and standard deviations of $\mu$ SBS values between the TC and non-TC group with or without the orthodontic load. Bars connected with a line are in the same statistical group (Tukey test, $\mathrm{a}=0.05$ ).

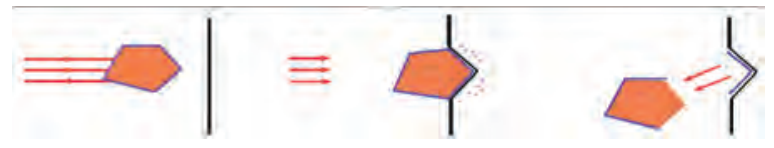

I Figure 6. The principle of CoJet treatment: the silica coated alumina particles create micro roughness of the surface due to the kinetic energy and leave silica embedded inside the surface, so it can react chemically with a primer (Silane) [21].

Table 2. Two-way ANOVA for $\mu$ SBS values (MPa). Note that the 2-way ANOVA showed highly significant differences (Model $p<0.0001)$. However there were higly significant interactions (Load x Thermal).

\begin{tabular}{llllll}
\hline Source & DF & Anova SS & $\begin{array}{c}\text { Mean } \\
\text { Square }\end{array}$ & $\begin{array}{c}\text { F } \\
\text { Value }\end{array}$ & Pr $>$ F \\
\hline Model & 3 & 110.1178850 & 36.7059617 & 13.25 & $<.0001$ \\
Error & 56 & 155.1204133 & 2.7700074 & & \\
$\begin{array}{l}\text { Corrected } \\
\text { Total }\end{array}$ & 59 & 265.2382983 & & & \\
Load & 1 & 38.86540167 & 38.86540167 & 14.03 & 0.0004 \\
$\begin{array}{l}\text { Thermal } \\
\text { Load }\end{array}$ & 1 & 3.81528167 & 3.81528167 & 1.38 & 0.2455 \\
+ Thermal & 1 & 67.43720167 & 67.43720167 & 24.35 & $<.0001$ \\
\hline
\end{tabular}

Table 3. Means and Standard deviations of the 4 tested groups. Same letters in the Tukey Grouping column mean no statistically significant difference.

\begin{tabular}{|c|c|c|c|c|c|c|}
\hline TRET & $\mathbf{N}$ & Mean & STD & \multicolumn{3}{|c|}{ Tukey Grouping } \\
\hline TC_Load (G1) & 15 & 8.4320 & 2.76480 & A & & \\
\hline Control (G4) & 15 & 6.3180 & 1.09754 & & B & \\
\hline Load (G2) & 15 & 5.8073 & 1.06452 & & B & C \\
\hline TC (G3) & 15 & 4.7020 & 1.04792 & & & $C$ \\
\hline
\end{tabular}

2). Therefore, no main effects could be shown. The subsequent one-way ANOVA and the Tukey test $(a=0.05)$ showed that thermal cycling with load (G1) had the greatest shear bond strength $(8.4 \pm 2.8 \mathrm{MPa})$ while the thermal cycling alone (G3) had the least shear bond strength (4.7 $\pm 1.1 \mathrm{MPa}$ ) among the groups. Comparing the results of $\mu \mathrm{SBS}$ values for the adhesive system with and without the application of TC eliminates the effect of the load (G3, G4) and showed that there was significant difference between them and there was a significant difference with load (G1, G2). The result shows a nonsignificant reduction in $\mu$ SBS values between the load without TC effect (G2) and TC without load (G3) (Fig. 5).

\section{Discussion}

The first and third null hypotheses had been rejected, the second one had been accepted.

The conditioning technique used in this study (17), gritblasting with CoJet $\left(\mathrm{Al}_{2} \mathrm{O}_{3}\right.$ silica coated sand) was selected for the following reasons: glass based ceramics can be etched with Hydrofluoric acid (HF) to achieve an excellent micromechanical surface topography for bonding. On the other hand, $\mathrm{ZrO}$ cannot be etched with $\mathrm{HF}$ at room temperature at all. Sandblasting with CoJet works well on glass-based ceramics as well. Since the orthodontists do not know which ceramic has been used, with the method used they are on the safe side. It would be the protocol of choice in the clinical routine [17].

Due to increased esthetics most MZ FDPs are glazed or stained, according to the study of Canigur et al. [4] "the CoJet yields higher bond strength values. The CoJet creates micro retentive sites by increasing surface area and roughness" [18-20] "silica coated particles not only roughen the surface, they also have a chemical effect: because of blasting pressure, the embedded silica and alumina particles can then chemically react with the silane coupling agent" (Fig. 6) [21]."The improved chemical bonding with silane coupling agents in this approach is advocated to be the key factor for a higher resin bond strength."

Since the orthodontist does not know the details of the fabrication process of the crown where a bracket should be bonded to, it is better to consider the $\mathrm{ZrO}$ surfaces were all glazed. With the gritblasting the glaze may be partially or totally removed but using CoJet. A silica layer is deposited regardless of the composition of the underlying surface, thus allowing the use of Silane as a primer.

Spontaneous debonding of brackets is one of the most common clinical problems in fixed orthodontic therapy. There are two major interfaces that can be subjected to deboning: the enamel or restorative material/adhesive interface and the adhesive/bracket interface [22]. In this study, we tested the restorative material ( $\mathrm{ZrO}) /$ adhesive interface and it was decided not to use brackets for the following reasons: The shear bond strength between orthodontic cement and the ceramic surface was the only topic of interest. If we had used brackets we would have had to deal with the bracket-cement interface as well, which was investigated in the past abundantly [23-25]. Furthermore, it was necessary to eliminate possible confounding factors such as geometry, mesh design of the bracket base, or bracket material, all of 
which may influence the test results [23-25]. Therefore, we opted for a shear bond test which is the closest to the clinical reality. We assume that the main reason for bracket failure is shear. The shear bond strength test was performed with an orthodontic resin composite cylinder in order to eliminate tilting moments as much as possible. However, we understand elastic and plastic deformation of the cylinder may have some negative effects on the shear bond strength measured. We are well aware that in orthodontic treatment brackets transmit forces to the teeth in all directions, however unexpected debondings usually occur under shear. The brackets used in this study were used to apply shear forces to the bonded cylinders and were attached to the resin-embedding material (Fig. 3).

Thermocycling is a standard procedure for accelerated ageing in bond strength tests in vitro. In this study, all the specimens of the TC group were thermocycled in a chewing simulator device for 5000 cycles between $5^{\circ} \mathrm{C}$ and $55^{\circ} \mathrm{C}$ with a dwell time of 30 seconds with the mechanical load component of the machine turned off. At the same time, all the specimens of the non$\mathrm{TC}$ group were stored in distilled water at $37 \pm 1^{\circ} \mathrm{C}$. Extensive water storage and thermal cycling seem to be important parameters to simulate intraoral conditions and to stress bonding interfaces. Literature data show that thermocycling had a much higher impact on the durability of the resin bond strength to zirconia than did water storage at a constant temperature alone [26] Loading the samples represented the clinical reality. In clinical orthodontic practice, bonding of brackets and placement of the arch wires can be done in the same visit, particularly after rebonding of debonded brackets. Hence, force could be applied to the bracket within the first hour after bonding. This force could affect polymerization of the orthodontic adhesive and subsequently its bond strength.

The force magnitude used for orthodontic tooth movements varies depending on the type of movement [16]. In this study, $70 \pm 15 \mathrm{~g}(0.69 \pm 0.14 \mathrm{~N})$ was applied. This force is considered the optimal orthodontic force. In the clinical situation the average force transmitted to a bracket during mastication was reported to be 40 to $120 \mathrm{~N}$, the surface area of the bracket is approximately $11.9 \mathrm{~mm}^{2}$ and therefore it should be able to resist stress values between 6 and $8 \mathrm{MPa}$ [16], during fixed orthodontic treatment for clinical success [27]. The mean bond strength values of brackets bonded to natural teeth are significantly lower than those obtained for surfaces other than enamel, especially when a chemical promoter such as silane is used during bonding [28]. These results may imply that universal primer application alone, prior to bonding, would already enhance the bond strength of the orthodontic resin composite tested. However, it is known that in vitro bond strength values are often higher than in clinical situations, and biodegradation of resin composites in the oral environment over time may even decrease these values [29,32]. In addition, aging procedures have a detrimental effect on the bond strength values of resin composites when compared to non-aging test conditions. [22,30,31].

As reported previously, long-term (two-year) water storage [25] or 6000 thermocyles [20] decreased the bond strength of bis-GMA resin composites, regardless of air abrasion or silica coating and silanization. Hence, because no long-term aging was performed in this study, the results should be carefully and critically evaluated, considering that bonding in orthodontics is semi-permanent. However, at least 24-month water storage should be preferred for orthodontic bond strength testing [32], since it is usually the average period for complete orthodontic treatment with fixed appliances, and significant decreases may be expected under such prolonged aging conditions compared to shorter durations of only a few days to several months $[30,33]$. The bond strength is affected by aging only when a mechanical pre-treatment is not applied prior to an MDP-containing primer [34]. Wegner and Kern [25] also showed that the bond strength of an MDPcontaining resin composite did not change significantly after aging [25]. For this reason, the use of universal primers containing methacrylate phosphoric acids and silane should be preferred after air-abrasion protocols. The results (Fig. 5) were not as anticipated. All samples of the present study were stored in water for the same time ( 2 weeks); the only difference is that some groups were subjected to additional stress (Load or TC) of the interface before being subjected to shear stress to failure. One could assume that additional stress would weaken the interface. This only happened for TC, which confirms the trend in other studies. However direct comparisons are difficult or problematic, because of the different methods used in different studies. The Kiel group has extensively looked into the bond strength of composites to ceramics, especially zirconium oxide ceramic. However they use tensile strength as a testing method and very long water storage (up to 2 years) and high numbers of TC $(37,500)$ [35-38]. As a general trend they found for most adhesive techniques that water storage with or without TC has a negative effect on bonded interfaces.

There are a few studies that use shear or microshear bond strength. When looking at the bond strength of surfaces that have been silicatized (Rocatec, CoJet or similar procedures) water storage and TC also decreased the shear bond strength $[20,39]$. On the other hand, Lüthy et al. [40] found for some bonding procedures no significant differences between TC and water storage and water storage alone).

Since the load applied corresponded to the load that is usually used in the clinic, one can expect that it has little effect on the bond strength, which confirms the clinical observations (few debondings of brackets). This explains that the control and load group showed the same shear bond strength. Since there are no other publications that have subjected samples to orthodontic load, it is not possible to compare the results of the present study with others.

It was surprising to see that the group with orthodontic load in combination with TC showed the best results, which is difficult to explain. It seems that there is a synergetic effect of load and TC. It is known that, due to polymerization shrinkage, stress will be build up at the interface. This stress can be slightly increased in one direction by the orthodontic load. Under TC cyclic dimensional changes are induced, which may damage the interface by creating additional stress 
and thus crack induction points. One may hypothesize that under slight load the internal stress relaxation that happens within the material is enhanced and thus stress induction points may be reduced.

In a clinical situation the crown material is not known to the orthodontist. The procedure used will work with any ceramic. Therefore, the proposed protocol is a safe approach.

\section{Conclusion}

Based on the results of this in vitro study obtained with Cojet, Monobond Plus and Heliosit Orthodontic and considering the limitations of in vitro results one can conclude that

- $\quad$ Under OL and TC, the highest bond strength was observed.

- $\quad$ Load or TC alone yielded similar or lower shear bond strengths.

- $\quad$ Sandblasting with CoJet and using Monobond Plus as primer is a good protocol for bonding to ZrO crowns in orthodontic therapy.

Therefore, it is recommended for future in vitro tests of adhesives for orthodontic purposes to test under OL and TC.

\section{Author Contributions}

HSH: Performed experiment, wrote manuscript. NA: Performed experiment, proofread manuscript. CS: Data analysis, proofread manuscript. CD: Consulting of orthodontic aspects of experiment, proofreading manuscript. JFR: Idea, experimental design, proofread manuscript.

\section{Acknowledgments}

The authors declare no conflict of interest related to this study. There are no conflicts of interest and no financial interests to be disclosed.

\section{References}

1. Studart AR, Filser F, Kocher P, Lüthy H, Gauckler $\sqcup$. Cyclic fatigue in water of veneer - framework composites for all-ceramic dental bridges. Dent Mater. 2007;23(2):177-185. doi: 10.1016/j. dental.2006.01.011.

[Full text links] [PubMed] Google Scholar(139) Scopus(73)

2. Al-Amleh B, Lyons K, Swain M. Clinical trials in zirconia. A systematic review. J Oral Rehabil. 2010;37(8):641-652. doi: 10.1111/j.1365-2842.2010.02094.x.

10.1111/j.1365-2842.2010.02094.x.
[Full text links] [PubMed] Google Scholar(378) Scopus(227)

3. Vult Von Steyern P, Carlson P, Nilner K. All-ceramic fixed partia dentures designed according to the DC-Zirkon technique. A 2-year clinical study. J Oral Rehabil. 2005;32(3):180-187. doi: 10.1111/j.1365-2842.2004.01437.x. [Full text links] [PubMed] Google Scholar(407)

4. Bavbek NC, Roulet JF, Özcan M. Evaluation of microshear bond strength of orthodontic resin cement to monolithic zirconium oxide as a function of surface conditioning method. J Adhes Dent. 2014;16(5):473-480. doi: 10.3290/j.jad.a32812. [Full text links] [PubMed] Google Scholar(9) Scopus(3)

5. Atsu SS, Kilicarslan MA, Kucukesmen HC, Aka PS. Effect of zirconium-oxide ceramic surface treatments on the bond strength to adhesive resin. J Prosthet Dent. 2006;95(6):430-436. doi: 10.1016/j.prosdent.2006.03.016.

[Full text links] [PubMed] Google Scholar(414) Scopus(191)

6. Grewal Bach GK, Torrealba Y, Lagravère MO. Orthodontic bonding to porcelain: a systematic review. Angle Orthod. 2014;84(3):555-560. doi: 10.2319/083013-636.1. [Full text links] [PubMed] Google Scholar(21) Scopus(10)

7. Studart AR, Filser F, Kocher P, Gauckler LJ. In vitro lifetime of dental ceramics under cyclic loading in water. Biomaterials.
2007;28(17):2695-2705. doi:10.1016/j.biomaterials.2006.12.033. [Full text links] [PubMed] Google Scholar(188) Scopus(105)

8. Stober T, Bermejo JL, Rammelsberg P, Schmitter M. Enamel wear caused by monolithic zirconia crowns after 6 months of clinical use. J Oral Rehabil. 2014;41(4):314-322. doi: 10.1111/joor.12139. [Full text links] [PubMed] Google Scholar(75) Scopus(49)

9. Zhang Y, Kim J.W. Graded structures for damage resistant and aesthetic all-ceramic restorations. Dent Mater. 2009;25(6):781790. doi: 10.1016/j.dental.2009.01.002.

[Full text links] [Free PMC Article] [PubMed] Google Scholar(99) Scopus(65)

10. Gillis I, Redlich M. The effect of different porcelain conditioning techniques on shear bond strength of stainless steel brackets. Am J Orthod Dentofacial Orthop.1998;114(4):387-392. [Full text links] [PubMed] Google Scholar(126) Scopus(61)

11. Saraç YŞ, KülünkT, Elekdağ-Türk S, et al. Effects of surfaceconditioning methods on shear bond strength of brackets bonded to different all-ceramic materials. Eur J Orthod. 2011;33(6):667-672. doi: 10.1093/ejo/cjq132.

[Full text links] [PubMed] Google Scholar(28) Scopus(18)

12. Kocadereli I, Canay S, Akca K. Tensile bond strength of ceramic orthodontic brackets bonded to porcelain surfaces. Am J Orthod Dentofacial Orthop. 2001;119(6):617-620. [Full text links] [PubMed] Google Scholar(124) Scopus(54)

13. Blatz BM, Sadan A Martin J et al. In vitro evaluation of shear bond strengths of resin to densely-sintered high-purity zirconium-oxide ceramic after long-term storage and thermal cycling. J Prosthet Dent. 2004;91(4):356-362.

[Full text links] [PubMed] Google Scholar(395) Scopus(194)

14. Klocke A, Kahl-Nieke B. Influence of force location in orthodontic shear bond strength testing. Dent Mater. 2005;21(5):391-396. doi: 10.1016/j.dental.2004.07.004.

[Full text links] [PubMed] Google Scholar(77) Scopus(35)

15. Klocke A, Kahl-Nieke B. Effect of debonding force direction on orthodontic shear bond strength. Am J Orthod Dentofacial Orthop. 2006;129(2):261-265. doi: 10.1016/j.ajodo.2004.07.048. [Full text links] [PubMed] Google Scholar(61) Scopus(20)

16. Abdelnaby YL, Al-Wakeel ES. Effect of early orthodontic force on shear bond strength of orthodontic brackets bonded with different adhesive systems. Am J Orthod Dentofacial Orthop. 2010;138(2):208-214. doi: 10.1016/j.ajodo.2008.09.034. [Full text links] [PubMed] Google Scholar(33) Scopus(6)

17. Karimipour-Saryazdi M. Influence of surface treatment of Y-TZP and luting cements on retention of Y-TZP crown. Master of Science thesis. Birmingham (AL): University of Birmingham; 2012.

Google Scholar(0)

18. Aboushelib MN, Matinlinna JP, Salameh Z et al. Innovations in bonding to zirconia-based materials : Part I. Dent Mater. 2008;24(9):1268-1272. doi: 10.1016/j.dental.2008.02.010. [Full text links] [PubMed] Google Scholar(207) Scopus(118)

19. Aboushelib MN, Mirmohamadi H, Matinlinna JP et al. Innovations in bonding to zirconia-based materials. Part II Focusing on chemical interactions. Dent Mater. 2009;25(8):989993. doi: 10.1016/j.dental.2009.02.011.

[Full text links] [PubMed] Google Scholar(127) Scopus(78)

20. Özcan M, Vallittu PK. Effect of surface conditioning methods on the bond strength of luting cement to ceramics. Dent Mater. 2003;19(8):725-731.

[Full text links] [PubMed] Google Scholar(626) Scopus(355)

21. Guggenberger R. [Rocatec system--adhesion by tribochemical coating]. Dtsch Zahnarztl Z. 1989:44(11):874-876. [Article in German]

Google Scholar(87)

22. Scribante A, Contreras-Bulnes R, Montasser MA, Vallittu PK. Orthodontics : bracket materials, adhesives systems, and their bond strength. Biomed Res Int. 2016;2016:1329814. doi: $10.1155 / 2016 / 1329814$.

[Full text links] [Free PMC Article] [PubMed] Google Scholar(9)

23. Abdelnaby YL. Effects of cyclic loading on the bond strength of metal orthodontic brackets bonded to a porcelain surface using different conditioning protocols. Angle Orthod. 2011;81(6):1064 1069. doi: 10.2319/030211-151.1.

[Full text links] [PubMed] Google Scholar(10) Scopus(10)

24. Hudson AP, Grobler SR, Harris AMP. Orthodontic molar brackets : the effect of three different base designs on shear bond strength. Int J Biomed Sci. 2011;7(1):27-34. [Full text links] [PubMed] Google Scholar(8) Scopus(5)

25. Kukiattrakoon B, Samruajbenjakul B. Shear bond strength of ceramic brackets with various base designs bonded to aluminous and fl uorapatite ceramics. Eur J Orthod. 2010;32(1):87-93. doi: 10.1093/ejo/cjp055. [Full text links] [PubMed] Google Scholar(20) Scopus(11)

26. Heintze SD, Rousson V. Survival of zirconia- and metalsupported fixed dental prostheses: a systematic review. Int Prosthodont. 2010;23(6):493-502. [PubMed] Google Scholar(318) Scopus(211)

27. Powers JM, Kim H, Turner DS. Orthodontic adhesives and bond strength testing. Semin Orthod. 1997 Sep;3(3):147-56. [PubMed] Google Scholar(90) Scopus(42) 
28. Cochran D, O'Keefe KL, Turner DT et al. Bond strength of orthodontic composite cement to treated porcelain. Am J Orthod Dentofacial Orthop. 1997;111(3):297-300. [Full text links] [PubMed] Google Scholar(87) Scopus(40)

29. Murray SD, Edin MR, Hobson RS. Comparison of in vivo and in vitro shear bond strength. Am J Orthod Dentofacial Orthop. 2003;123(1):2-9. doi: $10.1067 / \bmod .2003 .49$.

[Full text links] [PubMed] Google Scholar(87) Scopus(43)

30. Cheung GC, Botelho MG, Matinlinna JP. Effect of surface treatments of zirconia ceramics on the bond strength to resin cement. J Adhes Dent. 2014;16(1):49-56. doi: 10.3290/j.jad.a30753. [Full text links] [PubMed] Google Scholar(16) Scopus(11)

31. Özcan M, Cura C, Brendeke J. Effect of aging conditions on the repair bond strength lication of a microhybrid and a nanohybrid resin composite. J Adhes Dent. 2010;12(6):451-459. doi: 10.3290/j.jad.a17857

[Full text links] [PubMed] Google Scholar(35)

32. Oesterle L, Shellhart WC. Effect of aging on the shear bond strength of orthodontic brackets. Am J Orthod Dentofacial Orthop. 2008;133(5):716-720. doi: 10.1016/j.ajodo.2006.04.042 [Full text links] [PubMed] Google Scholar(32) Scopus(15)

33. Finnema KJ, Özcan M, Post WJ et al. In-vitro orthodontic bond strength testing: a systematic review and meta-analysis. Am J Orthod Dentofacial Orthop. 2010;137(5):615-622.e3. doi: 10.1016/j.ajodo.2009.12.021.

[Full text links] [PubMed] Google Scholar(69) Scopus(29)

34. Yoshida K, Tsuo Y, Atsuta M. Bonding of dual-cured resin cement to zirconia ceramic using phosphate acid ester monomer and zirconate coupler. J Biomed Mater Res B Appl Biomater. 2006;77(1):28-33. doi: 10.1002/jbm.b.30424.

[Full text links] [PubMed] Google Scholar(235) Scopus(134)
35. Kern $M$, Wegner SM. Bonding to zirconia ceramic: adhesion methods and their durability. Dent Mater 1998:14(1):64-71. [Full text links] [PubMed] Google Scholar(821) Scopus(460)

36. Wegner SM, Kern M. Long term resin bond strength to Zirconia ceramic. J Adhes Dent. 2000;2(2):139-147.

[PubMed] Google Scholar(413) Scopus(238)

37. Attia A, Lehmann F, Kern M. Influence of surface conditioning and cleaning methods on resion bonding to zirconia ceramic. Dent Mater. 2011;27(3):207-213. doi: 10.1016/j. dental.2010.10.004.

[Full text links] [PubMed] Google Scholar(104) Scopus(68)

38. Elsayed A, Younes F, Kern M. Tensile ond strength of So-called universal primers and universal multimode adhesives to zirconia and lithium disilicate ceramics. J Adhes Dent. 2017:19(3):221228. doi: 10.3290/j.jad.a38436

Google Scholar(5) Scopus(2)

39. Da Sliva EM, Miragaya L, Sabrosa CE et al. Stability of the bond between two resin cements and an yttria-stabilized zirconia ceramic after six months of aging in water. J Prosthet Dent. 2014;112(3):568-575. doi: 10.1016/j.prosdent.2013.12.003. [Full text links] [PubMed] Google Scholar(35) Scopus(25)

40. Lüthy $\mathrm{H}$, Loeffel $\mathrm{O}$, Hammerle $\mathrm{CH}$. Effect of thermocycling on bond strength of luting cements to zirconia ceramic. Dent Mater. 2006;22(2):195-200. doi: 10.1016/j.dental.2005.04.016 [Full text links] [PubMed] Google Scholar(336) Scopus(179)

\section{Hind S. HUSSEIN}

BDS, Courtesy Clinical Assistant Professor Department of Restorative Dental Sciences

College of Dentistry, University of Florida FL 32608 Gainesville, USA

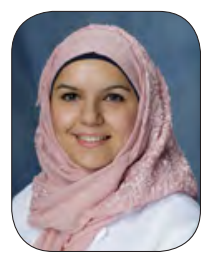

Dr. Hind S Hussein graduated in 2011 (BDS) from the Almustansiryah University, Baghdad, Iraq. Between 2012 and 2014 she worked in a public hospital and a private clinic in Baghdad. In 2013 she was certified in Orthodontics. In 2014 she completed her Advanced Post Graduate Multispecialty Residency qualifying as a General Dentist. In 2014, Dr. Hussein joined the University of Florida (UF) as Visiting scientist (Restorative Dental Science and Orthodontics). In 2017 she was certified as UF Graduate Assistant Teacher with a technology program. Since 2017 up to the present, she has been an UF, a Courtesy Clinical Assistant Professor, with the Operative Dentistry and Prosthodontics, of the Department of Restorative Dental Sciences. Since 2014 she has been successfully involved in many research projects in dental materials. In 2017, Dr. Hussein submitted two US patents. Dr. Hussein is a member of several professional organizations including the Iraqi Dental Association, AADR and IADR.

Ouestions

\section{Hydrofluoric acid is used to increase the surface roughnes for bonding for the following ceramics?}

口a. Zirconium Oxide;

b. Lithium disilicate ceramic only;

口c. All glass based ceramics;

d. Leucite reinforced ceramic only.

\section{The treatment with Co-jet sand provides the following?}

$\square$ a. Roughens the surface;

b. Roughens the surface and deposits a layer of silica;

Dc. Cleans the surface;

ad. Polishes the surface.

\section{Which surfaces can be primed with silane?}

$\square$ a. Base metals;

b. Gold alloys;

ac. Oxide ceramics e.g. Zirconium oxide;

d. Surfaces containing silica, e.g. glass based ceramics.

\section{Which is the ideal clinical protocol to bond to an all ceramic crown made out of an unknown ceramic?}

$\square$ a. Roughen surface with Co-jet, prime with Silane and use resin based orthodontic cement;

b. Etch with hydrofluoric acid, prime with silane and use resin based orthodontic cement;

ac. Etch with phosphoric acid, use universal primer and use resin based orthodontic cement;

$\square \mathrm{d}$. Roughen surface with Aluminumoxide sand, use silane and cement bracket with glass ionomer cement. 


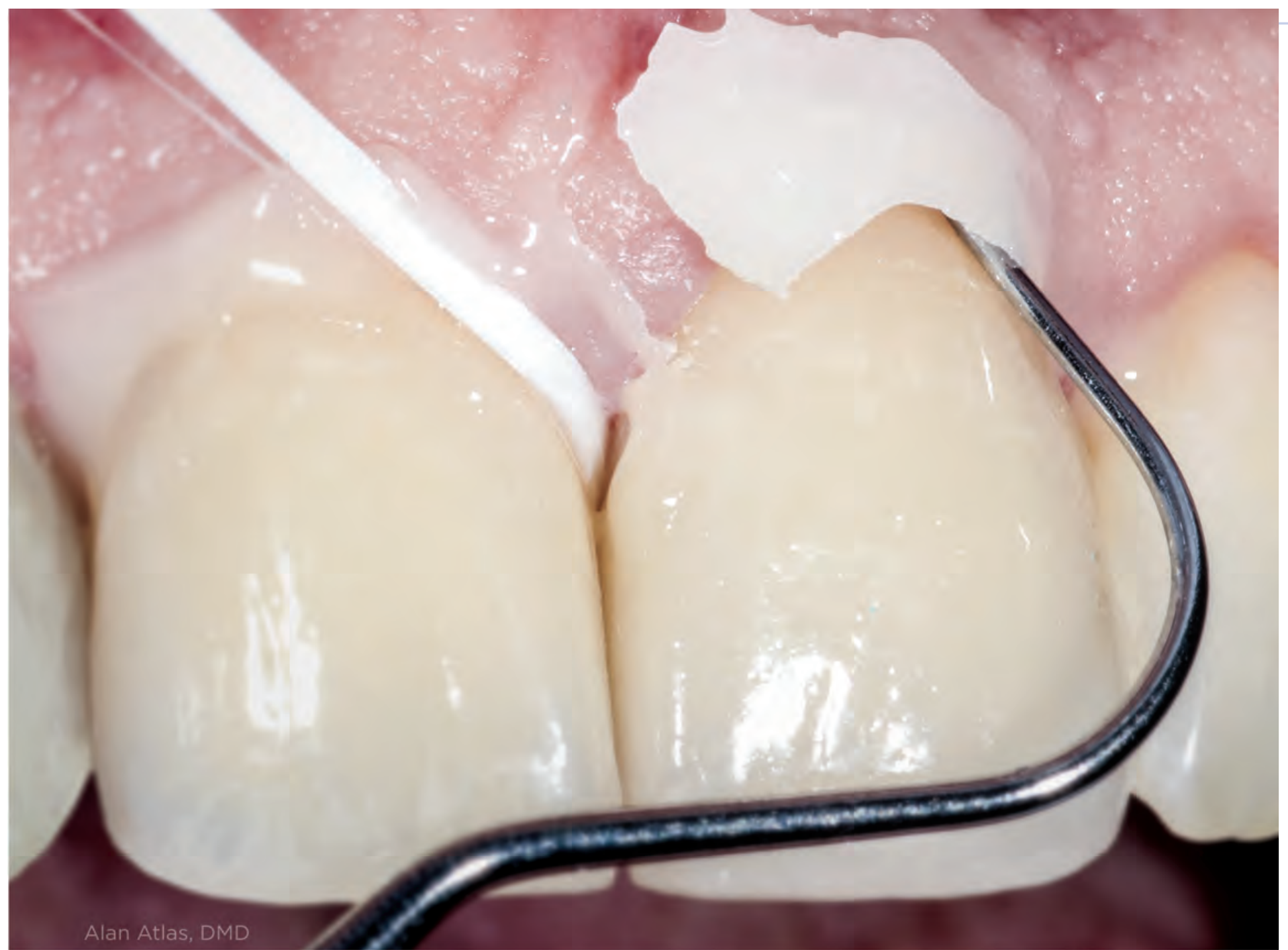

Calibra ${ }^{\circledR}$ Ceram

Adhesive Resin Cement

\section{Mighty. Easy to Cleanup.}
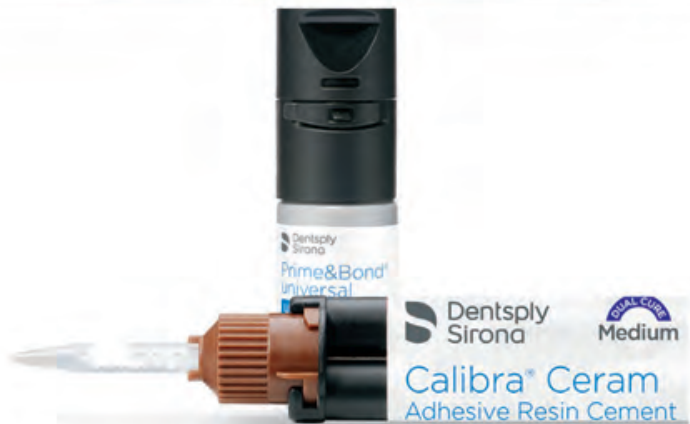

Calibra Ceram resin cement offers a wide tack cure window of up to 10 seconds and an extended 45-second gel phase*, giving you the time you need for a thorough and effective cleanup. It's ideal for non-retentive preps when used with Prime\&Bond universal ${ }^{\mathrm{TM}}$ Adhesive and for all-ceramic restorations that require extra strength.

Grab a sample at dentsplysirona.com and see for yourself why Calibra Ceram Cement is a mighty good choice for restorations that need more oomph.

-10-second tack cure window equals five-second wave cure per surface. For excess cement cleanup, monowave output LED lights with a single peak output around $470 \mathrm{~nm}$ are recommended. ML070014A (7-26-17)

Office \& Showroom

98A Vulturilor Street, $3^{\text {rd }}$ District

RO-030857 Bucharest, Romania

Tel: +40 774074094

e-mail: office.romania@dentsplysirona.com

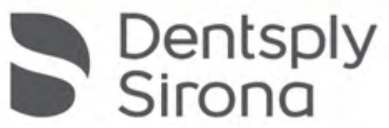




\section{INTRAORALSCANSFOR CAD/CAM APPLICATION Judit Borbély $^{1 \mathrm{a}^{*}}$, Alexandra Czigola $^{\text {1b }}$, Viktoria Vitai ${ }^{1 \mathrm{~b}}$, Ivett Róth ${ }^{\mathbf{1 b}}$, Péter Hermannc}

'Department of Prosthodontics, Faculty of Dentistry, Semmelweis University, H-1088 Budapest, Hungary

${ }^{a} \mathrm{DMD}$, PhD, Associate Professor

bDMD, Resident of Department of Prosthodontics

'DMD, MSc, PhD, Professor and Head of Department of Prosthodontics, Vice-Rector for Education Affairs of Semmelweis Univeristy, Budapest, Hungary

Introduction: There is no doubt the world of dentistry is rapidly changing. Digital innovations are replacing our traditional techniques. Dentists need to keep up with the speed of today's ever changing digital world.

The aim of the paper is to educate about the concept of digital dentistry, its advantages and limitations, and to provide an overview of digital impression taking procedures and the digital workflow for CAD/CAM application.

Materials and methods: The Department of Prosthodontics, Faculty of Dentistry, Semmelweis University (SU) published a series of articles in Hungarian dental paper as part of the continuing education program to educate Hungarian dentists at the postgraduate level. Digital technologies and their novel materials are also introduced into the SU undergraduate dental curricula. A Bachelor of Science (BSc) digital dental designer training program is also aimed at the Faculty of Dentistry SU in cooperation with the Neumann University of Technology and Economics to modernizate the classic profession of dental technician. This paper gives a summary of the basic knowledge published in digital dentistry series.

Results: The CAD/CAM technology offers a quick and comfortable experience to the patients and an efficient workflow to the dentist and dental technicians. The learning curve is steep to adopt that new technology both in the dental office and on the laboratory side. Educated dental students and digital designers have the potential to keep pace with the digital era change.

Keywords: CAD/CAM, scanner, intraoral, workflow, dental impression technics.

OPEN ACCESS This is an
Open Access article under the CC
BY-NC 4.0 license.
Peer-Reviewed Article
Citation: Borbély J, Czigola A, Vitai V,
Róth I, Hermann P. Intraoral scans for
CAD/CAM application. Stoma Edu J.
2018;5(2):110-117.
Academic Editor: Gerwin V.
Arnetzl, DMD, Arnetzl Dental Compe-
tence, A-8041 Graz, Austria
Received: May 15, 2018
Revised: May 24, 2018
Acccepted: June 06, 2018
Published: June 07, 2018
*Corresponding author: Assoc.
Professor Judit Borbély, DMD, PhD,
Department of Prosthodontics, Faculty
of Dentistry, Semmelweis University
Budapest, Szentkiályi u. 47, H-1088
Budapest, Hungary Tel/Fax: (36-1)
4591500 / 59338, e-mail: borbely.
judit@ @dent.semmelweis-univ.hu
Copyright: @ 2018 the Editorial
Council for the Stomatology Edu
Journal.

\section{Introduction}

The widespread use of digital technology is to transform our everyday life: computers and digital devices offer an easier, faster and more economical alternative to conventional methods. The digital revolution also has an impact on dental procedures. It is a fact that dentistry changes and undergoes dramatic developments. In order to meet the patients' requirements, it is important to expand our dental knowledge to digital technologies.

Present day dental students grow up in a world of digital innovation and technology, so the need to include digital technology in their curriculum is evident for them [1]. However the dental curriculum has not really changed in 50 years. It has not been revised. Much has been added to what dentists must know, considering digital technology, there are all those new technologies, new CAD/CAM materials etc. but the curriculum has not been changed [2]. Most practicing dentists received their professional training before the advent of the digital dental technology. Once they become interested in the new technologies and in developing new skills they demand continuing education courses. There is a severe need to include digital dentistry in the undergraduate and postgraduate education programs. If digital technologies and their novel materials are not introduced into the dental curricula dentists and technicians will not fully understand the range of new technologies available to them and will not be able to make informed decisions regarding the most appropriate techniques, systems or materials [1] Chatham et al. surveyed the undergraduate curricula of the UK dental schools in 2014 to determine the degree to which digital dental technologies have been introduced. Sixteen schools were surveyed and 11 replied. $55 \%$ of those schools did teach digital dental technology, $50 \%$ gave lectures or demonstrations while the other $50 \%$ allowed practical involvement by the student. Seventy-three percent of the schools that replied had dental laboratories using some, but not all the digital dental technology techniques [1].

\subsection{Aim}

The aim of this paper is basic digital education. To discuss the concept of digital dentistry, its advantages and limitations, and to provide an overview of digital impression-taking procedures, to clarify the basic steps of the digital workflow, to introduce the direct method of intraoral scanning to construct a virtual cast for CAD/ CAM application. The purpose of the paper also includes clarifying the difference between chairside and labside systems, discuss the features of intraoral impressiontaking such as accuracy, the time factor and the patient's subjective comfort, to present comparative data on the precision of digital impressions made by intraoral scanners to laboratory scanning of conventional casts and to compare the traditional impression-taking method to the digital one and provide a short summary on the advantages and difficulties of the scanning procedure. 


\section{Material and methods}

The Department of Prosthodontics, Faculty of Dentistry, Semmelweis University has been working with digital impression-taking systems since 2011. Digital technologies and their novel materials have been introduced into the department's undergraduate dental curricula. A Bachelor of Science digital dental designer training program is also aimed at the Faculty of Dentistry SU in cooperation with the Neumann University of Technology and Economics to modernizate the classic profession of dental technician. A series of articles has been published in the Hungarian dental paper in 2017 as part of the continuing education program to educate Hungarian dentists about digital dentistry. This paper gives a summary of the digital dentistry series.

\section{Results}

In 2018 all four Hungarian dental schools teach digital technology, they give lectures and demostrations and $50 \%$ have also practical training. All four dental laboratories of those schools use some digital techniques (Fig. 1). Dental technology educational programs are faced with serious challenges, including rapid changes in technology, inadequate funding for educational programs, and the need to develop curricula that reflect current industry needs [3]. The high cost to purchase equipment and the investment of time and expense in staff training encourages nonuniversity educational systems and trainings.

Manufacturers and commercial dental laboratories offer a selection of continuing education courses for international dentists. Some courses are accredited by universities and the participants are awarded certificates and European Credit Transfer System (ECTS) credits [4]. Online knowledge centers and webinars provided by manufacturers offer promising new opportunity for self-education [5].

Digital technology introduced new nomenclature for dental procedures: digital workflow, CAD/CAM systems, indirect CAD/CAM impression technique, direct CAD/ CAM impression technique, digital impressions, virtual casts, intraoral scanners, close or open systems, charside or labside systems. These elements are drafted in italics in the following text.

\subsection{Digital workflow}

\subsubsection{Indirect $C A D / C A M$ method}

The digital workflow starts with a device which is suitable for mapping real forms. Indirect CAD/CAM method is built on conventional impressions. The virtual cast is created by digitizing the gypsum cast (or the conventional impression) with a laboratory scanner [6] (Fig. 2). The virtual cast is a realistic, colorful digital model of the patient's oral cavity. This method has some distorting effects enclosed: conditions of impression-taking, material properties of alginate, silicone or gypsum (shrinkage of impression material, dilation or shrinkage of gypsum) and sectioning of casts. Furthermore, the laboratory scanner has some degree of distortion.

The laboratory scanner creates a 3-dimensional set of points based on information of the sectioned cast.

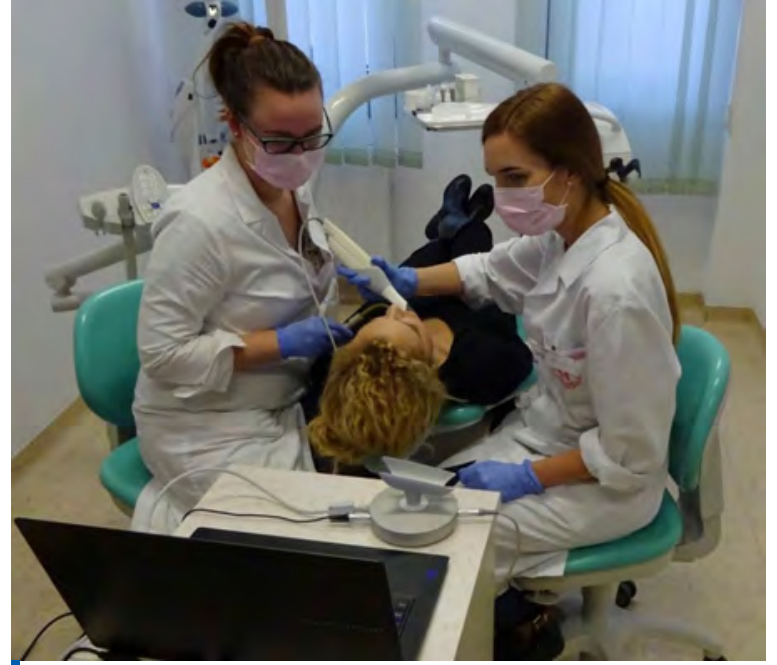

Figure 1. Dental students practice digital impression taking at the Department of Prosthodontics of Semmelweis University, Budapest.

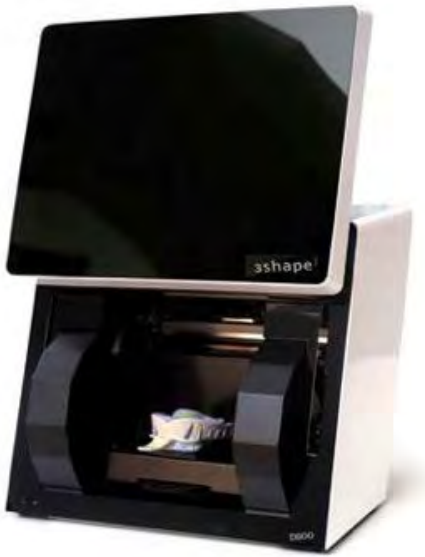

Figure 2. Laboratory scanner creates a 3-dimensional set of points by information of sectioned cast or impression.

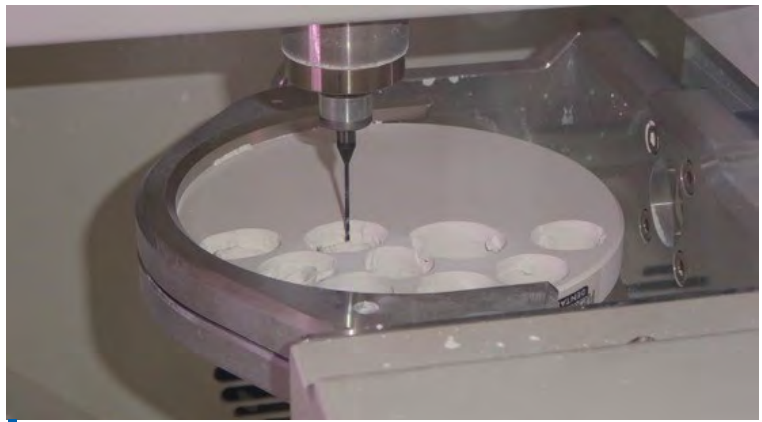

Figure 3.CAM (Computer-Aided Manufacturing) machine milled crowns from zirconia block.

The computer makes the virtual cast that serves as basis for CAD/CAM workflow. During CAD (ComputerAided Design) the dental technician designs dental restorations, most often crowns, veneers, inlays or onlays and bridges. The CAD software enables the technician to design the framework of the restorations or the anatomical, final form. Applying CAM (ComputerAided Manufacturing) the restorations are milled from solid blocks with dental milling CNC machines (Fig. 3). There are different types of materials to mill: ceramics, zirconia, PMMA, metal alloys or titanium.

\subsubsection{Direct $C A D / C A M$ method}

The Direct $C A D / C A M$ method means that the digital 
data set is created by intraoral scanning. Intraoral scanners are intraoral devices for capturing direct optical impressions [6] (Fig. 4). Intraoral scanners are based on different data capture principles: confocal laser technology, confocal microscopy, triangulation, wavefront sampling, multiscan imaging, stereophotogrammetic video, accordion fringe interferometry $[7,8]$.

It is important that the user takes digital impressions according to the manufacturer's instructions. This method can eliminate many inaccuracies derived from indirect CAD/CAM impression process. However, the traditional principles of the impression-taking procedure are still alive, soft tissue control and isolation remain basic principles. The scanning process ends with biterecord. There are intraoral scanners which can also determine the tooth-color.

The next step following the digital impression-taking procedure is to evaluate the quality of the virtual cast (Fig. 5). Inaccuracies can be eliminated by the dentist directly chairside within this step. The occlusal and axial reduction, the insertion direction can be observed on the computer screen with built in tools of software. The margin line can also be checked enlarged by the software.

Any imperfections of the virtual cast can be corrected without the need to retake the whole impression. Additional images of the areas of interest can be added to previous scan. When satisfied with the impression and resulting virtual cast, it is sent to laboratory with the digital worksheet via e-mail.

There are open and closed dental CAD/CAM systems. Closed systems'filescan beopened by the manufacturer's CAD software only. Closed systems are CEREC AC and E4D systems. Most intraoral scanners work with an open system and they are compatible with several types of CAD softwers and milling machines (for example 3Shape TRIOS, Planmeca PlanScan, CEREC Omnicam, iTero Element, Carestream CS 3500, 3M True Definition, GC Aadva, DWIO Dental Wings, KaVo Lythos, Dentium Rainbow, Zfx IntraScan, MFI Condor IOS, etc) (7).

\subsection{Direct CAD/CAM workflow}

\subsubsection{Labside system}

The labside workflow of CAD/CAM technology means The labside workflow of CAD/CAM technology means that the dental technician processes data coming from the dental office. The technician performs the preparatory work on the virtual cast, model occlusion with CAD software and design restoration on the computer screen (Fig. 6).

The technician sets the margin line and the space for the cement. After that the framework or the full-contour restoration is designed. The anatomical occlusion surface and contour of the teeth can be made individually. The software contains the color of the restoration, so the suitable block is chosen for the milling. Digital planning does not exclude model making. From the digital data a polimer model can be made by milling, 3D printing or with stereolithography (SLA) [9]. The final restoration can be checked on this model (Figs. 7, 8).

Another option of the computer-assisted production is centralised production in a milling centre. In this variation, it is possible for the local laboratory to design

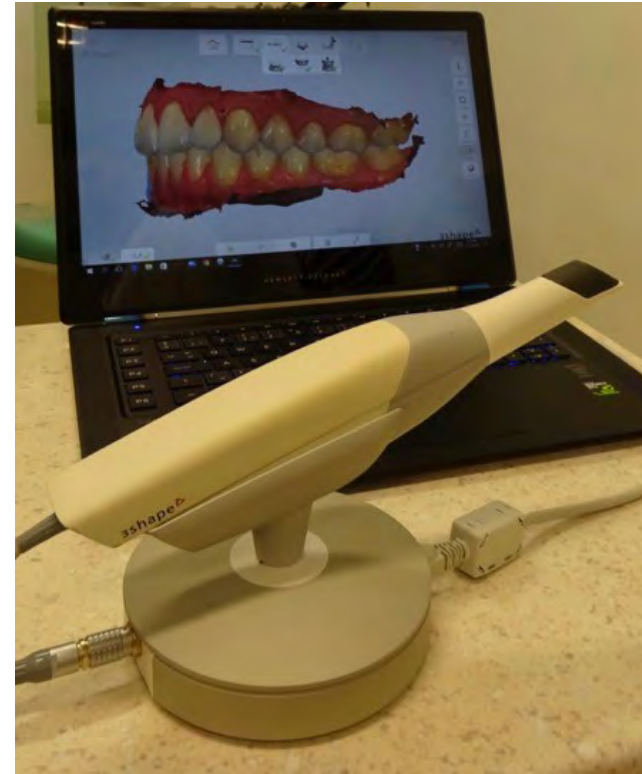

Figure 4. Trios intraoral captures optical impressions of the prepared teeth for the direct CAD/CAM method.

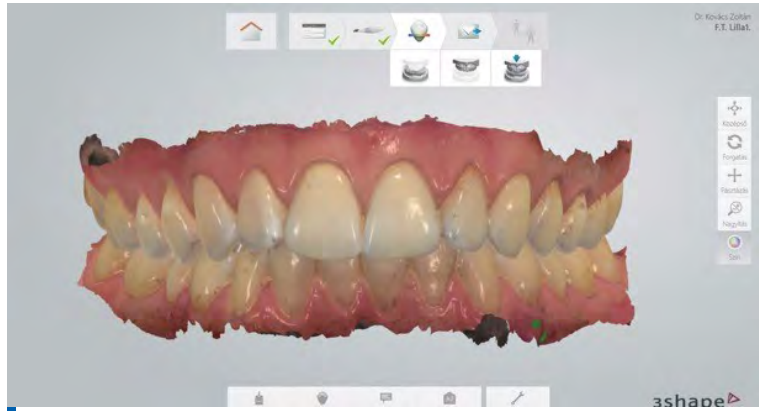

Figure 5. Full arch virtual casts in ICP position on computer screen after scanning.

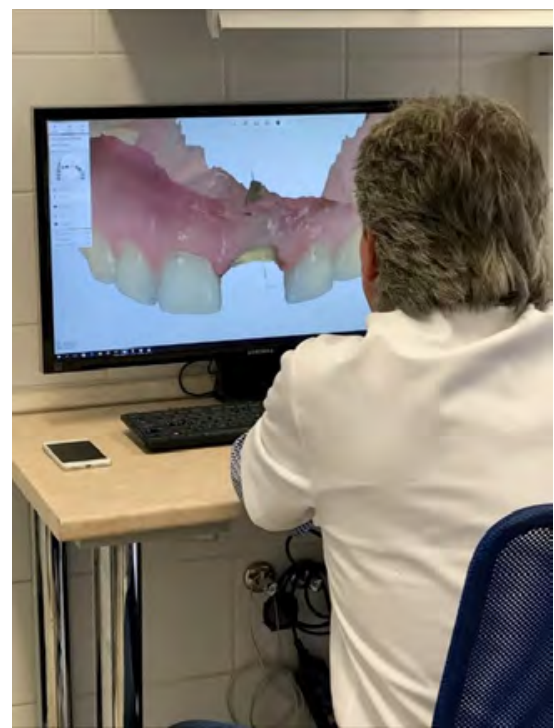

Figure 6. Dental technician designs restoration on computer screen with CAD software.

the restoration, then data sets are sent for milling to the centre. Procera is a well-known example for milling centre. It is specialised for milling technically sensitive materials like high strength ceramics and titanium (Figs. 9, 10).

\subsubsection{Chairside systems}

We must not forget that initially intraoral scanners were developed for chairside solutions (CEREC). The main 
idea was to make restorations without the need for dental laboratory. A chairside system means that every step of the workflow is in the hands of the dentist. Digital impressions are taken in the dental office with an intraoral scanner, designing the restoration is done chairside and even the milling and finishing is done in the office. Its great advantage is that it offers One Day Dentistry. Inlays, onlays, solo crowns can be made for patients within a few hours. Monoblocks restorations are milled with the CAM unit, which need small adjustments (staining, polishing, sintering) before cementation.

The main difference between those restorations milled by labside and chairside systems are the extension and the materials used. Chairside systems are made for solo restorations as mentioned before (veneers, crowns, inlays, onlays, small full contours), and temporaries. Labside milling in the dental laboratory or in the milling centres offers you more options due to the precision of 5-axis milling and high-strength materials, labside offers extended prosthetic appliances.

\section{Discussion \\ 4.1. Features of taking digital impressions - accuracy, time factor, patient's comfort \\ There are numerous factors that can easily describe the clinical use of the digital impression procedure. The investigation of some of these factors can be measured objectively, for example accuracy and scanning time. This is a well-researched area in literature. Other features of intraoral scanners can be described with subjective parameters for example patient's comfort and dentist's satisfaction.}

\subsubsection{Accuracy of digital impressions}

The fit of the final restoration depends on the quality of the impression, therefore accuracy of intraoral scanners is one of the most important features. Accuracy consists of trueness and precision. Trueness describes how close our data are to the original true value. Precision shows the relative deviation of the repeated measurements [10] (Fig. 11).

In a blind study, crowns developed using intraoral scanning technology were preferred over crowns generated using conventional impressions and criteria of marginal fit, contacts, occlusion, and time of adjustment in nearly $70 \%$ of cases [11]. It was found that digital quadrant impression methods achieve a level of precision, comparable to the conventional impression techniques (precision ranged from 18.8 to $58.5 \mu \mathrm{m}$ ). However, there are significant differences in terms of absolute values and deviation pattern [12].

The direct digitalisation with Lava C.O.S. showed statistically significantly higher accuracy compared to the conventional procedure of impression-taking and indirect digitalisation when datasets were generated and superimposed by a best fit algorithm. It could be shown that direct digitalisation accomplished the most accurate results, followed by digitized polyether impression, and indirect digitalisation [13].

According to a study in 2015 the following scanners were found acceptable in clinical practice when
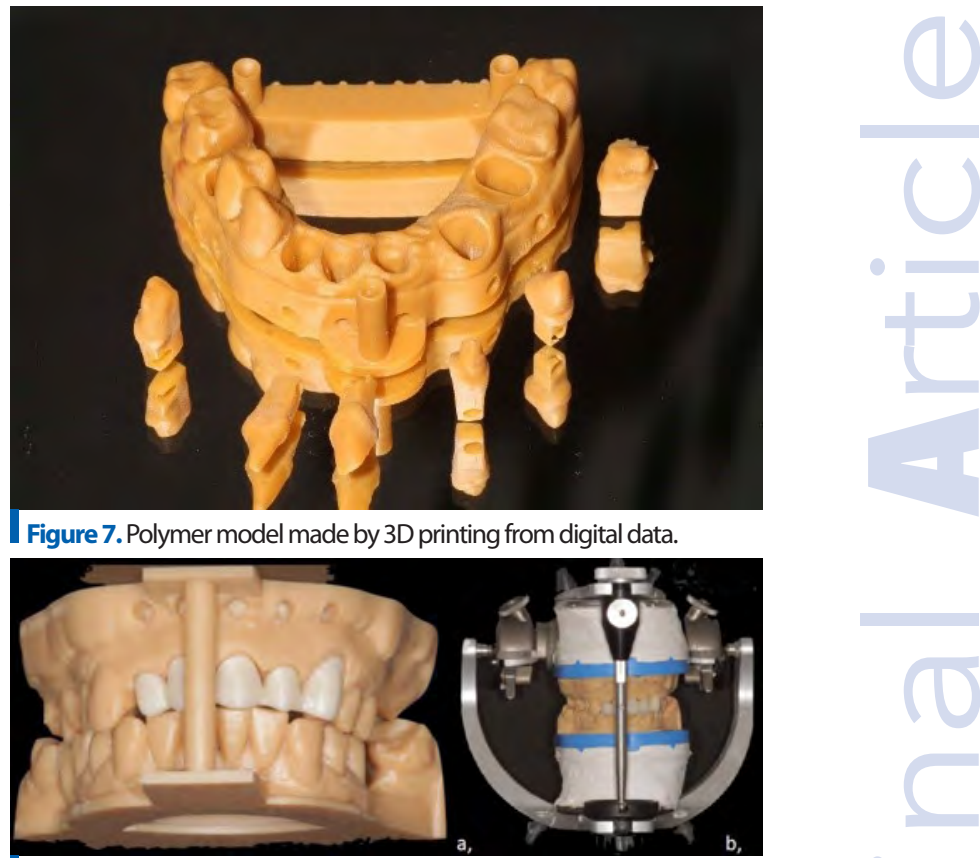

Figure 8. Polymer models are printed with pins holding the ICP position and mounted on an adjustable articulator for veneering.

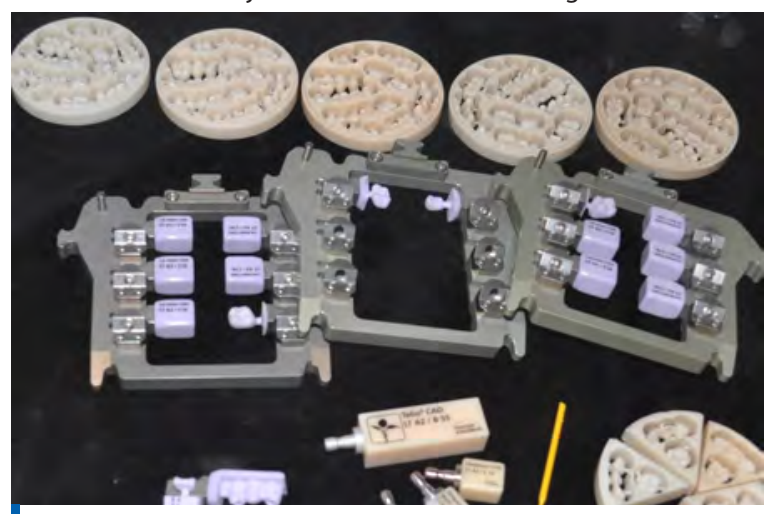

Figure 9. CAM/Computer Assisted Manufacturing: Blocks for zirconiumdioxide frameworks, lithium disilicate monolithic restorations and PMMA temporary restorations.

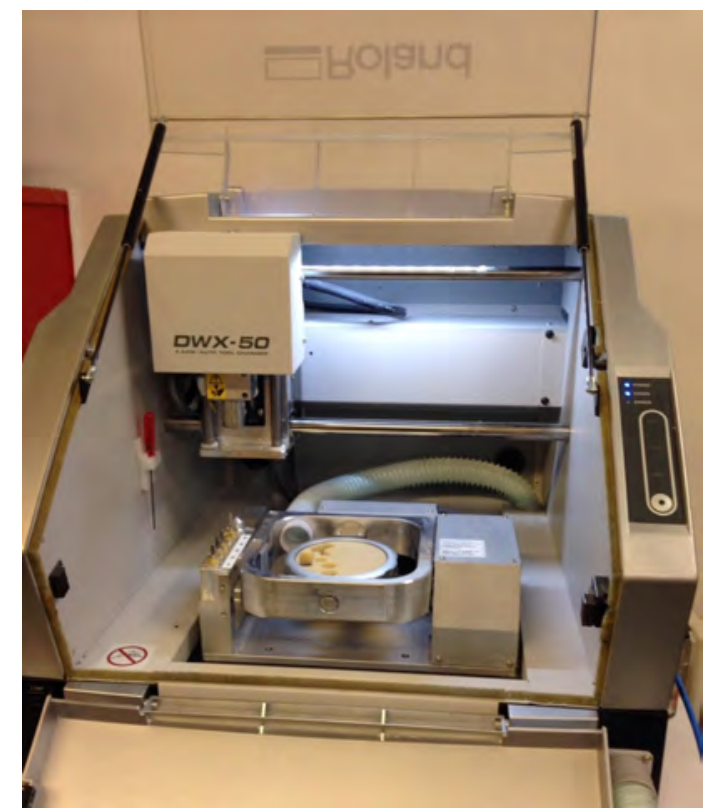

Figure 10. PMMA block manufactured in Roland DG DWX-50 milling machine. Advantage of PMMA temporary restorations fabricated by CAD/ CAM technology is that they last long. Polymer's resistancy is much better than temporary materials used for conventional chairside technique. 
CEREC, TRIOS) were made from a PMMA model for comparison [17] (Fig. 12).

\subsubsection{Time efficiency (factor) of digital impressions}

We have found numerous studies comparing the time needed for digital and conventional impressiontaking techniques. When investigating the whole treatment time an average of $260 \mathrm{~s}$ is needed for a digital impression and $620 \mathrm{~s}$ for a conventional one. Bite registration with intraoral scanner took five times less than with the conventional technique [18].

Although scanning time extends when there are abutment teeth in the arch. Scanning 1 abutment is 23 minutes, 2 abutments 22 minutes and the whole arch is 13 minutes faster than conventional impression-taking. As the number of prepared teeth increases, the time of the intraoral scanning gets closer to the conventional impression-taking time. In these studies participants had experience in taking conventional impressions [19]. In Lee and Galucci's study dental students had no previous experience on taking impressions. Intraoral scanning took half the time of the conventional technique. Consequently, the study shows that without experience intraoral scanning is still a time saving technique. It seems that digital technology reduces patients' time spent in the dental office [20].

4.1.3. Evaluation of the digital impression-taking procedure based on the dentist's and the patient's subjective comfort

In 2016 Joda et al. investigated digital and conventional implant impression procedures. They found the usability and the efficiency of intraoral scanners more favourable by students (88\%) and dentists (64\%) compared to conventional methods [21].

According the previous studies patients prefer digital impressions to conventional ones. During conventional impressions patients reported breathing difficulties and they felt vulnerable, especially when upper impressions were taken. They were afraid of repeating conventional impressions rather than repeating digital ones [22].

Overall both dentists and the patients found it less stressful when impressions were taken digitally.

\subsection{Intraoral scanning possibilities; advantages and difficulties}

In the next session we would like to introduce the features of the new technology, which can be a benefit or an initial difficulty when we use an intraoral scanner [23].

\subsubsection{Difficulties of intraoral scanning}

Learning the process of intraoral scanning is not an easy task, it is important to follow the instructions given by the manufacturers. Digital impression taking is very different from conventional impression procedure.

During scanning as the scanner-head goes above the surface of the tooth the software adds new data to the images that have already been taken. The inappropriate use leads to insufficient or inaccurate virtual model. For implant scanning scan bodies are used, which are supported by the manufacturers (Fig. 13).

These scan bodies should be compatible with the

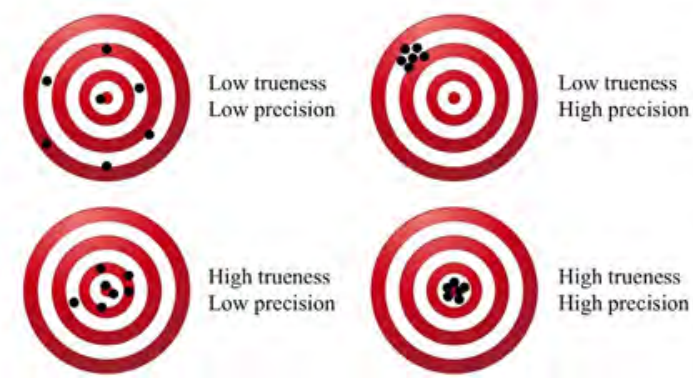

Figure 11. Fit of the final restoration depends on the quality of the impression. Accuracy consists of trueness and precision. Trueness shows how close is our data to the original true value. Precision shows the relative deviation of repeated measurements.

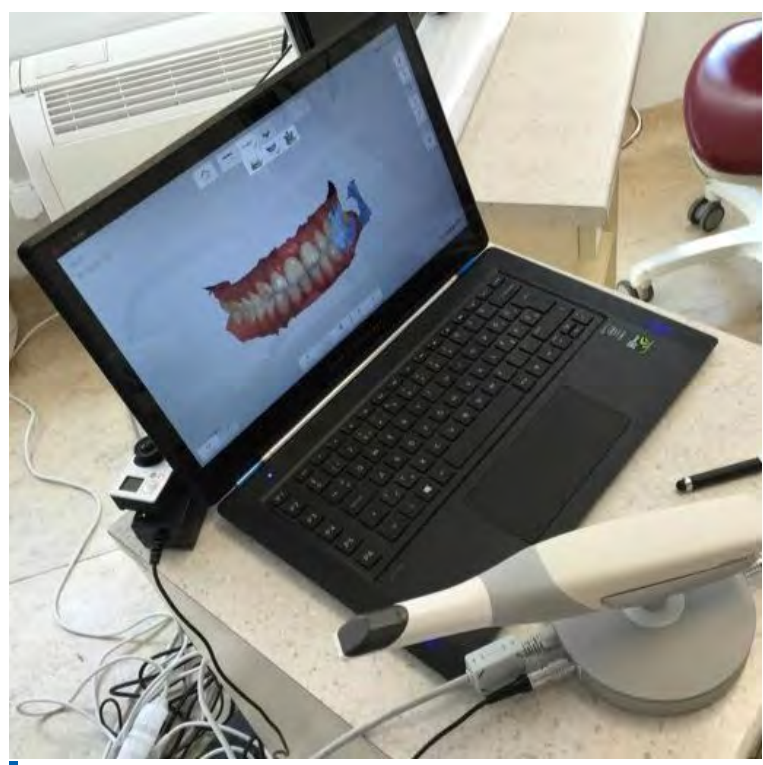

Figure 12. Less time is needed for a full arch intraoral scan compared to the conventional impression taking procedure.

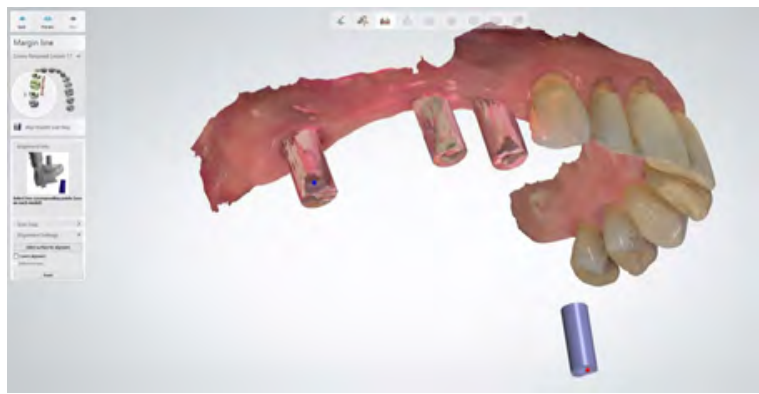

Figure 13. Scan bodies are used for implant scanning, they provide the necessary information for designing the prosthetic appliance.

CAD software in order to plan the digital prosthetic appliance. Manufacturers have already faced the need to start production of hybrid scan bodies, which are compatible with different systems.

If we are not properly informed about the scanners' features prior to the purchase, it may be an unpleasant surprise that some companies charge a data management fee. In such a case, after scanning the data, it is entered into the cloud operated by the company, from which it can only be sent to the laboratory after payment of the fee. However, most manufacturers provide an open system, which allows to export the STL files for free.

Limitation of intraoral scanners is that they are very expensive, however the cost of equipment is expected 


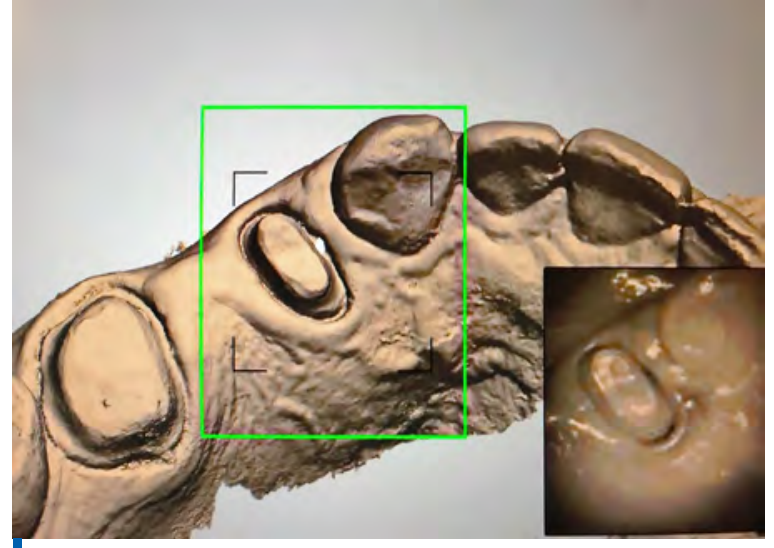

Figure 14. When digital impression taken, the virtual model is appearing continuously on computer screen. Additional scans are integrated to the incomplete (white) areas.

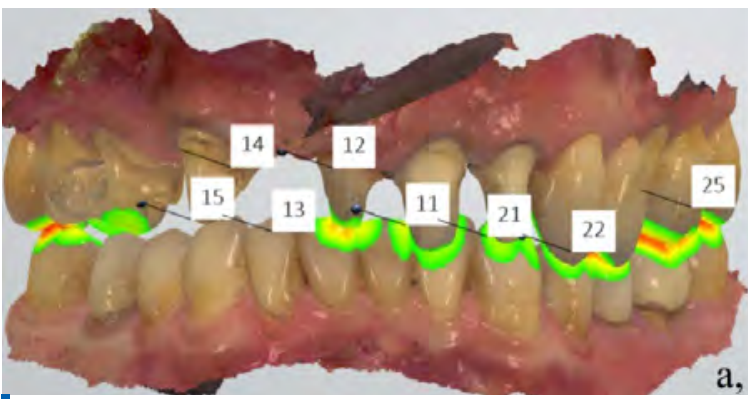

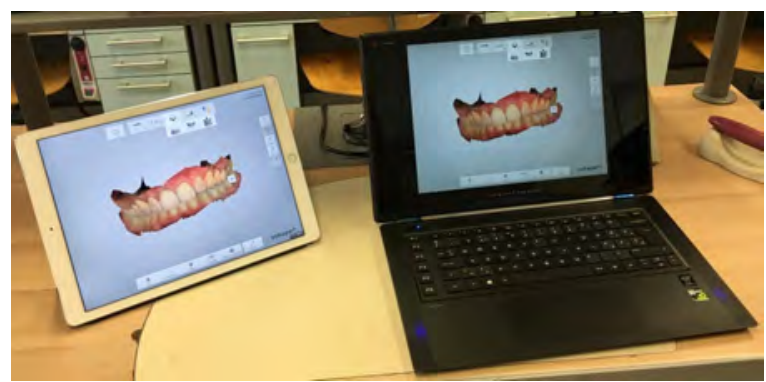

Figure 15. Scanned image can be displayed on computer screen and simultaneously on dental laboratory devices. It helps communication between lab and dental office.

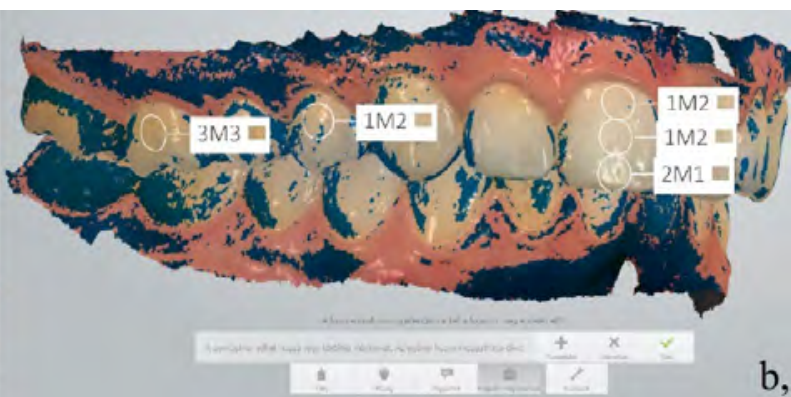

Figure 16. Built in software features of intraoral scanners (such as occlusal analysis) make dentists' work lot easier. Some scanners determine tooth shade and are equipped with intraoral cameras, thus expanding the possibilities of communication between dental lab and dentists.

to decrease in the future as the cost of production of scanners is declining.

\subsubsection{Advantages of intraoral scanning}

One great advantage is that the virtual model can be evaluated immediately chairside on the computer screen and the preparation can be modified if needed (Fig.14).

Built-in features of the software help to find not properly scanned surfaces and scan the approximal areas. The software provides data on adequate material thickness corresponding to the type of the dental appliance. The virtual model can be modified easy and quick, there is no need to rescan the whole arch.

Scanning is more time-efficient than conventional impression-taking. No time needed for mixing, setting, disinfection or casting.

In addition, digital impression taking is an environmentfriendly procedure, as it eliminates the large amount of hazardous waste generated by conventional impressions in dental practices. Ease of documentation is an important advantage. Digital models never wipe, break, wear out. Patient documentation can be stored digitally on a hard disk or in the cloud and can be recalled at any time. (Fig. 15)

Intraoral scanners have additional functions such as color display and intraoral camera. These functions also help patient communication as they make the lesions visible. Some scanners are able to determine tooth shade and forward that information to the dental laboratory (Fig. 16).

The scanned data are also an excellent tool for treatment follow up and to evaluate the patients' dental status. At the University of Zurich, Zimmermann et al. created a digital database, which records the patient's

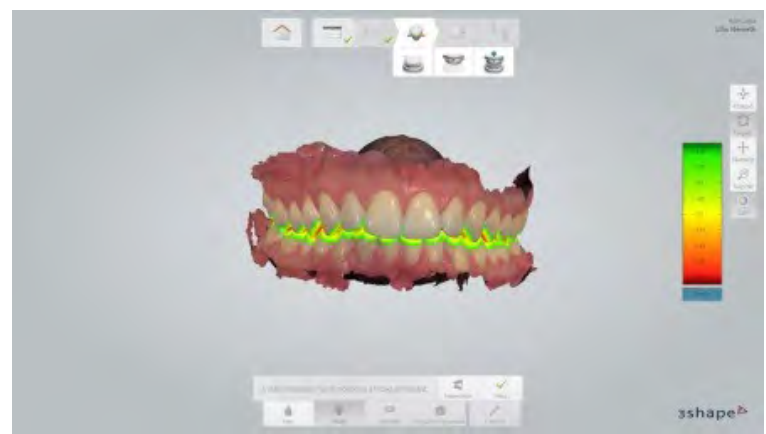

Figure 17. Digital impressions save the original form and shape of patient's teeth. The data can be stored for years and help planning of dental treatment later.

initial status and treatment scans. The final aim is the evaluation of long term changes in the dental status, such as dental migration, rotation, gingiva recession, abrasions etc. [7, 24] (Fig. 17).

Data of intraoral scanning can be fused with data of other 3 dimensional methods, such as CT and CBCT. This option opens up completely new perspectives for diagnosis, treatment plan, and planning of dental surgeries, already used in orthodontics and dental implantation. Modern undergraduate educational programs in implant dentistry (including digital prosthetic treatment) can provide proffessional care and a high treatment quality for the patients [25].

\section{Conclusions}

Digital dentistry is here to stay and it offers quick and comfortable experience to the patients and an efficient workflow to the dentist and dental technicians. The learning curve is steep to adopt that new technology both in the dental office and on the laboratory side. 
To have the potential to keep pace with the digital era change there is a need for education at the undergraduate and postgraduate university levels and also at the level of the dental designer training programms.

\section{Author contributions}

All the authors (JB, AC, WV, IR, PH) declare to be accountable for the whole content of the article.

\section{Acknowledgment \\ Not applicable.}

\section{References}

1. Chatham C, Spencer MH, Wood DJ, Johnson A. The introduction of digital dental technology into BDS curricula. Br Dent J. 2014;217(11):639-642. doi: 10.1038/sj.bdj.2014.1049. Google Scolar(6)

2. Available from https ://www.3shape.com/en/knowledge-center/ news-and-press/news/2014/go-digital Last accessed 15th May 2018

3. Bobich AM, Mitchell BL. Transforming Dental Technology Education: Skills, Knowledge, and Curricular Reform. Journal of Dental Education. 2017;81(9):eS59-eS64. doi: 10.21815/ JDE.017.035.

Google Scholar(1)

4. Available from https://www.planmeca.com/education/trainingfor-dental-professionals/ Last accessed 15th May 2018

5. Available from https://www.3shape.com/en/knowledge-center/ webinars Last accessed 15th May 2018

6. Kóbor A, Kivovics P, Hermann P. [Dental materials and Odontotechnology]. Budapest, HU: Semmelweis kiadó; 2015

7. Zimmermann M, Mehl A, Mörmann WH. et al. Intraoral Scanning Systems - a current overview. Int J Comput Dent. 2015;18(2):101129.

[Pubmed] GoogleScolar(38) Scopus(20)

8. Logozzo S, Zanetti E, Franceschini G, et al. Recent advances in dental optics- part-l: 3D intraoral scanners for restorative dentistry. Opt Lasers Eng. 2014;54(3):203-221. GoogleScolar(91) Scopus(39)

9. Tartaglia GM, Penchev P, Sforza C. Integrating digital technologies for dental prostheses: from impression to single crowns. A pilot study. Stoma Edu J. 2015;2(2):162-167. GoogleScolar(1)

10. Güth JF, Runkel C, Beuer F, et al. Accuracy of five intraoralscanners compared to indirect digitalization. Clin Oral Investig. 2017;21(5):1445-1455. doi: 10.1007/s00784-016-1902-4 [Full text links] [Pubmed] Google Scolar (21) Scopus(11)

11. Henkel GL. A comparison of fixed prostheses generated from conventional vs digitally scanned dental impressions. Compend Contin Educ Dent. 2007;28(8):422-424,426-428,430-431. [Pubmed] Google Scolar(88) Scopus(34)
12. Ender A, Zimmermann M, Attin T, et al. In vivo precision of conventional and digital methods for obtaining quadrant dental impressions. Clin Oral Investig. 2016;20(7):1495-1504. doi: 10.1007/s00784-015-1641-y [Full text links] [Free full text] [Pubmed] Google Scolar(43) Scopus(20)

13. Güth JF, Keul C, Stimmelmayr M, et al. Accuracy of digital models obtained by direct and indirect data capturing. Clin Oral Investig. 2013;17(4):1201-1208. doi: 10.1007/s00784-012-0795-0. [Full text links] [Pubmed] Google Scolar(156) Scopus(79)

14. Hack GD, Patzelt SBM. Evaluation of the accuracy of six intraoral scanning devices: an in-vitro investigation. ADA Professional Product Overview 2015;10(4):1-5. Google Scolar(11)

15. Patzelt SB, Vonau S, Stampf S, et al. Assessing the feasibility and accuracy of digitizing edentulous jaws. J Am Dent Assoc. 2013;144(8):914-920

[Full text links] [Pubmed] Google Scholar(57) Scopus(34)

16. Gan N, Xiong Y, Jiao T. Accuracy of intraoral digital impressions for whole upper jaws, including full dentitions and palatal soft tissues. PLoS One. 2016;11(7):e0158800. doi: 10.1371/journal. pone.0158800.

[Full text links] [Free PMC Article] [Pubmed] Google Scolar(6) Scopus(6)

17. Vecsei B, Joós-Kovács G, Borbély J, et al. Comparison of the accuracy of direct and indirect three-dimensional digitizing processes for CAD/CAM systems - An in vitro study. J Prosthodont Res. 2017;61(2):177-184. doi: 10.1016/j.jpor.2016.07.001. [Full text links] [Pubmed] Google Scolar (7) Scopus(2)

18. Yuzbasioglu E, Kurt H, Turunc R, et al. Comparison of digital and conventional impression techniques: evaluation of patients' perception, treatment comfort, effectiveness and clinical outcomes. BMC Oral Health 2014;14(1):10.

[Full text links] [Free PMC Article] [Pubmed] Google Scolar(118) Scopus(66)

19. Patzelt SB, Emmanouilidi A, Stampf S, et al. Accuracy of full-arch scans using intraoral scanners. Clin Oral Investig. 2014;18(6):16871694. doi: 10.1007/s00784-013-1132-y.

[Full text links] [Pubmed] Google Scolar(155) Scopus(83)

20. Lee SJ, Gallucci GO. Digital vs. conventional implant impressions: efficiency outcomes. Clin Oral Implants Res. 2013;24(1):111-115. doi: 10.1111/j.1600-0501.2012.02430.x

[Full text links] [Pubmed] Google Scolar(162) Scopus(95)

21. Joda T, Lenherr P, Dedem P et al. Time efficiency, difficulty, and operator's preference comparing digital and conventional implant impressions: a randomized controlled trial. Clin Oral Implants Res. 2017;28(10):1318-1323. doi: 10.1111/clr.12982. [Full text links] [Pubmed] GoogleScolar(12) Scopus(4)

22. Schepke U, Meijer HJ, KerdijkW, et al. Digital versus analog complete-arch impressions for single-unit premolar implant crowns: Operating time and patient preference. J Prosthet Dent. 2015;114(3):403-406. doi: 10.1016/j.prosdent.2015.04.003. [Full text links] [Pubmed] Google Scolar(30) Scopus(15)

23. Available from: http://zdigitaldentistry.com/en/knowledgebase Last accessed 15th May 2018

24. Zaruba M, Ender A, Mehl A. New applications for threedimensional follow-up and quality control using optical impression systems and OraCheck. Int J Comput Dent. 2014;17(1):53-64.

[Pubmed] GoogleScolar(11) Scopus(6)

25. Gebistorf MC, Bader CL, TakeichiT, Katsoulis J. Prosthetic reconstructions and referring implant survival in a postgraduate program: a retrospective study. Stoma Edu J. 2016;3(2):223-234.

\section{Judit BORBÉLY \\ DMD, PhD, Associate Professor Department of Prosthodontics, Faculty of Dentistry Semmelweis University Budapest Szentkirályi u. 47, H-1088 Budapest, Hungary}

Doctor Borbély is an Associate Professor at the Department of Prosthodontics, Semmelweis University, Budapest, Hungary. She graduated from the Dental Faculty of Semmelweis University of Medicine, Budapest, Hungary in 2001, then she began to specialize in prosthodontics. She received her PhD degree in 2008 on visual and digital methods for tooth shade selection. She also works in private practice focusing on prosthodontics and aesthetic dentistry. Since 2011 she has been working with digital impressioning systems. She conducts ongoing clinical research in digital prosthodontics and materials research. She presents lectures, hands-on clinical and postgraduate courses on ceramics, tooth shade selection and intraoral scanning. She is a presidential member of the Hungarian Prosthodontic Association and Hungarian Dental Association, she is a member of Society for Color and Appearance in Dentistry and Hungarian Academy of Esthetic Dentistry. 


\section{Ouestions}

\section{Intraoral scanners cannot be based on:}

Da. Confocal laser technology;

b. Confocal microscopy;

Dc. Triangulation;

$\square$ d. Scanning probe microscopy.

\section{It is not true for open CAD/CAM systems:}

Da. Files can be opened by the manufacturer's CAD software only;

bb. For example 3Shape Trios and Planmeca Planscan;

Dc. It is compatible with several types of CAD softwares;

d. It is compatible with several types of milling machines.

\section{What does accuracy consist of?}

Da. Trueness and deviation;

b. Precision and deviation;

Dc. Trueness and precision;

ad. Quality and quantity.

\section{Which material cannot be milled by dental CNC machines?}

Da. PMMA;

ab. Ceramic;

Dc. Titanium;

ad. Gold.

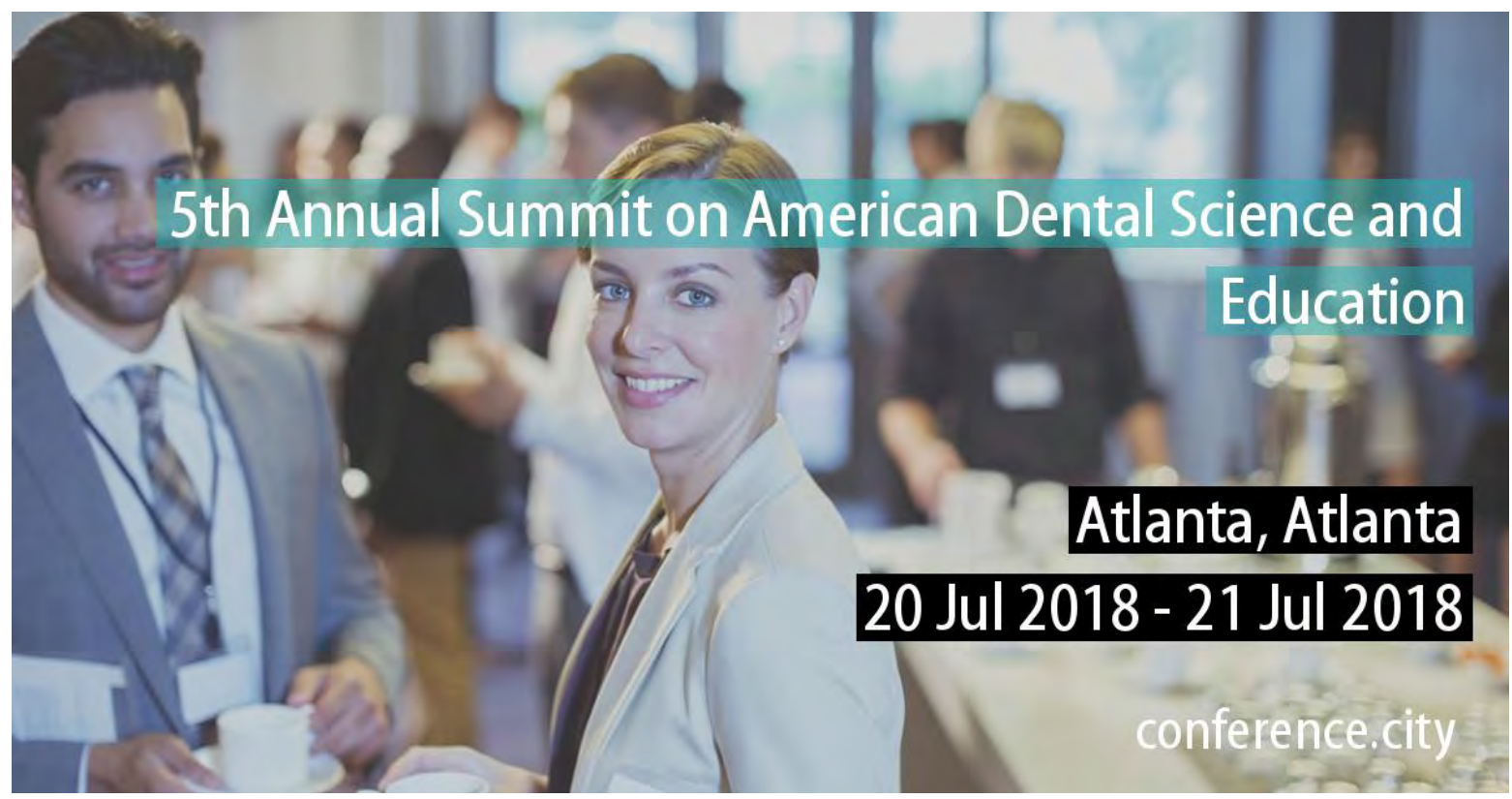

https://americandentaledu.conferenceseries.com/ 


\title{
COMPARISON OF DENTAL STATUS AND ORAL FUNCTION BETWEEN THE ELDERLY WITH AND WITHOUT TEMPOROMANDIBULAR DISORDERS Minh Son Nguyen ${ }^{1,2 a^{*}}$, Ülle Voog-Oras $^{\text {1b }}$, Triin Jagomägi'c, Mare Saag ${ }^{\text {1d }}$
}

'Institute of Dentistry, Faculty of Medicine, University of Tartu, Raekoja plats 6, 51003 Tartu, Estonia

2Department of Prosthodontics, Faculty of Stomatology, Danang University of Medical Technology and Pharmacy, 99 Hung Vuong, Danang, Vietnam

\author{
aDDS, PhD, Head of Department \\ ${ }^{\mathrm{b} M D}$, PhD, Associate Professor \\ 'DDS, PhD, Associate Professor \\ dDDS, PhD, Professor, Head of Institute
}

\begin{abstract}
DOI: 10.25241/stomaeduj.2018.5(2).art.6

Introduction: Temporomandibular disorders (TMD) are a group of disorders that may cause functional limitations. The aim of the study was to compare the differences in dental status, oral behaviour, and mandibular functional limitations between TMD and non-TMD elderly people in Vietnam.

Methodology: The sample consisted of 146TMD and 112 non-TMD elderly. The dental and periodontal status were evaluated with DMFT and CPI indices. The participants self-rated frequency of oral behaviour activities (21-item Oral Behaviour Checklist) and mandibular functional limitations (20-item Jaw Functional Limitation Scale).

Results: The mean number of missing teeth in TMD group was $9.6 \pm 8.6$, while it was $7.6 \pm$ 6.4 in non-TMD group ( $p=0.036)$. Gingival bleeding in TMD group was detected at $18.3 \pm$ 10.2 teeth, which was less than in non-TMD group $(21.0 \pm 8.7, p=0.023)$. The mean number of sextants with a 0-3 mm clinical attachment loss was high for non-TMD group $(1.4 \pm 2.0$, $p=0.021)$, while the mean number of excluded sextants was high for TMD group $(1.3 \pm 1.8$, $p=0.037$ ). The TMD elderly group reported more frequent instances of "Hold, tighten, or tense muscles"than non-TMD group. No significant differences were found in the self-rated mandibular functional limitations between the two groups.

Conclusion: TMD were associated with missing teeth and periodontal diseases. There was no association between TMD and mandibular functional limitations. The elderly suffering from TMD tended to have increased frequency of holding, tightening, or tensing muscles. Keywords: dental caries, elderly, mastication, oral function, temporomandibular disorders.
\end{abstract}

OPEN ACCESS This is an
Open Access article under the CC
BY-NC 4.0 license.
Citation: Nguyen MS, Voog-Oras Ü,
Jagomägi I, Saag M. Comparison of dental
status and oral function in the elderly with
and without temporomandibular disor-
ders. Stoma Edu J. 2018:5(2):118-124.
Academic Editor: Hiroshi Ogawa, DDS,
MDSc, PhD, Associate Professor, Niigata
University, Niigata, Japan
Received: May 22, 2018
Revised: May 28, 2018
Acccepted: June 18, 2018
Published: June 20, 2018
*Corresponding author:Dr. Minh Son
Nguuyen, DDS, PhD Institute of Dentistry,
Faculty of Medicine, University of Tartu 6
Raekoja Plats, Tartu51003, Estonia. Tel:
+84983060321, Fax: +3727319856,e-mail:
minhson1883@ggmail.com
Copyright: $\odot 2018$ the Editorial Council
for the Stomatology Edu Journal.

\section{Introduction}

Temporomandibular disorders (TMD) are the group of disorders affecting the temporomandibular joint and structure-related joint. The prevalence of TMD in the older adult population varies from $33 \%$ to $56.6 \%[1,2]$ TMD often cause orofacial pain, limit the function of the masticatory system, and also impact on quality of life [3].

Multiple factors contribute to the TMD process. Dentition is a part of the masticatory system, and the global burden of dental caries and periodontal diseases can increase the risk of TMD in the older adult population [4]. Our previous studies indicate that more than $50 \%$ suffer from TMD [2]. Studies on TMD at the age over 60 years old also reported that $17.5-52.2 \%$ of patients had less than 20 teeth, and $10.9-34.3 \%$ were edentulousness [5-7]. After dental pain, TMD is the most the common cause of pain in the orofacial area; therefore, dental diseases and TMD may share symptoms and clinical comorbidities.

The parafunctional habits of bruxism and teeth clenching have been regarded as risk factors for TMD pain [8-10]. TMD patients are also limited in their daily activities and have increased frequency of oral parafunction [11,12]. The cumulative risk factors of ageing contribute to the increasing signs of TMD, including limited mouth opening, muscular tenderness, and TMJ sounds, all of which can affect on masticatory performance. Ohrbach et al. [13] and Markiewicz et al. [14] initially developed the Diagnostic Criteria for Temporomandibular Disorders (DC/TMD) axis II to determine the presence of parafunctional and functional limitations of the masticatory system. However, norms have not yet been established for those instruments, particularly in the older adult population. Regardless of whether or not elderly with TMD have more limited oral function compared to those free from TMD, because many factors such as dental status, neuromuscular changes, and psychosocial factors can influence oral function of this age group.

Therefore, the aim of the study was to compare the differences in dental status, oral behaviours, and functional limitations of the masticatory system between the TMD and non-TMD elderly people.

\section{Materials and methods}

The total sample comprised 258 volunteer participants aged 65-74 years in Danang City, Vietnam. Based on clinical examination of TMD according to DC/TMD axis 
I [15], our previous study revealed that $56.6 \%(n=146)$ of the total sample were diagnosed with TMD (TMD group) and $43.4 \%(n=112)$ were free of TMD (nonTMD group) [2]. In the current study, the participants of both groups were invited to examine dental status and evaluate oral function.

Written informed consent that explained oral examination procedures was obtained from each participant. This study was registered and approved by the Human Research Ethics Committee of the Danang University of Medical Technology and Pharmacy (No. 523/CN-DHKTYDDN 2014) and was performed in accordance with the World Medical Association's Helsinki Declaration.

\subsection{Clinical examination of dental status}

The dental status of each participant was examined by using the Decayed Missing Filled Teeth (DMFT) index. The primary caries appeared on the crown or root of a tooth, or secondary carious lesions nest to the restoration was considered a decayed tooth (DT). A missing tooth (MT) was a tooth lost due to caries or any other reason. A filled tooth (FT) was considered with at least one filled surface and without any caries. The DMFT score was the sum of the DT, MT, and FT scores and ranged from 0 to 32 .

\subsection{Clinical examination of periodontal status}

Periodontal status was evaluated using the modified Community Periodontal Index (CPI). The modified CPI records two indicators of periodontal status: gingival bleeding and periodontal pockets. All teeth present were probed ( 6 sites per tooth) to record any presence of bleeding on probing and periodontal pocket depth (PPD). PPD was scored as follows: score 0 (a PPD of 0-3mm, no pocket), score 1 (a PPD of 4-5mm, shallow pocket), and score 2 (a PPD of $\geq 6 \mathrm{~mm}$, deep pocket).

\subsection{Clinical examination of clinical attachment loss (CAL)}

CAL estimates accumulated lifetime destruction of the periodontal attachment. CAL was measured from the cementoenamel junction to gingival sulcus or pocket at 6 sites per index tooth of each sextant. The CAL severity was recorded based on the highest CAL score of the index tooth as follows: score 0 (CAL 0-3 mm), score 1 (CAL 4-5 mm), score 2 (CAL $\geq 6 \mathrm{~mm}$ ). The sextant was excluded if there were less than two teeth present.

The first author conducted procedure of dental and periodontal examination according to the WHO's Oral Health Survey guidelines (2013). A pilot study of a group of 25 elderly people was performed to calibrate the examiner before the study was carried out. Ten percent of the participants were re-examined after three days to test the reliability of the examination procedure. The calculated Kappa-values were above 0.85 , indicating a high degree of intra-examiner and inter-examination reliability.

\subsection{Evaluation of oral function}

All participants were interviewed face-to-face on the functional limitations of their masticatory system based on the 20-item Jaw Functional Limitation Scale
Table 1. Comparisons of dental caries status between the TMD and nonTMD elderly participants.

\begin{tabular}{rccc}
\hline Variable & $\begin{array}{c}\text { TMD } \\
(\mathbf{n}=\mathbf{1 4 6})\end{array}$ & $\begin{array}{c}\text { Non-TMD } \\
(\mathbf{n}=\mathbf{1 1 2})\end{array}$ & p-value \\
\hline Sound teeth & & & \\
\hline Number of subjects & 131 & 110 & \\
Percent \% & 89.7 & 98.2 & $0.009^{* a}$ \\
Mean number of teeth & $15.5 \pm 9.4$ & $17.6 \pm 8.7$ & 0.070 \\
\hline Decayed teeth & & & \\
\hline Number of subjects & 120 & 108 & \\
Percent \% & 82.2 & 96.4 & $<0.001^{* a}$ \\
Mean number of teeth & $6.3 \pm 5.6$ & $6.5 \pm 5.4$ & 0.684 \\
\hline Missing teeth & & & \\
\hline Number of subjects & 134 & 106 & \\
Percent \% & 91.8 & 94.6 & 0.463 \\
Mean number of teeth & $9.6 \pm 8.6$ & $7.6 \pm 6.4$ & $0.036^{* b}$ \\
\hline Filled teeth & \multicolumn{3}{c}{} \\
\hline Number of subjects & 12 & 10 & \\
Percent \% & 8.3 & 8.9 & 1.000 \\
Mean number of teeth & $0.2 \pm 0.9$ & $0.3 \pm 1.1$ & 0.710 \\
\hline Caries experience & & & \\
\hline Number of subjects & 143 & 111 & 0.635 \\
Percent \% & 97.9 & 99.1 & \\
\hline Mean DMFT & $16.0 \pm 9.5$ & $14.4 \pm 8.7$ & 0.152 \\
\hline & & & \\
\hline
\end{tabular}

a Fisher's exact test, ${ }^{\text {b }}$ Student t-test, ${ }^{*}$ statistically significant TMD: Temporomandibular disorders, DMFT: Decayed Missing Filled Teeth

(JFLS-20) [13] and the frequency of parafunctional behaviours based on the 21-item Oral Behaviour Checklist (OBC-21) [14].

JFLS-20 assesses the limitation of mastication ( 6 items), mandibular mobility (4 items), verbal and emotional expression communication items (8 items), swallowing, and yawning. Each item was scored on a scale of 0-10 points $(10$ points $=$ the most limited mandibular function).

OBC-21 determines the frequency of oral parafunctional activities during sleep and waking hours. Each item was scored from 0 (never) to 4 (all the time). In the current study, each item on the JFLS-20 and OBC-21 surveys was categorised as No (score $=0$ ) and Yes (score $\geq 1$ ).

The data was analysed using Version 17.0 of the Statistical Package for Social Sciences software (SPSS Inc., Chicago, III., USA). The comparisons of dental status, the frequency of parafunctional behaviours, and functional limitations of the masticatory system between the two groups was performed using Chisquare test and Student's t-test. A confidence level of $95 \%$ and a two-sided $p$-value of $<0.05$ were used to reveal significant differences.

\section{Results}

Prevalence of DMFT was $97.9 \%$ in the TMD group and $99.1 \%$ in the non-TMD group ( $p=0.635$ ). There were significant differences in prevalence between the TMD and the non-TMD groups in terms of sound 
Table 2. Comparisons of periodontal status between the TMD and nonTMD elderly.

\begin{tabular}{|c|c|c|c|}
\hline Variable & $\begin{array}{c}\text { TMD } \\
(n=146)\end{array}$ & $\begin{array}{c}\text { Non-TMD } \\
(\mathrm{n}=112)\end{array}$ & p-value \\
\hline \multicolumn{4}{|l|}{ Gingival bleeding } \\
\hline $\begin{array}{c}\text { Number of } \\
\text { participants (\%) }\end{array}$ & $135(92.5)$ & $110(98.2)$ & 0.467 \\
\hline $\begin{array}{c}\text { Mean number of } \\
\text { teeth }\end{array}$ & $18.3 \pm 10.2$ & $21.0 \pm 8.7$ & $0.023^{* c}$ \\
\hline \multicolumn{4}{|c|}{ Prevalence of participants having highest score of PPD } \\
\hline PPD 0-3 mm & $15(10.7)$ & $15(13.4)$ & 0.514 \\
\hline PPD 4-5 mm & $46(32.9)$ & $50(44.6)$ & 0.056 \\
\hline $\mathrm{PPD} \geq 6 \mathrm{~mm}$ & $78(55.7)$ & $47(42.0)$ & $0.030^{* a}$ \\
\hline \multicolumn{4}{|c|}{ Mean number of teeth present with PPD } \\
\hline PPD $0-3 \mathrm{~mm}$ & $12.3 \pm 10.2$ & $14.4 \pm 9.7$ & 0.085 \\
\hline PPD 4-5 mm & $7.3 \pm 7.9$ & $8.3 \pm 8.1$ & 0.342 \\
\hline $\mathrm{PPD} \geq 6 \mathrm{~mm}$ & $1.0 \pm 3.6$ & $0.6 \pm 1.7$ & 0.210 \\
\hline \multicolumn{4}{|c|}{ Prevalence of participants having highest score of CAL } \\
\hline CAL 0-3 mm & $2(1.4)$ & $12(10.7)$ & $0.001^{* \mathrm{~b}}$ \\
\hline CAL 4-5 mm & $38(26.0)$ & $42(37.5)$ & $0.048^{* a}$ \\
\hline $\mathrm{CAL} \geq 6 \mathrm{~mm}$ & $45(30.8)$ & $25(22.3)$ & 0.128 \\
\hline Excluded sextants & $61(41.8)$ & $33(29.5)$ & $0.042^{* a}$ \\
\hline \multicolumn{4}{|c|}{ Mean number of sextants with CAL and excluded sextants } \\
\hline CAL 0-3 mm & $0.9 \pm 1.4$ & $1.5 \pm 2.0$ & $0.021^{* c}$ \\
\hline CAL 4-5 mm & $2.4 \pm 2.0$ & $2.7 \pm 2.2$ & 0.184 \\
\hline $\mathrm{CAL} \geq 6 \mathrm{~mm}$ & $1.5 \pm 1.7$ & $1.0 \pm 1.7$ & 0.100 \\
\hline Excluded sextants & $1.2 \pm 1.8$ & $0.8 \pm 1.4$ & $0.037^{* \mathrm{c}}$ \\
\hline $\begin{array}{l}\text { a Chi-square test, b } \\
\text { statistically significant. } \\
\text { PPD: Periodontal pocke }\end{array}$ & $\begin{array}{l}\text { r's exact } \\
\text { pth; CAL: }\end{array}$ & , 'Stude & to-test, \\
\hline
\end{tabular}

teeth $(89.7 \%$ and $98.2 \%, \mathrm{p}=0.009)$ and decayed teeth $(82.2 \%$ and $96.4 \%, \mathrm{p}<0.001)$. The number of missing teeth was statistically higher in the TMD group $(9.6 \pm$ 8.6 teeth) than in the non-TMD group $(7.6 \pm 6.4, \mathrm{p}=$ 0.036 , Table 1).

Regarding periodontal status, gingival bleeding was detected at $18.3 \pm 10.2$ teeth in the TMD group, which was lower than $21.0 \pm 8.7$ teeth in the non-TMD group $(p=0.023)$. The prevalence of older adults with PPD $\geq 6 \mathrm{~mm}$ was higher in the TMD group (55.7\%) than in the non-TMD group ( $42 \%, p=0.030$ ). Concerning clinical attachment loss, occurrences of CAL 4-5 mm was $37.5 \%$ for the non-TMD group and $26.0 \%$ for the TMD group $(p=0.048)$; whereas, a high prevalence of excluded sextants was significantly related to the TMD group ( $41.8 \%, p=0.042)$. The mean number of sextants with CAL 0-3 mm was $0.9 \pm 1.4$ in the non-TMD group, which was statistically lower than $1.5 \pm 2.0$ sextants of the non-TMD group $(p=0.021)$; however, the TMD group had more excluded sextants $(1.3 \pm 1.8)$ than the non-TMD group $(0.7 \pm 1.4, p=0.037)$.

Comparing the functional limitations of mastication revealed no differences between the TMD and nonTMD group. Most participants in the TMD elderly group had masticatory limitations related to chewing tough food $(82.2 \%)$, followed by chewing chicken (69.2\%), and chewing hard bread (66.4\%); the results for the non-TMD group were $75.9 \%, 64.3 \%$, and $56.3 \%$, respectively. The mean score (standard error) of each
Table 3. Comparisons of functional limitations of masticatory system between the TMD and non-TMD elderly.

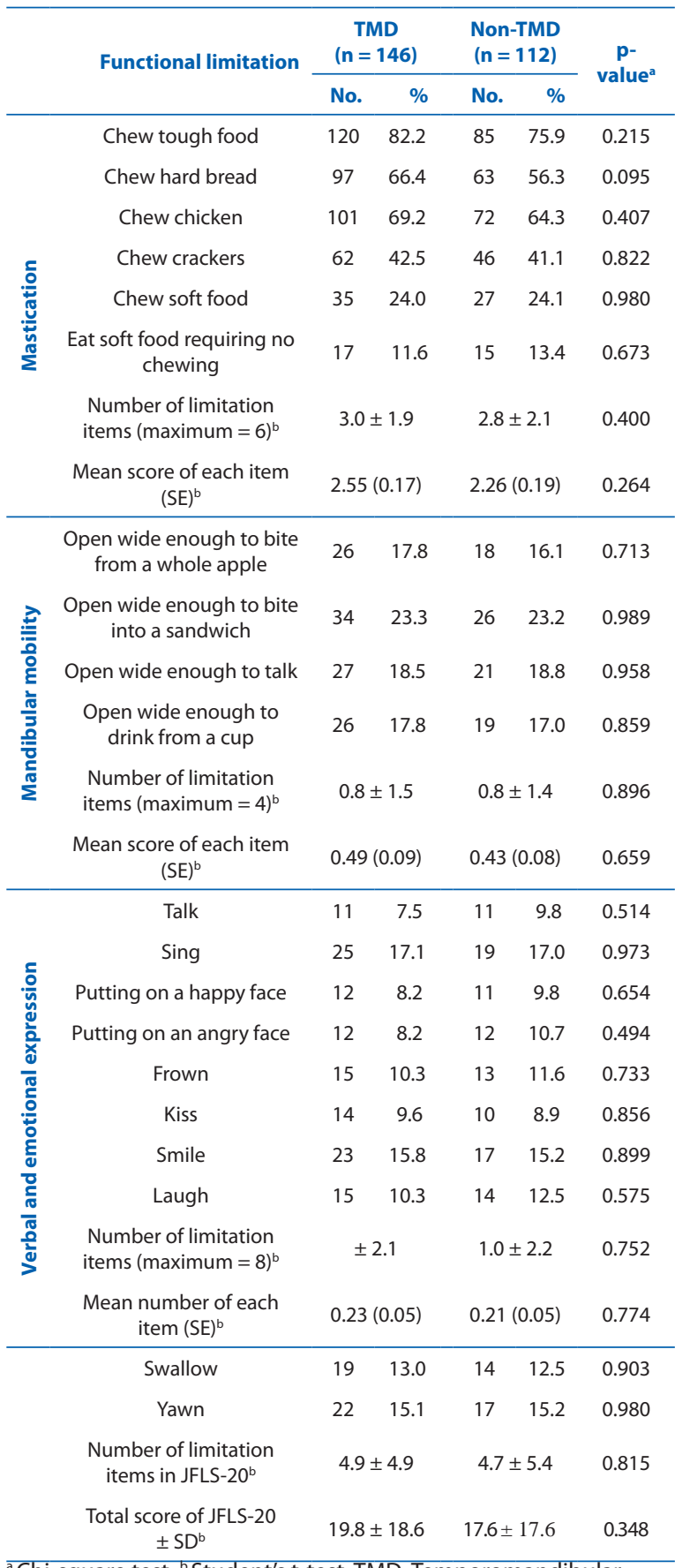

${ }^{a}$ Chi-square test, ${ }^{\mathrm{b}}$ Student's t-test. TMD: Temporomandibular disorders, SE: standard error, JFLS-20: 20-item Jaw Functional Limitation Scale.

of the masticatory items was $2.55(0.17)$ for the TMD group, compared to $2.26(0.19)$ for the non-TMD group $(p=0.260)$. The prevalence of limitations of mandibular mobility ranged from $17.8 \%$ to $23.3 \%$ in the TMD group, which were similar with the variation of $16.1 \%$ to $23.2 \%$ in the non-TMD group ( $p>0.05$ ). There were no significant differences between the two groups regarding limitations of verbal and emotional expression. The total score of JFLS-20 was $19.8 \pm 18.6$ in the TMD group and $17.6 \pm 17.6$ in the non-TMD group $(p=0.348$, Table 3$)$.

There were significant differences in the prevalence of parafunctional activities between the TMD and non-TMD groups in terms of "Hold, tighten, or tense 
muscles without clenching" $(7.5 \%$ and $1.8 \%, \mathrm{p}=$ $0.036)$ and "Eating between meals that food requires chewing" (43.2\% and 57.1\%, $p=0.026)$. The TMD group also tended to have more prevalent parafunctions of "Press tongue forcibly against teeth" and "Place tongue between teeth" ( $p=0.067$ and $p=0.079$, respectively) compared to the non-TMD group. No significant differences were found in the mean number of parafunctional items between the two groups ( $p=$ 0.928, Table 4).

\section{Discussion}

The current study highlighted a different dental status between the TMD elderly and non-TMD elderly groups. OurTMD elderly group lost an average of $9.6 \pm 8.6$ teeth and were higher than the non-TMD group; in other words, our study was in accordance with previous findings indicating that there was association of TMD with missing teeth [16-18]. When individuals lose many teeth, their chewing pattern can be changed and have impact on masticatory performance. Numerous studies indicated that chronic unilateral chewing increases the risk of TMD $[18,19]$. In addition, tooth loss causes social limitations, psychological disorders, and reduces the quality of life, all of which have been regarded as factors contributing to TMD.

The main finding of our study was that periodontal diseases have influence on TMD. PPD $\geq 4 \mathrm{~mm}$ indicates periodontal tissue destruction due to inflammation, while the CAL measurement estimates lifetime accumulated destruction of the periodontal attachment. These measures permit comparisons the severity of periodontal diseases between population groups. Our finding indicated that PPD and CAL were worse in the TMD group than in the non-TMD group. More than half of the TMD group had PPD $\geq 6 \mathrm{~mm}$ and over $70 \%$ of those had the CAL $\geq 6 \mathrm{~mm}$ and excluded sextants. All these numbers were comparatively high compared to $42 \%$ and $51.8 \%$, respectively, in the non-TMD group. In the elderly population, periodontal diseases are the most frequent cause of tooth loss; therefore, TMD was significantly associated with both periodontal diseases and tooth loss in the current study.

Gingival bleeding does not affect single tooth but can affect many remaining teeth in the mouth, but the TMD group had more missing teeth than the nonTMD. Therefore, the number of teeth with gingival bleeding was observed less in the TMD group in our study. Periodontal inflammation has been considered a potential risk factor for other diseases. Proinflammatory cytokines enhance the pathogenesis of periodontal diseases. Interleukin (IL-1) and tumour necrosis factor alpha (TNF-a) represent proinflammatory cytokines that stimulate a number of events which occur during infection with periodontal pathogens. Graves et al. found a widespread presence of IL-1 and TNF in the connective tissue and loss of alveolar bone along with periodontal inflammation [20]. High levels of IL-1 and TNF- $\alpha$ are a response to the inflammatory process and they might penetrate into the TMJ synovial fluid and cause bone tissue resorption; therefore, the degree of endogenous cytokine control is important for bone tissue destruction in the TMJ structure [21].
Table 4. Comparisons of parafunctional behaviours between the TMD and non-TMD elderly.

\begin{tabular}{lcccc}
\hline \multirow{3}{*}{ Parafunctional habit } & $\begin{array}{c}\text { TMD } \\
(n=146)\end{array}$ & $\begin{array}{c}\text { Non-TMD } \\
(n=112)\end{array}$ & $\begin{array}{c}p- \\
\text { value }^{a}\end{array}$ \\
\cline { 2 - 4 }$n$ & $n$ & $\%$ & $n$ &
\end{tabular}

Sleep activities

Clench or grind teeth when asleep

$\begin{array}{lllll}16 & 11.0 & 9 & 8.0 & 0.431\end{array}$

Sleep in a position that puts pressure on the jaw

$\begin{array}{lllll}57 & 39.0 & 44 & 39.3 & 0.968\end{array}$

Waking activities

Grind teeth together during waking hours

Clench teeth together during waking hours

Press, touch, or hold teeth together other than while eating

Hold, tighten, or tense muscles without clenching

Hold or put jaw forward or to the side

Press tongue forcibly against teeth

Place tongue between teeth

Bite, chew, or play with your tongue, cheeks or lips

Hold jaw in rigid or tense position

Hold between the teeth or bite objects

Use chewing gum

Play musical instrument that involves use of mouth or jaw Lean with your hand on the jaw

Chew food on one side only

Eating between meals that food requires chewing

Sustained talking

Singing

Yawning

Hold telephone between your head and shoulders

$9 \quad 6.2$

7

6.3

0.977

$\begin{array}{lllll}12 & 8.2 & 10 & 8.9 & 0.840\end{array}$

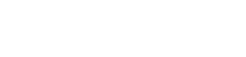

$\begin{array}{llll}19.2 & 24 & 21.4 & 0.655\end{array}$

$\begin{array}{lllll}11 & 7.5 & 2 & 1.8 & \mathbf{0 . 0 3 6}\end{array}$

$\begin{array}{lllll}17 & 11.6 & 11 & 9.8 & 0.64\end{array}$

$\begin{array}{lllll}31 & 21.2 & 14 & 12.5 & 0.067\end{array}$

$\begin{array}{lllll}32 & 21.9 & 15 & 13.4 & 0.079\end{array}$

$\begin{array}{lllll}27 & 18.5 & 19 & 17.0 & 0.750\end{array}$

$\begin{array}{lllll}17 & 11.6 & 10 & 8.9 & 0.480\end{array}$

$\begin{array}{llllll}8 & 5.5 & 8 & 7.1 & 0.583\end{array}$

$\begin{array}{lllll}20 & 13.7 & 19 & 17.0 & 0.468\end{array}$

$\begin{array}{lllll}4 & 2.7 & 1 & 0.9 & 0.392\end{array}$

$\begin{array}{lllll}50 & 34.2 & 36 & 32.1 & 0.722\end{array}$

$\begin{array}{lllll}82 & 56.2 & 63 & 56.3 & 0.989\end{array}$

$\begin{array}{lllll}63 & 43.2 & 64 & 57.1 & \mathbf{0 . 0 2 6}\end{array}$

$\begin{array}{lllll}67 & 45.9 & 49 & 43.8 & 0.732\end{array}$

$\begin{array}{lllll}33 & 22.6 & 34 & 30.4 & 0.159\end{array}$

$\begin{array}{lllll}48 & 32.9 & 43 & 38.4 & 0.353\end{array}$

Number of parafunctional habits

\begin{tabular}{cccccc}
\hline 0 & 15 & 10.3 & 12 & 10.7 & \\
$1-4$ & 72 & 49.3 & 54 & 48.2 & \\
$5-8$ & 36 & 24.7 & 31 & 27.7 & 0.921 \\
$\geq 9$ & 23 & 15.8 & 15 & 13.4 & \\
\hline
\end{tabular}

Mean number of $\quad 4.40 \pm 3.71 \quad 4.36 \pm 3.23 \quad 0.928$

$\begin{array}{llll}\text { parafunctional habits } \pm \text { SD }^{\mathrm{b}} & 4.40 \pm 3.71 & 4.36 \pm 3.23 & 0.928\end{array}$

a Chi-square test, ${ }^{b}$ Student's t-test, " statistically significant.

TMD: Temporomandibular disorders, SD: standard deviation.

Regarding peripheral sensitization, nociceptive afferents in the periodontal ligament could be activated when periodontal tissues under pressure become painful due to bacterial infections. Afferent nerve fibres carry the impulse to the trigeminal spinal tract nucleus and stimulate interneurons. The efferent fibres of the inhibitory interneurons synapse, which lead to the elevator muscle reaction, bring the teeth away from the noxious stimulus $[22,23]$. These repetitions might cause masticatory muscle dysfunction. The 
findings of Jeon et al. [19] suggested a positive correlation between chronic periodontitis and TMDrelated muscle pain, while Fabri et al. [24] found that there were clinical comorbidities between periodontal disease and craniofacial pains. All these studies support our findings indicating that periodontitis accumulated over time might be a risk factor for TMD.

TMD are a group of disorders that disrupt function or cause parafunction of the masticatory system. Surprisingly, the number of oral parafunctional activities was equal across two groups; participants in both groups had a range of 4-5 parafunctional behaviours. Our study is in accordance with Leketas et al.'s study [25] indicating that the behaviours of "Lean with your hand on the jaw", "Chew food on one side only", and "Sleep in a position that puts pressure on the jaw" were the most common in the TMD group. Meulen et al. [26] showed that these parafunctional behaviours often had higher scores than other parafunctional items when evaluating the validity items of OBC-21 in the Dutch population. This could suggest that the frequency of parafunctional behaviours affected TMD. The current study found that 2 out of 21 items of OBC were significantly associated with TMD among the elderly. The TMD group had higher frequency of "Hold, tighten, or tense muscles without clenching", but a lower frequency of "Eating between meals (i.e., food that requires chewing)" than the non-TMD group. These findings could be explained by muscular activity. The increasein the frequency of tensing muscles heightened the risk of TMD between 2.9-10.8 times [25]. Based on an electromyography study, Ohrbach et al. found [27] a high score of masseter muscular activity in subjects with tense muscles. A high activity of masseter muscle in combination with the neuromuscular change in older age would cause muscular disorders, a subgroup of TMD. This also explained why the TMD elderly group had a lower frequency of eating between meals in our study because of muscular impairment.

The current study reported difficulty chewing tough and hard food in most participants, but none indicating that TMD was related to functional limitations of mastication; such findings contrast with findings of Brandini et al. [28]. In older adults, the rate of loss was often higher in the posterior than the anterior teeth; therefore, the impaired masticatory performance was prevalent in both groups in our study. There were no differences between the two groups concerning other functional limitations related to mandibular mobility and verbal/emotional expression. However, limited mouth opening could occur with increasing age. Ikebe et al. found that $7.9 \%$ of elderly Japanese exhibited this limitation [29]. Similarly, our study demonstrated that approximately $23 \%$ of examinees self-reported a reduced mouth opening capacity to perform daily activities. The age-related degeneration of the temporomandibular joints and muscle weakness could contribute to such limitation in older people.

Although the prevalence of functional limitations was high in the TMD group, there were no correlations between the functional limitations of masticatory system and TMD when compared to the non-TMD group. This suggests that multiple factors could affect the function of the masticatory system in the elderly, including chronic orofacial pain, psychological disorders, and age-related reduction of the motor function of masticatory muscles [29-31]. The important finding of the current study was that determining the JFLS-20 score of older adults might enable us to predict $\mathrm{TMD}$, as the prevalence of TMD is correlated with an increasing JFLS-20 score in the general population [13]. The limitation of the study was that we only studied the oral function and parafunctional behaviours based on self-rated questionnaires. There is a need for more clinical research on this aspect.

\section{Conclusion}

Temporomandibular disorders were associated with missing teeth and periodontal diseases. There was no association between TMD and mandibular functional limitations among the elderly. The elderly suffering from TMD tended to have increased frequency of holding, tightening, or tensing muscles.

\section{Conflicts of interest}

The authors declare that they have no conflict of interest.

\section{Author contributions}

MSN searched literature, performed clinical studies, data acquisition and statistical analysis, and wrote draft of manuscript. ÜVO, TJ, and MS designed protocol, interpreted data, and edited the manuscript. All authors read and approved the final manuscript.

\section{Acknowledgements}

This study was supported by the Estonian Science Foundation grant ESF 9255, the Estonian Research Council IUT 20-46, and the Internationalization Programme DoRa of the European Social Fund, which is carried out by the Foundation Archimedes. The authors would like to thank the volunteer participants from the Hoa Vang, Hai Chau, Thanh Khe, and Cam Le districts of Danang City in Vietnam for their cooperation and agreement to provide data on their oral health and temporomandibular joint status.

\section{References}

1. Unell $L$, Johansson A, Ekbäck G, et al. Prevalence of troublesome symptoms related to temporomandibular disorders and awareness of bruxism in 65- and 75-year-old subjects. Gerodontology. 2012;29(2):e772-e779. doi:10.1111/j.17412358.2011.00558.x

[Full text links] [PubMed] Google Scholar(25) Scopus(9)

2. Nguyen MS, Jagomägi T, Nguyen T, et al. Symptoms and signs of temporomandibular disorders among elderly Vietnamese. Proc Singap Healthc. 2017;26(4):211-216. doi:10.1177/2010105817694907.

[Full text links] Google Scholar(1) Scopus(1)

3. Niibo P, Pruunsild C, Voog-Oras Ü, et al. Contemporary management of TMJ involvement in JIA patients and its orofacial consequences. EPMA J. 2016;7(1):1-9. doi:10.1186/ s13167-016-0061-7.

[Full text links] [Free PMC Article] [PubMed] Google Scholar(7) Scopus(2)

4. Kossioni EA. Recommended action plans for oral health in older Europeans. Stoma Edu J. 2018;5(1):6-7. doi: 10.25241/ stomaeduj.2018.5(1).edit.2.

[Full text links] Google Scholar() 
5. Sipilä K, Näpänkangas R, Könönen $M$, et al. The role of dental loss and denture status on clinical signs of temporomandibula disorders. J Oral Rehabil. 2013;40(1):15-23. doi:10.1111/j.13652842.2012.02345.x

[Full text links] [PubMed] Google Scholar(25) Scopus(15)

6. Katyayan PA, Katyayan MK, Patel GC. Association of edentulousness and removable prosthesis rehabilitation with severity of signs and symptoms of temporomandibular disorders. Indian J Dent Res. 2016;27(2):127-136. doi: 10.4103/0970-9290.183129.

[Full text links] [PubMed] Google Scholar(2) Scopus()

7. Nguyen MS, Voog-Oras Ü, Jagomägi T, et al. Tooth loss and risk factors among elderly Vietnamese. Stoma Edu J. 2016;3(34):178-183. doi: 10.25241/stomaeduj.2016.3(3-4).art.7. [Full text links] Google Scholar(1)

8. Manfredini D, Lobbezoo F. Relationship between bruxism and temporomandibular disorders: a systematic review of literature from 1998 to 2008. Oral Surg Oral Med Oral Pathol Oral Radiol Endod. 2010;109(6):e26-50. doi:10.1016/j.tripleo.2010.02.013. [Full text links] [PubMed] Google Scholar(255) Scopus(149)

9. Romaniuc D, Fala V, Lacusta V, et al. Manifestation of sleep bruxism according to the age of patients. Stomatol Edu J. 2018;5(1):31-37. doi: 10.25241/stomaeduj.2018.5(1).art.3. [Full text links]

10. Kino K, Sugisaki M, Haketa T, et al. The comparison between pains, difficulties in function, and associating factors of patients in subtypes of temporomandibular disorders. J Oral Rehabil. 2005;32(5):315-325. doi:10.1111/j.1365-2842.2004.01439.x. [Full text links] [PubMed] Google Scholar(88) Scopus(47)

11. Michelotti A, Cioffi I, Festa P, et al. Oral parafunctions as risk factors for diagnostic TMD subgroups. J Oral Rehabil. 2010;37(3):157-162. doi:10.1111/j.1365-2842.2009.02033.x. [Full text links] [PubMed] Google Scholar(146) Scopus(65)

12. Ohrbach $R$, Larsson $P$, List T. The jaw functional limitation scale: development, reliability, and validity of 8-item and 20-item versions. J Orofac Pain. 2008;22(3):219-230. [Full text links] [PubMed] Google Scholar(95) Scopus(57)

13. Markiewicz MR, Ohrbach R, McCall WD Jr. Oral behaviors checklist: reliability of performance in targeted waking-state behaviors. J Orofac Pain. 2006;20(4):306-316.

[Full text links] [PubMed] Google Scholar(47) Scopus(29)

14. Tallents RH, Macher DJ, Kyrkanides S, Katzberg RW, Moss ME. Prevalence of missing posterior teeth and intraarticular temporomandibular disorders. J Prosthet Dent. 2002;87(1):45 50. doi: $10.1067 / \mathrm{mpr} .2002 .121487$.

[Full text links] [PubMed] Google Scholar(144) Scopus(63)

15. Mundt T, Mack F, Schwahn C, et al. Association between sociodemographic, behavioral, and medical conditions and signs of temporomandibular disorders across gender: results of the study of health in Pomerania (SHIP-0). Int J Prosthodont. 2008;21(2):141-148.

[Full text links] [PubMed] Google Scholar(28) Scopus(14)

16. Nguyen MS, Jagomägi T, Nguyen T, et al. Occlusal support and temporomandibular disorders among elderly Vietnamese. Int J Prosthodont. 2017;30(5):465-470. doi:10.11607/ijp.5216. [Full text links] [PubMed] Google Scholar(0) Scopus(0)

17. Jeon $\mathrm{HM}$, Ahn YW, Jeong $\mathrm{SH}$, et al. Pattern analysis of patients with temporomandibular disorders resulting from unilateral mastication due to chronic periodontitis. J Periodontal Implant Sci. 2017:47(4):211-218. doi:10.5051/jpis.2017.47.4.211. [Full text links] [Free PMC Article] [PubMed] Google Scholar(0)
Scopus(0)

18. Graves D, Cochran D. The contribution of interleukin-1 and tumor necrosis factor to periodontal tissue destruction. J Periodontol. 2003;74(3):391-401. doi:10.1902/jop.2003.74.3.391. [Full text links] [PubMed] Google Scholar(824) Scopus(470)

19. Ahmed N, Petersson A, Catrina Al, et al. Tumor necrosis factor mediates temporomandibular joint bone tissue resorption in rheumatoid arthritis. Acta Odontol Scand. 2015;73(3):232-240. doi:10.3109/00016357.2014.994561.

[Full text links] [PubMed] Google Scholar(7) Scopus(5)

20. Wadachi R, Hargreaves KM. Trigeminal nociceptors express TLR4 and CD14: a mechanism for pain due to infection. J Dent Res. 2006;85(1):49-53. doi:10.1177/154405910608500108. [Full text links][Free PMC Article][PubMed]Google Scholar(208) Scopus(135)

21. Yin CS, Lee YJ, Lee YJ. Neurological influences of the temporomandibular joint. J Bodyw Mov Ther. 2007; 11 (4):285294. doi: 10.1016/j.jbmt.2006.11.007.

[Full text links] Google Scholar(26) Scopus(11)

22. Fabri GMC, Siqueira SRDT, Simione $C$, et al. Refractory craniofacial pain: is there a role of periodontal disease as a comorbidity? Arq Neuropsiquiatr. 2009;67(2B):474-479. doi:10.1590/S0004-282X2009000300018.

[Full text links] [PubMed] Google Scholar(13) Scopus(5)

23. Leketas M, Šaferis V, Kubilius R, et al. Oral Behaviors and parafunctions: comparison of temporomandibular dysfunction patients and controls. J Craniofac Surg. 2017;28(8):1933-1938. doi:10.1097/SCS.0000000000003945.

[Full text links] [PubMed] Google Scholar(0) Scopus(0)

24. van der Meulen MJ, Lobbezoo F, et al. Validity of the ora behaviours checklist: correlations between OBC scores and intensity of facial pain. J Oral Rehabil. 2014;41(2):115-121. doi:10.1111/joor.12114.

[Full text links] [PubMed] Google Scholar(15) Scopus(8)

25. Ohrbach R, Markiewicz MR, McCall JWD. Waking-state oral parafunctional behaviors: specificity and validity as assessed by electromyography. Eur J Oral Sci. 2008;116(5):438-444. doi:10.1111/j.1600-0722.2008.00560.x.

[Full text links] [PubMed] Google Scholar(48) Scopus(34)

26. Brandini DA, Benson J, Nicholas MK, et al. Chewing in temporomandibular disorder patients: an exploratory study of an association with some psychological variables. J Orofac Pain 2011;25(1):56-67.

[Full text links] [PubMed] Google Scholar(43) Scopus(25)

27. Ikebe K, Hazeyama T, Iwase $K$, et al. Association of symptomless TMJ sounds with occlusal force and masticatory performance in older adults. J Oral Rehabil. 2008;35(5):317-323. doi:10.1111/ j.1365-2842.2007.01841.x

[Full text links][PubMed]Google Scholar(17) Scopus(8)

28. Furuta M, Komiya-Nonaka M, Akifusa S, et al. Interrelationship of oral health status, swallowing function, nutritional status, and cognitive ability with activities of daily living in Japanese elderly people receiving home care services due to physical disabilities. Community Dent Oral Epidemiol. 2012;41(2):173181. doi:10.1111/cdoe.12000.

[Full text links] [PubMed] Google Scholar(88) Scopus(48)

29. Durham J, Touger-Decker R, Nixdorf DR, et al. Oro-facial pain and nutrition: a forgotten relationship? J Oral Rehabil. 2014:42(1):7580. doi:10.1111/joor.12226.

[Full text links] [PubMed] Google Scholar(3) Scopus(2)
Minh Son NGUYEN

Danang University of Medical Technology and Pharmacy 99 Hung Vuong, Danang, Vietnam

Dr. Minh Son Nguyen completed dental curriculum at the Hue University of Medicine and Pharmacy, Vietnam (2001-2007). He has been the lecturer of the Danang University of Medical Technology and Pharmacy Vietnam since 2008 and appointed as the Head of the Department of Prosthodontics in 2014. More than ten articles were published in international peer-reviewed journals, four manuscripts have been submitted for publication, and fourteen abstracts were presented at international conferences, all of which are his scientific achievements during the period of the Doctoral curriculum at the University of Tartu, Estonia (2014-2018). His research interest is related to prosthodontics, community dental health, geriatric dentistry, occlusion, orofacial pain, and temporomandibular disorders. 


\section{Questions}

\section{What is true for temporomandibular disorders (TMD)?}

口a. TMD mainly cause parafunctional behaviors;

b. The most prevalent orofacial pain is from TMD;

ac. It only affects temporomandibular joint;

$\square \mathrm{d}$. TMD signs tend to increase with aging.

\section{The Diagnostic Criteria for Temporomandibular Disorders (DC/TMD) axis II is} used to evaluate:

口a. Clinical signs of temporomandibular disorders:

b. Quality of life related to temporomandibular disorders;

c. Psychological domains and oral function;

$\square$ d. The balance of occlusion.

\section{Which is not considered as oral parafunction:}

a. Limited mouth opening;

b. Bruxism;

ac. Clenching;

$\square$ d. Unilateral chewing habit.

\section{Prevalence of edentulousness among TMD population is:}

ㅁa. $0-5 \%$.

b. $11-35 \%$;

ac. $51-70 \%$;

ad. Over $80 \%$.

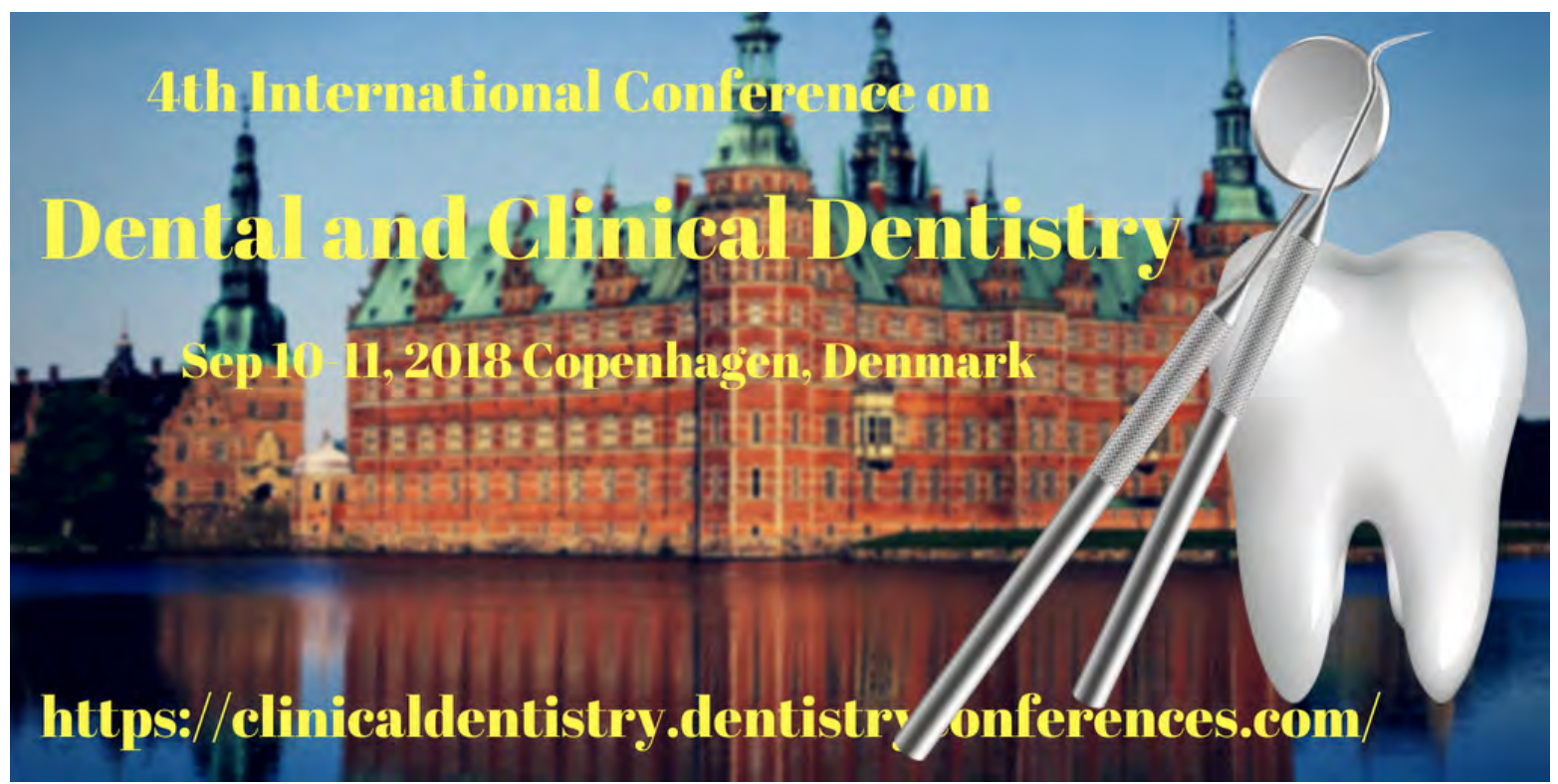

https://clinicaldentistry.dentistryconferences.com/ 


\section{EOS 2018-94 ${ }^{\text {th }}$ Congress of the European Orthodontic Society}

Date: 17 - 21 June 2018

Location: Edinburgh, UK

Event types: Conference, Exhibition, Workshops

Visit event website: http://www.eos2018.com/

\section{Europerio 9 Amsterdam 2018}

Date: 20 - 23 June 2018

Location: Amsterdam, Netherlands

Event types: Conference, Exhibition, Workshops

Visit event website: http://www.efp.org/europerio9/

programme/registration.html

\section{$23^{\text {rd }}$ Euro Congress on Dental Health and Technology}

Date: 21 - 22 June 2018

Location: Oslo, Norway

Event types: Conference, Exhibition, Workshops

Visit event website: https:/www.eventbrite.com/e/23rd-

euro-congress-on-dental-health-and-technology-cse-as-

tickets-45829286630

\section{$31^{\text {st }}$ International Conference on Dental Science \&Advanced Dentistry}

Date: 25 - 26 June 2018

Location:Vancouver, Canada

Event types: Conference, Exhibition

Visit event website: https://advancedentistry.dentalcongress. com/scientific-program

\section{Roots Summit Berlin 2018}

Date: 28 June - 01 July 2018

Location: Berlin, Germany

Event types: Conference, Exhibition, Workshops

Visit event website: https://www.roots-summit.com/program/

\section{General Practice Symposium}

Date: 29 - 30 June 2018

Location: Lyon, France

Event types: Conference, Exhibition, Workshops

Visit event website: https://www.congres.clinic-all.fr/english

\section{$23^{\text {rd }}$ Intemational Conference on Dentistry and Dental Materials}

Date: 19 - 20 July 2018

Location: Rome, Italy

Event types: Conference, Exhibition, Workshops

Visit event website: https://dentalmaterials.

dentistryconferences.com/scientific-program

\section{$5^{\text {th }}$ Annual Summit on American Dental Science and \\ Education}

Date: 20 - 21 July 2018

Location: Atlanta, GA, USA

Event types: Conference, Exhibition

Visit event website: https://americandentaledu.

conferenceseries.com/scientific-program

\section{$32^{\text {nd }}$ Asia Pacific Dental and Oral Health Congress}

Date: 23 - 24 July 2018

Location: Sydney, Australia

Event types: Conference, Exhibition, Workshops

Visit event website: https://www.dentalcongress.com/asiapacific/scientific-program

$33^{\text {rd }}$ International Conference on Dental and Oral Health Date: 13 - 14 August 2018

Location: Dubai, UAE

Event types: Conference, Exhibition, Workshops

Visit event website: https://dentalmanagement.dentalcongress. com/scientific-program

\section{World Dental Implants and Orthodontics Congress}

Date: 17 - 18 August 2018

Location:Tokyo, Japan

Event types: Conference, Exhibition, Workshops

Visit event website: https://orthodontics.conferenceseries.com/ scientific-program

\section{Annual Congress on Endodontics and Prosthodontics}

Date: 17 - 18 August 2018

Location:Tokyo, Japan

Event types: Conference, Exhibition, Workshops

Visit event website: https://endodontics.conferenceseries.com/ scientific-program

\section{The 20 ${ }^{\text {th }}$ CSA Annual Meeting \& 2018 China Dental Show}

Date: 29 August - 01 September 2018

Location: Shanghai, China

Event types: Conference, Exhibition, Workshops

Visit event website: http://www.chinadentalshow.com/

cdsabouten/index.htm

\section{SSP-SSIO Congress 2018}

Date: 31 August - 01 September 2018

Location: Bern, Swiss

Event types: Conference, Exhibition, Workshops

Visit event website: https://together18.ch/\#section-agenda

\section{2 ${ }^{\text {nd }}$ Annual World Dentistry Summit}

Date: 31 August - 01 September 2018

Location: Boston, MA, USA

Event types: Conference, Exhibition, Workshops

Visit event website: http://americandental.conferenceseries.

com

\section{FDI 2018 - The World Dental Federation 2018}

Date: 05 - 08 September 2018

Location: Buenos Aires, Argentina

Event types: Conference, Exhibition, Workshops

Visit event website: http://fdicongress2018.org/ 
Canadian Association of Orthodontists Annual Session 2018

Date: 06 - 08 September 2018

Location: Vancouver, BC, Canada

Event types: Conference, Exhibition, Workshops

Visit event website: https://cao-aco.org/contact/

$3^{\text {th }}$ Asia Pacific Dental and Oral Care Congress

Date: 07 - 08 September 2018

Location: Auckland, New Zealand

Event types: Conference, Exhibition, Workshops

Visit event website: https://dentalcare.conferenceseries.com/

scientific-program $4^{\text {th }}$ International Conference on Dental and Clinical Dentistry Date: 10-11 September 2018

Location: Copenhagen, Denmark

Event types: Conference, Exhibition, Workshops

Visit event website: https://clinicaldentistry.

dentistryconferences.com/scientific-program

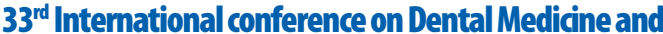 Surgery}

Date: 10-11 September, 2018

Location: Singapore, Singapore

Event types: Conference, Exhibition, Workshops

Visit event website: https://oralsurgery.conferenceseries.com/ scientific-program

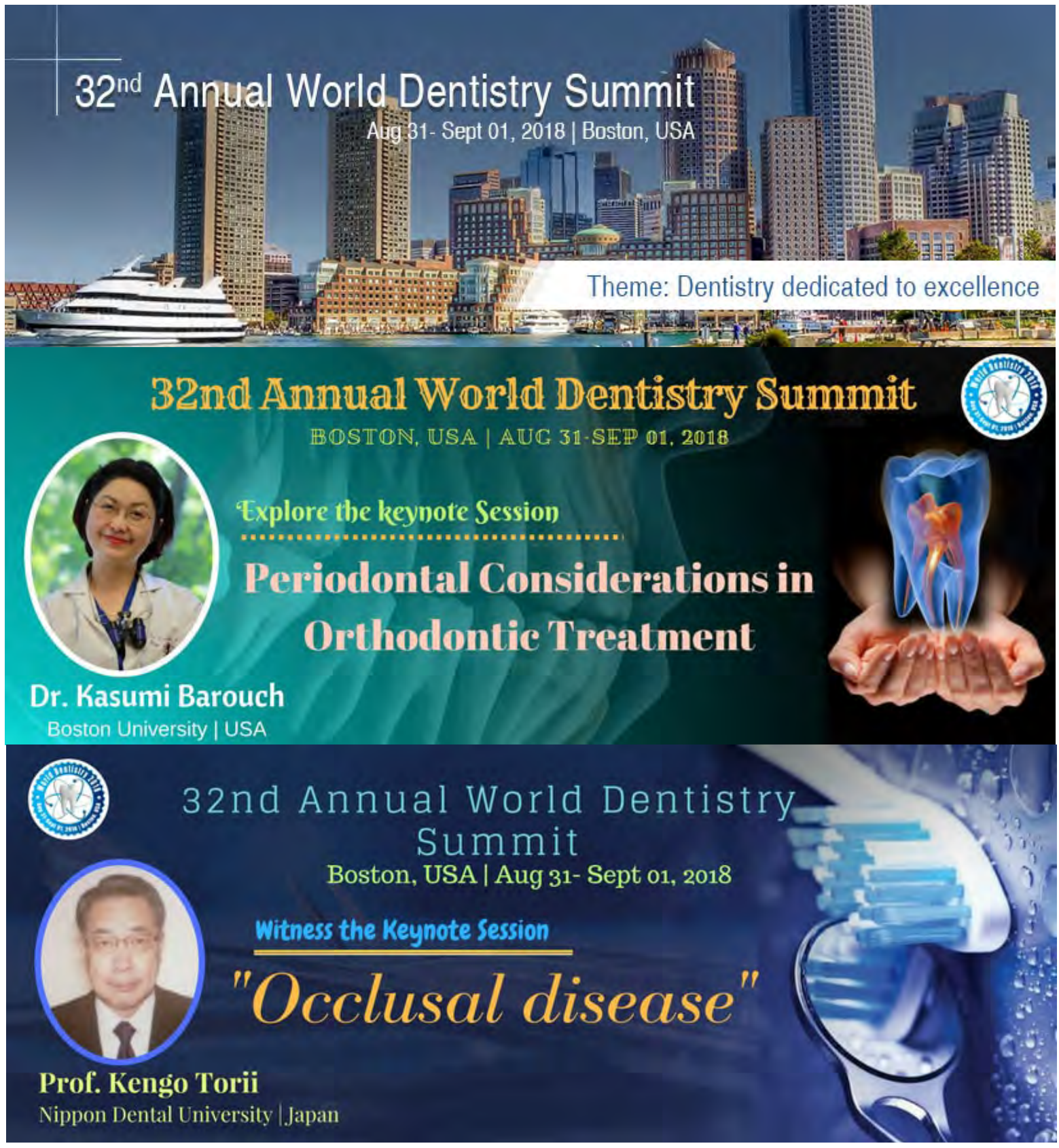

https://americandental.conferenceseries.com/symposium.php 


\section{The way to reach the gold standard in dental surgery: Integrated Surgical Studio Design KYRI}

When I went to the Cologne Dental Exhibition, IDS 2017, I still had in mind the surgery room at the University Dentistry Hospital where I had had my practical training in oral surgery. WHO estimates that dental treatments cause significant stress in over $30 \%$ of patients. Their being afraid of the dentist and of the pain caused is much higher in the case of oral surgery or oral implantology.

While at the IDS 2017, out of the many dental pieces of equipment we noticed at the Tecno-Gaz S.p.A stand (I43038 Sala Baganza (PR), Italy), the Integrated Surgical Studio Design called KYRI was the most innovative. It is the concept of dental ergonomics for the dental surgery room, a new way of conceiving space, which provides:

1. Professionalism: provides the best possible working way that allows you to achieve true potential.

2. Modularity: organizes space according to personal needs, clinical needs and the patient's perception.

3. Versatility: space can adapt, develop, change according to your ideas and opportunities.

4. Welcoming: your space conveys positivity, cleanliness and visual appeal, and at the right time it can turn into a surgical room.

5. Integrated: space conceived and organized according to labor ergonomics, ensuring efficiency and productivity.

6. Uniqueness: you are different from your colleagues, work differently and have different habits even if you perform similar treatments.

Here are the components of the Integrated Surgical Studio KYRI Design:

- KYRI UNIT for long-term dental and surgical treatment, a perfect combination of an operating table and a dental chair, with four engines that provide 5-axis movements, and a 3D motion orbital headrest. It allows a level of flexibility that cannot be achieved in a common dental chair. It has an advanced electronic position control system controlled by a wireless pedal. It is equipped with pressure sensors to adapt via the Human Pressure Spot Compensation System to the patient's anatomical structure.

- $\quad$ KYRI CART with maximum instrumental freedom through 5 slots that allows the dentist to perform from regular surgery to implants, equipped with two powerful micromotors, one of which is for implantology with a peristaltic pump and torque adjustment. All controls are placed under the membrane, allowing fast cleaning and hygiene. It has a separate power supply that ensures total operating autonomy and allows the continuous use of disinfectant solutions or special instrument liquids.

- $\quad$ KYRI WATER UNIT turns the dental surgery into a multifunctional integrated one allowing cleaning and control of the surgical suction thanks to the cannula support with two cannulae.

- $\quad$ KYRI DSS, a sophisticated surgical vacuum cleaner that fully meets the dental surgery requirements with reduced noise: $46.4 \mathrm{~dB}$.

The Integrated Surgical Studio Design KYRI also includes some smart trolleys designed for the needs of modern dental surgery and professional work chairs.

In Italy, I had the opportunity to work in a clinic equipped with an Integrated Surgical Studio Design KYRI. Allow me to share the impact and the impression I have been left with:

- $\quad$ non-traumatic visual impact helps the patient overcome the classic fear of dental surgery.

- maximum harmony and perception of the highest quality.

- $\quad$ maximum flexibility for any treatment

Let me assure you that your patients and your clinical team deserve to have the satisfaction of working in a unique technological environment.

Florin - Eugen Constantinescu

DMD, PhD Student

Editorial Director, Product News

DOI: 10.25241/stomaeduj.2018.5(2).prodnews.1

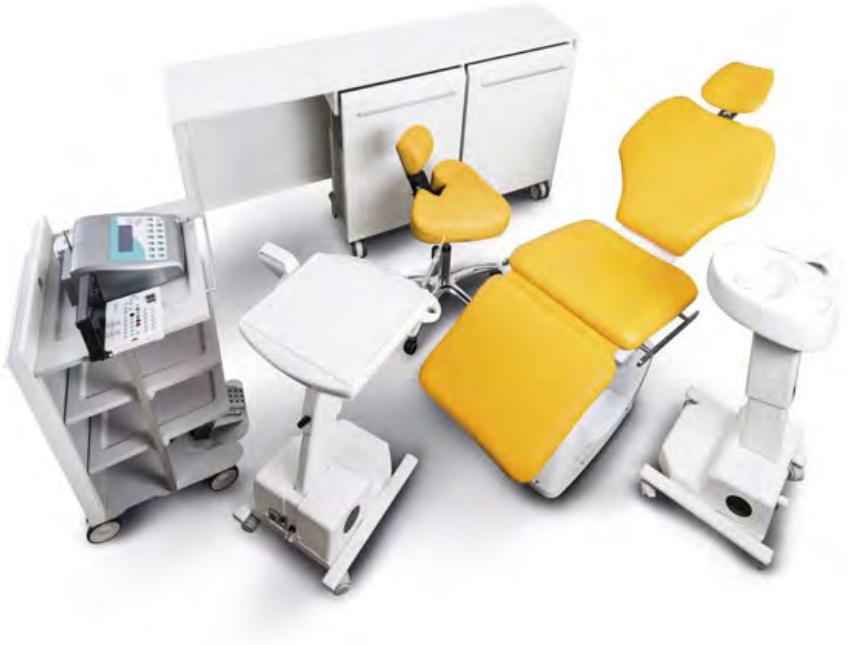

The Integrated Surgical Studio Design KYR

(Tecno-Gaz S.p.A., I-43038 Sala Baganza (PR), Italy)

http://www.tecnogaz.com/en/Surgical-furniture/integrated-surgical-studio-design.aspx 


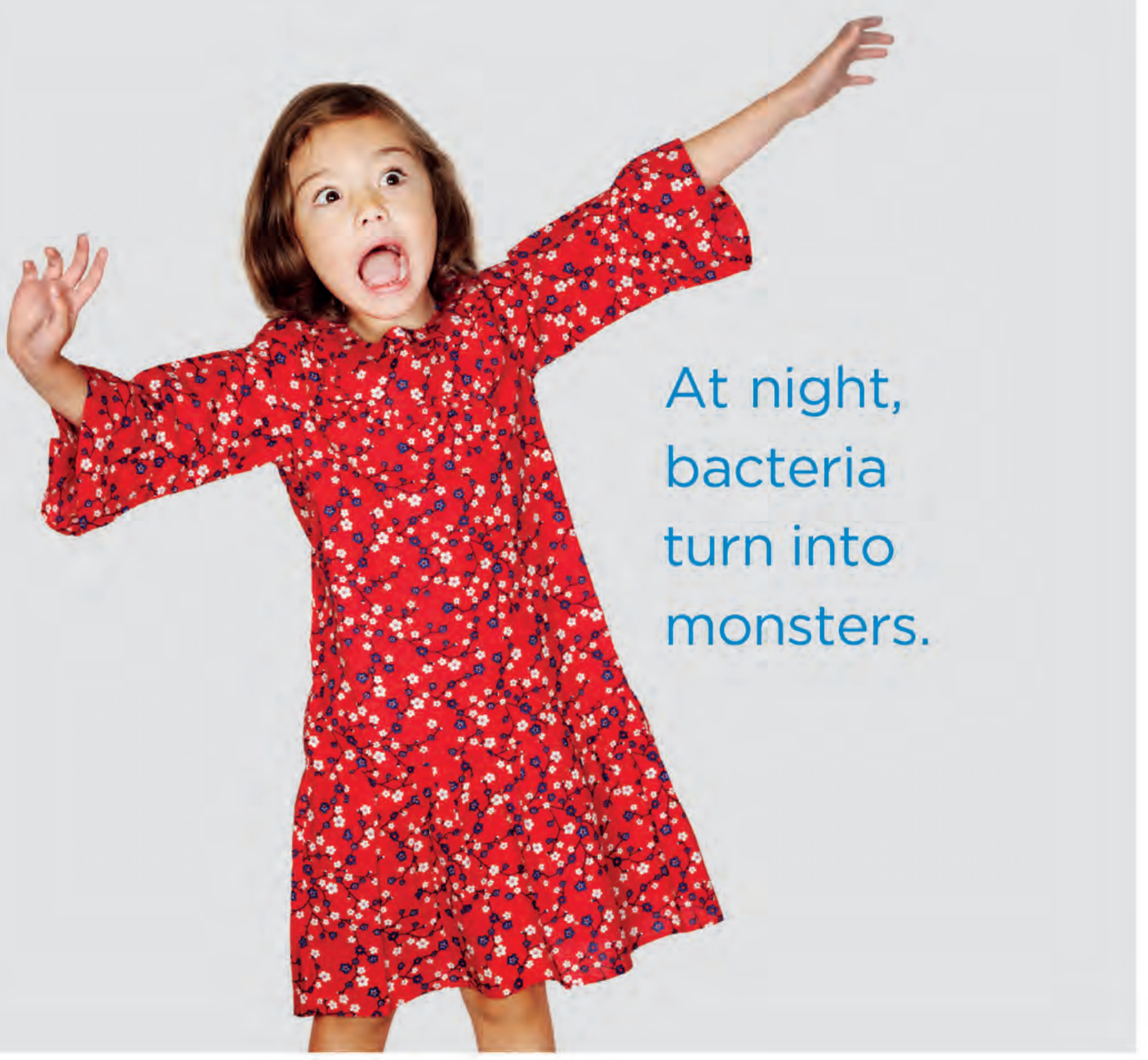

\section{We care. We protect you.}

... and there is a bit of truth in every cliché.

Over the course of a day, a total of eight billion bacteria form in your treatment center. They might not turn into monsters at night, but should not be underestimated. That means taking infection prevention seriously. And that's why an automatic cleaning system prevents infections and can save you up to 2.5 hours of your time per month.

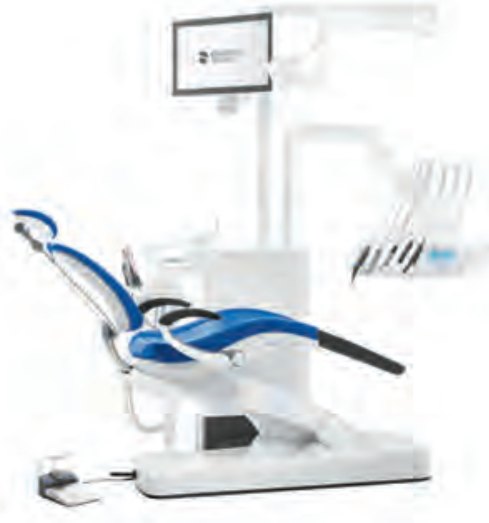




\section{Color in Dentistry A Clinical Guide to Predictable Esthetics}

Authors: Stephen J. Chu / Rade D. Paravina / Irena Sailer / Adam J. Mieleszko Publisher: Quintessence Publishing, Germany

Language: English

ISBN: 978-0-86715-745-1

Edition: $1 / \mathrm{e}$

Publish Year: 2017

Pages: 256, illustrated

Price: $108.00 €$

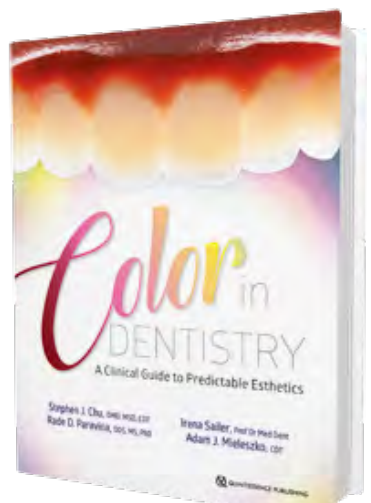

\section{Florin-Eugen}

Constantinescu

DMD, PhD Student

Holistic Dental \& Medical Institute of

Bucharest-ROPOSTURO, Bucharest, Romania

e-mail:

dr.florin.constantinescu@gmail.com

Choosing the color in dentistry is a challenge for every practitioner. In time, a number of authors have dealt with this issue

The book entitled "Color in Dentistry. A Clinical Guide to Predictable Esthetics" brings new insights into the subject, the materials used and the new technologies to which practitioners have access. It is an update on color education and training. The book is divided into twelve chapters. After the presentation of color education and training, the physics of color, color perception and color mixing are developed to facilitate their understanding. Chapter three presents data on the elements that affect the choice of the optimal color: illumination, clinical lighting challenges, contrast effects and optical illusions, viewer-associated effects, and other appearance attributes. The importance of evaluating the optical properties of teeth (white), gum (pink) and skin are developed in the chapter called The United Colors of Dentistry. The fifth chapter discusses conventional visual matching, shade guides, shade matching factors, and shade matching protocol. Chapter six talks about the development of technology-based shade systems, color measurement, workflow and protocol. The following chapters introduce camera system equipment, principle-based concepts, image management and color communication to better understand digital photography. The material selection for the final esthetic outcome in dentistry is developed in Chapter 8 . The following chapter presents color-matching strategies for discolored non-vital and vital tooth stumps as well and gingival, implant abutment and periimplant soft tissue. The following chapters describe in depth the esthetics with pink restorative materials and steps to a successful shade match. The last chapter sums up the presentation of 24 clinical cases from the simplest, such as shade monitoring for tooth whitening cases to the most complex as implant-retained silicone auricular prostheses. The book contains as well an appendix, an index, is richly illustrated with 890 images and helps facilitate communication between dentists and technicians.

By reading "Color in Dentistry" we understand the best protocol to follow in choosing the color for any clinical situation we want to restore as best we can.

DOI: 10.25241/stomaeduj.2018.5(2).bookreview.1

\section{Shortcuts in Esthetic Dentistry}

Author: Ronaldo Hirata

Publisher: Quintessence Publishing, Germany

Language: English

ISBN: 978-85-7889-111-4

Edition: 2/e

Publish Year: 2017

Pages: 686, illustrated

Price: $240.00 €$

\section{SHORTCUTS}

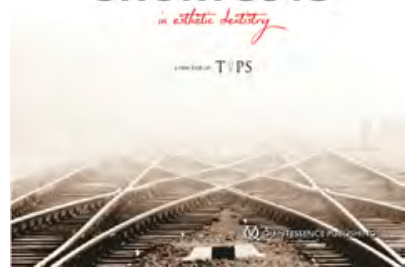

In the five chapters of the book entitled "Shortcuts in Esthetic Dentistry. A new look on TIPS", Dr. Ronaldo Hirata reveals simple and practical solutions to common questions and problems in order to cope with the difficulties of aesthetic restorative dentistry. Each chapter is based on a series of questions the reader can ask and the author answers in detail on the basis of the latest scientific evidence and eloquent case presentations.

The questions raised by dental bleaching, such as concepts of bleaching substances are given pertinent answers and edifying cases are presented. The second chapter covers composite resins, longevity and maintenance of composite restorations and adhesive systems to perform operative and restorative dentistry. Questions about esthetic restorations and previous makeovers, why and how, a simpler way and where science is going are provided with specific rules for each clinical situation in the next chapter.

The last two chapters address the topic of esthetic restorations and sculpture in posterior teeth and inlays and onlays, such as indirect partial restorations in composites and ceramics where they give the most relevant examples and many useful insights.

Throughout the book, the author makes a presentation of the steps of the simplified procedures, providing the reader with advice on how to implement the concepts described.

Clinicians will frequently return to "Shortcuts in Esthetic Dentistry", a book that is exceptionally illustrated by the 2,800 figures, because they find effective solutions for their clinical practice covering the most common problems raised by contemporary aesthetic dentistry.

DOI: 10.25241/stomaeduj.2018.5(2).bookreview.2

\section{Iulia}

Ciolachi

$\mathrm{DMD}$

Holistic Dental \& Medical Institute of

Bucharest-ROPOSTURO, Bucharest Romania

e-mail:driuliaciolachi@yahoo.ro 


\section{Orthodontic Therapy}

Fundamental Treatment Concepts

DDS, PhD

Romania

e-mail:

Authors: Herbert F. Wolf / Andrea Wichelhaus

Publisher: Georg Thieme Verlag KG, Germany

Language: English

ISBN: 978-3-13-200851-9

Edition: 1/e

Publish Year: 2018

Pages: 580, illustrated

Price: $229.00 €$

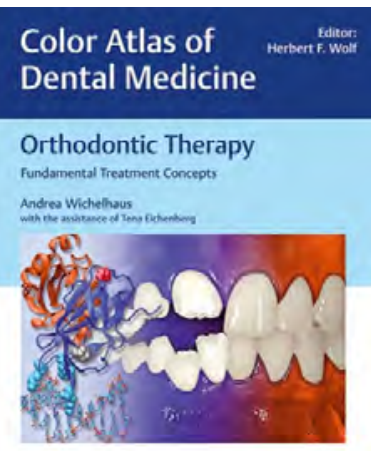

QThieme

In the series Color Atlas of Dental Medicine Drs Herbert F. Wolf and Andrea Wichelhaus present the book entitled Orthodontic Therapy discussing the diagnosis, prevention and treatment of dental and maxillary anomalies, extensively illustrated. This book is divided into 7 chapters. The fundamental problems in orthodontics, namely biomechanical factors, extrusion, intrusion, rotation, torque, force and resorption relationship, orthodontic dental movement, hereditary anomalies, genetics, mechanobiology and orthodontic side effects are the subject of the first chapter. Treatment of lateral and anterior crossbite in primary and early mixed dentition, crossbite in late mixed dentition and in adults, and treatment of laterognathia in adults, definition and therapy of deep bite in mixed and permanent dentition, orthodontic mechanics for bite raising and orthognathic surgery and deep bite are developed in Chapter 2 and 3. rthodontic problems of open bite, treatment of open bite in the primary, mixed and permanent dentition, treatment of open bite and Angle Class I, II and III, biomechanics, extraction, molar intrusion, and orthognathic surgery of open bite are described along chapter 4. Chapters 5 and 6 analyze the orthodontic treatment of Class II and III malocclusions. The chapters approach orthodontic problems, cause and differential diagnosis, treatment in the late mixed and permanent dentition, adult treatment and stability parameters. Extraction therapy is the theme of the last chapter, in which we are acquainted with extraction therapy in the early mixed and permanent dentition and in Class I, II and III anomalies and stability parameters. The book is accompanied by an index. This book is the result of many years of clinical research and practical activity and reflects the therapeutic concept of orthodontic treatment of the universities in Ulm, Basel and Munich. The book is an update of the basic principles of biology, mechanics, and biomechanics using the latest materials and techniques. It provides the reader with concepts of treatment from functional orthodontics to the integration of retained teeth, anchorage options, finishing and retention and aesthetic alternatives. The therapeutic methods are thoroughly presented and illustrated eloquently and extensively through almost 4,000 images. The book addresses experienced orthodontists and trainees as a guide, which should be present in any library.

DOI: 10.25241/stomaeduj.2018.5(2).bookreview.3

\section{The Workbook}

Florin-Eugen Constantinescu

DMD, PhDStudent Holistic Dental \& Medical Institute of Bucharest-ROPOSTURO, Bucharest,

Romania

e-mail:
Author: Carlos A. Ayala Paz

Publisher: Quintessence Publishing, Germany

Language: English

ISBN: 978-85-7889-093-3

Edition: $1 / \mathrm{e}$

Publish Year: 2017

Pages: 252, illustrated

Price: $200.00 €$

The "Workbook" by Dr. Carlos A. Ayala Paz, one of the most renowned dental photographers, makes a plea for the current clinical photography to become an artistic act.

First, the author gives us the common terms that he uses during the ten chapters. After describing the possibilities of flashlightes and those of shaping the light there follows an analysis of the modifiers, hard and soft light, and beauty dish, hard and soft setup. In the following chapters, the author thoroughly comments on the criteria how to obtain the best image of the face, eyes and lips through illumination. The technical conditions for lighting for teeth, macro and micro for Canon and Nikon cameras are amply presented and illustrated. A special presentation is devoted to illuminating the gingiva.

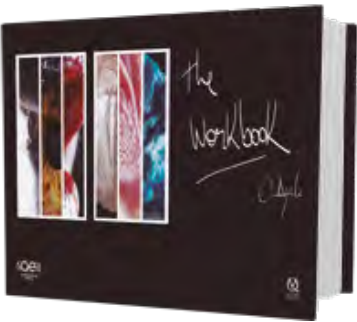

The last chapter presents details for getting the best photos in the dental laboratory. The author fully succeeds in pursuing the goal of simplifying techniques and reducing equipment for macro and micro photography to obtain a more natural image of the teeth and mouth. The book addresses both dental practitioners and dental technicians providing technical and practical support to make their own activity visible in the best conditions. 


\section{Implant Therapy in the Esthetic Zone Current Treatment Modalities and Materials for Single-tooth Replacements}

Authors: Daniel Buser / Stephen Chen / Daniel Wismeijer (Ed.)

Publisher: Quintessence Publishing, Germany

Language: English

ISBN: 978-3-86867-343-2

Edition: $1 / \mathrm{e}$

Publish Year: 2017

Pages: 444, illustrated

Price: $86.00 €$

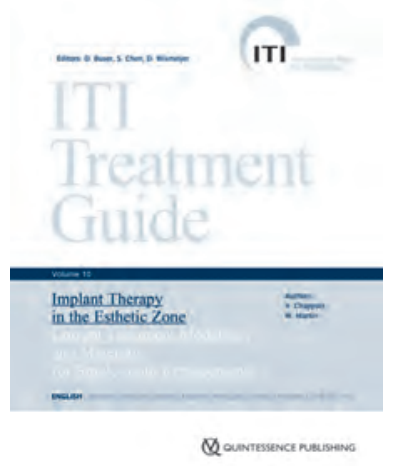

\section{Florin-Eugen Constantinescu}

DMD, PhD Student

Holistic Dental \& Medical Institute of Bucharest-ROPOSTURO, Bucharest Romania e-mail:

dr.florin.constantinescu@gmail.com

In current practice dental implants are used more and more frequently to replace missing teeth, whose therapeutic success can be ensured by applying treatment methods that meet the highest clinical standards.

The ITI Treatment Guide series written by well-known clinicians and practitioners is a compendium of evidence-based implant techniques and procedures for everyday practice.

Volume 10 of the ITI Treatment Guide series entitled "Implant Therapy in the Esthetic Zone" edited by Dr. Daniel Buser, Professor and Chair at the Department of Oral Surgery and Stomatology at the University of Bern, Dr. Stephen Chen, Clinical Associate Professor at the School of Dentistry at the University of Melbourne and Dr. Daniel Wismeijer, Professor of Oral Implantology and Prosthetic Dentistry at the Academic Center for Dentistry of Amsterdam (ACTA), presents current treatment modalities and materials for single tooth replacements. The book is divided in ten chapters. Following the discussion on the topic approached in the introductory chapter, the second chapter presents the statements and recommendations of the 5th ITI Consensus Conference. A protocol for evaluating and planning treatment for patients whose aesthetic requirements demand the replacement of a single tooth with a dental implant is presented in the following chapter. Next, we are told how to select biomaterials for implantation procedures and which are the surgical considerations for optimal aesthetic results in different surgical situations encountered in the aesthetic area. The sixth chapter deals with the prosthetic management for optimal esthetic outcomes starting from the clinical examination of the planned implant site before and after placement using temporary prostheses, communication with the dental laboratory, abutment design, restorative material selection, and delivery. A consistent chapter is allocated to clinical case presentations developing the restorations made in various surgical situations encountered in the aesthetic area. In the eighth chapter the authors honestly present the possible esthetic complications they faced. The penultimate chapter mentions the conclusions reached by the authors in the treatment of patients whose aesthetic requirements demanded the replacement of a single tooth with a dental implant.

This volume, based on the latest references in the specialty literature gathered in the last chapter, is consistently enriched with over 1380 compelling quality illustrations.

This volume of the ITI Treatment Guide series provides the reader with an evidence-based approach to replace teeth in the aesthetic area with dental implants, from consultation to follow-up, to the choice of biomaterials and surgical procedures leading to an optimal esthetic treatment outcome according to the most advanced possibilities offered by oral implantology today.

DOI: 10.25241/stomaeduj.2018.5(2).bookreview.5

The Books Review is drafted in the reviewer's sole wording and illustrates his opinions.

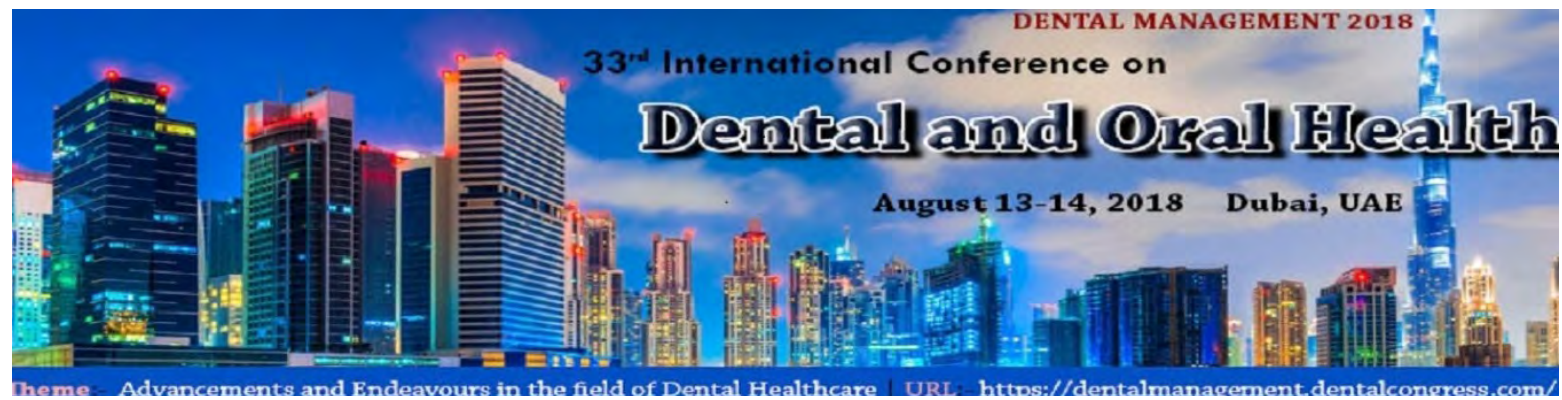

$\underline{\text { https://dentalmanagement.dentalcongress.com }}$ 


\section{Submitting the Article}

The journal publishes articles written in English. All articles will be accompanied by the signed copyright form which can be returned by e-mail, fax (as scanned documents). All the responsibility for the originality of the material sent belongs to the author(s) alone. Each article will be evaluated by the peer-review committee composed of two independent peer-reviewers, in a blinded fashion, according to the peer-review protocol. All articles will be sent to the editor-in-chief at the following e-mail address: stomatology.edu@gmail.com. The articles will also be sent at the e-mail address of the co-editors-in-chief from your area (Americas, Europe, Asia-Pacific).

\section{Articles sent for publishing}

Stomatology Edu Journal (Stoma Edu J) publishes:

- original articles;

- reviews;

- case reports;

- consensus declaration coming from an association or from a group of specialists;

- letters to the editor.

All articles must be up to 3,000 and 5,000 words for metaanalysis (the word count is for the manuscript text only). Letters to the editor must not exceed 400 words of text and have no more than 3 authors. Letters to the editor can be related to an article already published in the journal or it can represent original scientific contributions or events news/presentations etc. of interest for the reader. If, following the peer-review process, the article requires only minor changes (language changes etc.) then the manuscript is accepted for publication in its revised form without further input from the author. In case the changes are considered more important (scientific errors or an incorrect use of the language that can affect the quality of the scientific message) the author will be contacted by a member of the editorial committee and it will only be published after he approves the changes considered necessary by the peer reviewers. In some cases, based on the written approval of the author(s), the peer-reviewers and the chief-editor or the publisher the article may be published alongside the comments of the reviewer(s).

\section{Authors}

Each author must be able to prove his active participation in the study by contributing to the concept, protocol, data gathering or analysis, their interpretation or by critically revising the manuscript. Any other persons who have contributed to the paper, like study participants or colleagues, will be mentioned in the "Contribution" section.

\section{Permissions and Ethics}

For citations, tables, figures etc. which are not original, these must be accompanied by the written permission for their use and the full reference must be provided. Photographs of identifiable persons must be sent alongside the written permission of the person(s) and all regions that may allow the identification of the subject must be covered.

The author must have obtained, for all studies including human subjects, the permission of the subjects to be part of the study whilst keeping their anonymity. By sending the article, the author declares that he obtained this permission from all his subjects. All studies must respect the Helsinki Declaration (1975).

For human and animal studies, the authors must have obtained the approval of the ethics committee from the University/Institute/etc. where the study was done.

\section{Writing the article}

The article must be written in conformity with the general recommendations of the International Committee of Medical Journal Editors. http://www.icmje.org/icmjerecommendations.pdf

The Stomatology Edu Journal (Stoma Edu J) uses doubleblind review, which means that both the reviewer and author name(s) are not allowed to be revealed to one another for a manuscript under review. The identities of the authors are concealed from the reviewers, and vice versa.

To facilitate this, please include the following separately: Title page (with author details): This should include the title, authors' names and affiliations, and a complete address for the corresponding author including an e-mail address.

Blinded manuscript (no author details): The main body of the paper (including the references, figures, tables and any Acknowledgements) should not include any identifying information, such as the authors' names or affiliations.

The articles must be sent either as a Microsoft Word 2000 document (*.doc) or as a Microsoft Word 2003 document $\left({ }^{*}\right.$.docx).

The article will be written using Times New Roman font, size 12 for the characters with one and half (1 $1 / 2$ ) spaces between paragraphs. The manuscript must be sent in its final form. The pages will be numbered with the manuscript containing the following sections: title, authors, abstract, keywords, the text of article, contributions, acknowledgments, references, the figures and the tables legend.

Please also check the Author's Guidelines for the Abstract. A. The title of the manuscript will have a maximum of 100 characters without spaces, written in title case, centered capitals, and in 12 point bold Times New Roman font at the top of page. Abbreviations should be avoided within the title.

B. The author(s) will send their full name(s) and surname(s), the highest academic position, their full titles and their affiliations. All names are listed together and separated by commas. Provide exact and correct author names as these will be indexed in official archives. Affiliations should be keyed to the author's name with superscript numbers and be listed as follows: Laboratory, Department, Institute, Organization, City, State abbreviation (USA, Canada, Australia), and Country (without detailed address information such as city zip codes or street names).

The correspondent author will send his/her full name and surname, the highest academic position, his/her full title, his/her affiliation, his/her institution address, his/ her telephone, fax and e-mail. The authors will send this information in the same format as that in the published articles.

\section{The Structured Abstract}

The abstract can have a maximum of 250 words. After the abstract, the author(s) must mention a maximum of 5 keywords. Keywords must be selected from Medline Mesh.

The abstract for Original Scientific Articles should be no more than 250 words using the following structure: Introduction; Methodology; Results; Conclusion.

The abstract for Review Articles should be no more than 250 words with the authors covering all the following information regarding the subject presented under the following subheadings: Background, Objective, Data Sources, Study Selection, Data Extraction, Data Synthesis. The abstract for Case Reports should be no more than 250 words using the following structure: Aim, Summary and Key learning points: provide up to 5 short statements of the report. 
The abstract for Clinical Articles should be no more than 250 words using the following structure: Aim, Methodology, Results and Conclusions. Abbreviations are not accepted in the title or the abstract.

\section{The Article Text}

\section{Headings and Sub-headings}

Except for special names (e.g. GABAergic), capitalize only the first letter of headings and subheadings. Headings and subheadings need to be defined in Times New Roman, 12, bold. You may insert up to 5 heading levels into your manuscript (not more than for example: 3.2.2.1.2 Heading title).

For original articles:

Introduction - a presentation of the most important aspects in the studied domain without doing a review of the literature. The purpose of this part is to present and backup the hypothesis on which the study was based. Material and Methods - this section will include all required information so that the reader can verify the validity of the study including, but not limited to, subjects, measurements, statistics and ethics. The methods used should be discussed (why the methods have been chosen, which the limitations/advantages). A paragraph about the statistical analysis is required as well.

Results - the results of the study will be presented in a descending order of importance. An interpretation of the results will not be done in this section.

Discussion - the authors will present the way the results backup the original hypothesis, as well as the way in which the results are backed up or contradicted by the published literature. A paragraph must be dedicated to presenting the limitations of the study.

Conclusion - The conclusion presents the implications of this latest work. In addition, authors may consider discussing future plans or recommendations for future research etc.

For all other types of articles we recommend the use of a clear structure based on sections and sub-sections.

\section{E. Acknowledgments}

Acknowledge persons who have made substantive contributions to the study. Specify grant or other financial support, citing the name of the supporting organization and grant number.

\section{F. References}

- The references will be written using the Vancouver style (https://www.imperial.ac.uk/media/imperial-college/ administration-and-support-services/library/public/ vancouver.pdf). All references that are identified with DOI (Digital Object Identifier) must be mentioned.

- For each reference use active links to the full text, free PMC article, PubMed, Google Scholar, and Scopus pages, were they exist, including the number of citations for the last two databases:

Singbartl G. Pre-operative autologous blood donation: clinical parameters and efficacy. Blood Transfus. 2011;9(1):10-18. doi:10.2450/2010.0088-10.

[Full text links] [Free PMC Article] [PubMed] Google Scholar(39) Scopus(23)

- The references will be numbered, in the order they appear in the text, in square brackets, as such: [3], [5,7-9]. - All sources found in the text must be present in the bibliography and all the papers mentioned in the bibliography must appear in the text. For references with more than 5 authors, list the first 3 authors followed by "et al." - Full-page ranges should be given in expanded form (e.g., 426-429, not 426-9).

- If non-English-language titles are translated into English, bracketed indication of the original language should follow the title.

- All journals will be abbreviated and italicized names of journals according to the style in PubMed; refer to the National Library of Medicine (NLM) Journals Database (http://www.ncbi.nlm.nih.gov/nlmcatalog/journals) if needed. Journal names will be abbreviated according to the List of Title Word Abbreviations

- Information obtained from sources which are not published yet, but accepted for publishing will include at the end of the reference the mention "in print" between round parentheses.

- If the cited results have not been published yet the mention will be "personal communication" written in the text of article between round parentheses.

- Only references read by the authors of the article will be cited.

- An original article will have at most 50 references, a review will have at most 100 references, a letter to the editor 5 references, whilst all other types of articles will have the minimum number of references required.

\section{Curriculum Vitae - Ultra Short version}

Please provide a brief presentation of the first author and his contribution in the field, of maximum 130 words (with a $3.5 \times 4.5 \mathrm{~cm}$ color photo).

\section{Figures, Images, Tables}

All illustrations must be numbered and cited in the text in order of appearance.

Figures and Images will be drawn professionally and sent in separate file(s) as jpeg, tiff or png files. Illustrations should preferably fill single column width $(54 \mathrm{~mm})$ after reduction although in some cases $113 \mathrm{~mm}$ (double column) and $171 \mathrm{~mm}$ (full page) widths will be accepted. See the Image quality specifications chart for details. Image files also must be cropped as close to the actual image as possible.

In the text, each figure must be represented by a number, a title and a description. The authors will indicate where should the figure be placed in the text. All images or figures must come from the author's personal collection or the author must have rights to publish the image or figure. All images must be at or above intended display size, with the following image resolutions: Line Art 800 dpi, Combination (Line Art + Halftone) 600 dpi, Halftone 300 dpi. We do not accept images or figures taken from the Internet.

The Tooth Identification System used in manuscripts must conform to the FDI International System. Units used in manuscripts must conform to the Système Internationale d'Unités (SI).

Tables will be included in the text and each table will have a number and a short description if required.

\section{Ownership Rights}

By sending the article for publication the author(s):

- take full responsibility for the scientific content of the text and for the accuracy of the send data;

- become (co)author(s) of the manuscript (all further plagiarism accusation are addressed solely to the author(s) who signed the manuscript);

- declare they are the rightful owners of the images, figures and/or information sent for publishing and that they have the permission to publish all the materials for which they do not own the intellectual property rights;

- declare that the message/content of the manuscript is not influenced in anyway by commercial interests/ previous engagements/ any sort of relations with other people or companies;

- transfer all rights for the manuscript to the Editorial Council for the Stomatology Edu Journal.

\section{Other}

Previously mentioned limitations can be ignored in special cases with the agreement of the chief-editor and/or the publisher. All published materials cannot be returned.

Not taking into consideration the recommen-dations mentioned before can lead to delay in publishing the materials or may lead to not publishing the article. 


\section{SUBSCRIPTION}

\section{I want to subscribe to Stona.edj}

- 1 year Subscription (4 issues of the journal) - 280 RON (72 Euro for foreign subscribers)

- 2 years Subscription ( 8 issues of the journal) - 540 RON (136 Euro for foreign subscribers)

- Single Issue - 80 RON (20 Euro for foreign subscribers)

Please send the filled subscription at the following e-mail: roposturo@gmail.com.

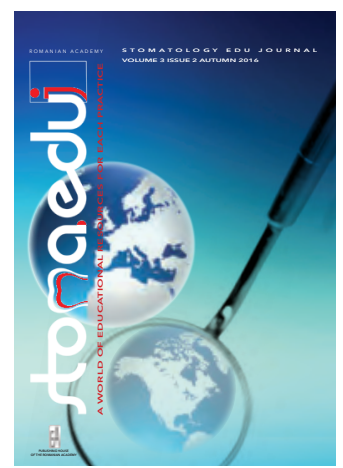

\section{PLEASE COMPLETE ALL THE SUBSCRIPTION FIELDS IN CAPITAL LETTERS!}

Name.

Surname

Mrs. $\square$ Mr. $\square$ Ms.

Home Address

City........................................ Sector Post office code............................. Mobile phone....

E-mail: Web.

Student $\square$ Resident $\square$ Specialist doctor $\square$ Primary doctor

Competence.

Institution

Activity domain: $\square$ Private $\square$ Public

Department.

Position.

Specialty Institution address

City.

Sector

Phone.

District

Post office code

.............

Web

CUI (Institution Unique Registration Code)

VAT Payer: $\square$ Yes $\square$ No

Invoice - please fill all the necessary details for invoice:

Name.

CNP (Personal Identification Number)....

Or

Institution

CUI (Institution Unique Registration Code).

Date.

After filling the subscription, please send it together with the proof of payment to:

\section{ROMANIAN ACADEMY PUBLISHING HOUSE}

13, Calea 13 Septembrie, $5^{\text {th }}$ District

RO-050711 Bucharest, Romania

Tel: +4021 31881 46, 40213188106

Fax: +402131824 44

e-mail: edacad@ear.ro

www.ear.ro

\section{S.C. MANPRES DISTRIBUTION S.R.L.}

1, Piaţa Presei Libere, Corp B 3rd floor, room 301-302, $1^{\text {st }}$ District RO-013701 Bucharest, Romania Tel/Fax: +4021 3146339 e-mail: abonamente@manpres.ro www.manpres.ro 

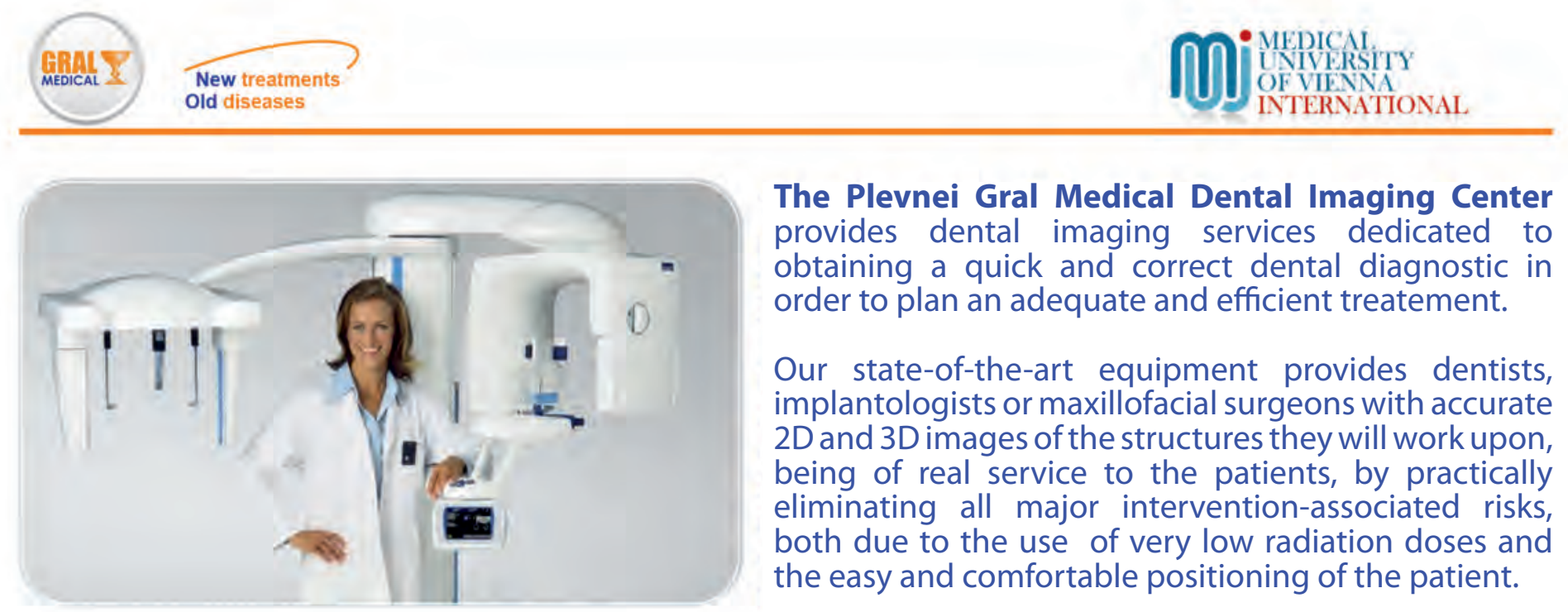

The Plevnei Gral Medical Dental Imaging Center provides dental imaging services dedicated to obtaining a quick and correct dental diagnostic in order to plan an adequate and efficient treatement.

Our state-of-the-art equipment provides dentists, implantologists or maxillofacial surgeons with accurate 2D and 3D images of the structures they will work upon, being of real service to the patients, by practically eliminating all major intervention-associated risks, both due to the use of very low radiation doses and the easy and comfortable positioning of the patient.

\section{ORTHODONTIC X-RAYS (RADIOGRAPHS)}

Profile (lateral) cephalometric views

Standard OPG (Orthopantomogram) for adults and children (magnification 1.3-1.6)

Orthodontic diagnostic photos

\section{X-RAYS (RADIOGRAPHS) FOR SPECIAL TREATMENTS}

Standard OPG (Orthopantomogram) for adults and

children (magnification 1.3-1.6)

Ortoradial orthopantogram for adults and

children (magnification 1.3-1.6)

Orthopantogram with reduced for adults and children

Combination for the same patient

(standard OPG +orthoradial+ reduced shadow)

Four-view TMJ- right to left joint

Anterior maxillary sinus panoramic radiographs

Posterior maxillary sinus panoramic radiographs

Salivary gland panoramic radiographs

Prophile (lateral) cephalometric radiographs

Orthodontic diagnostic photos

\section{D CT SCANS}

Full maxilla and mandible CT scan

Maxilla and maxillary sinus CT scan

Mandible and mandible

Mandible and mandibular canal CT scan

Partial maxillary and mandibular CT scan

TMJ CT scan

CT scan of included teeth

\section{MRI -CT}

Ortho-maxillofacial MRI

Ortho-maxillofacial CT

Examination of the throat using a special protocol for: cavum; oropharynx, oral cavity, tongue, soft palate, salivary glands, larynx and hypopharynx is conducted only at 79-91, Traian Popovici Street, $3^{\text {rd }}$ District,

RO-031422 Bucharest, ROMANIA

Tel: 021-323.00.00 | 0731-494.688
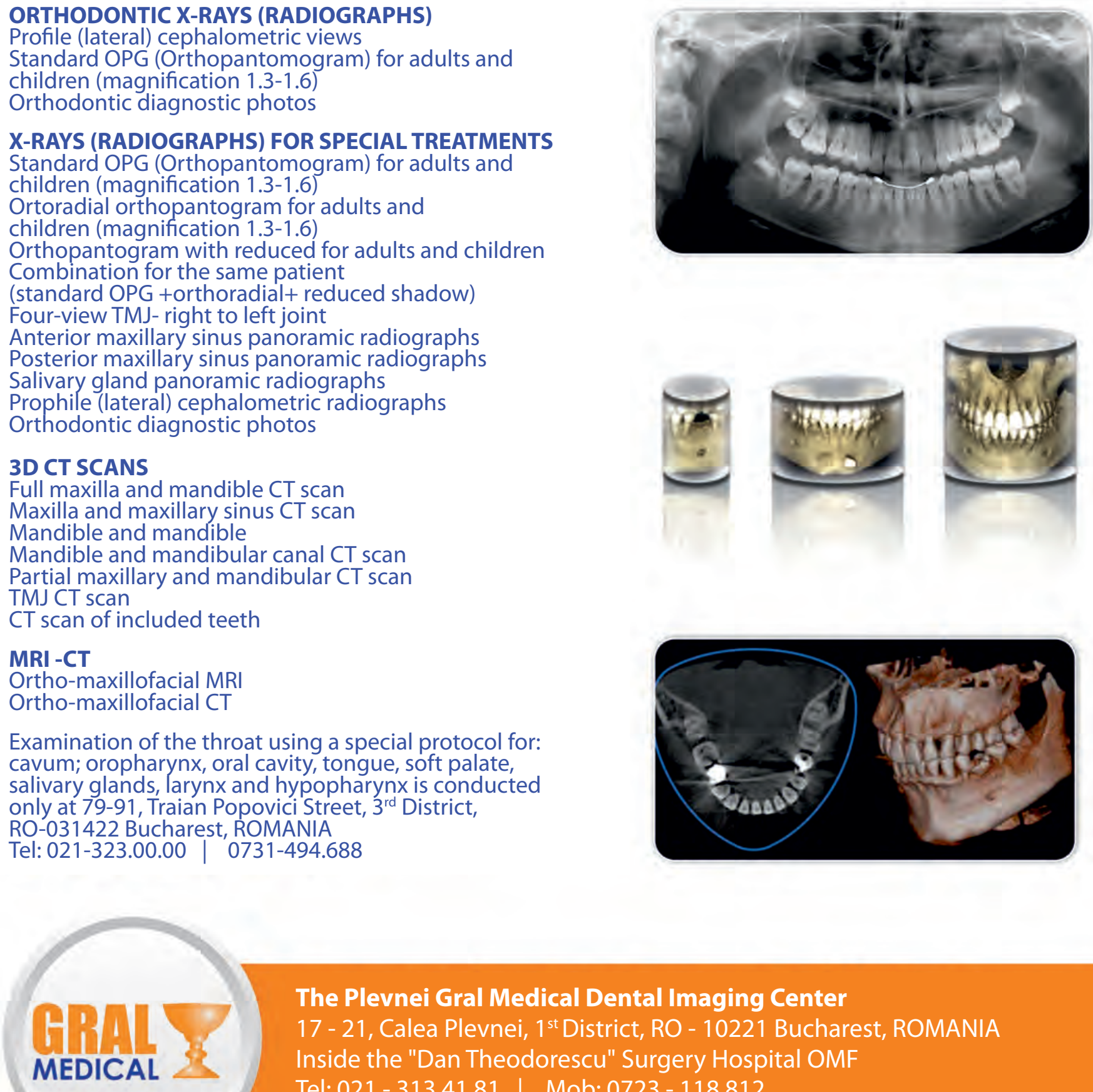

The Plevnei Gral Medical Dental Imaging Center

17 - 21, Calea Plevnei, $1^{\text {st }}$ District, RO - 10221 Bucharest, ROMANIA Inside the "Dan Theodorescu" Surgery Hospital OMF Tel: $021-313.41 .81$ | Mob: $0723-118.812$ 
